Derek Kennet

\title{
Chapter 7 \\ The Pottery
}

\section{Introduction}

A total assemblage of 205,267 sherds was retrieved from excavated contexts at Paithan during the 1998 and 1999 seasons. From this assemblage, the pottery from five trenches or test pits ('Main sequences'), along with a selection of assemblages from other trenches ('Secondary assemblages'), was selected as the study sample, comprising 86,787 sherds or about $42 \%$ of the total excavated assemblage. The remaining $58 \%$ was inspected for imported wares and other key diagnostics, but was not further studied. This includes most of the material from Trenches $\mathrm{C}$ and $\mathrm{E}$ plus material from Trench A other than TP1.

The 'Main sequences' were selected as providing the most reliable and complete overview of the Paithan sequence, whilst the 'Secondary assemblages' were selected in order to supplement these by covering aspects of the excavations that were not included in the 'Main sequences'.

The study of the Paithan pottery was undertaken during 3 weeks in February 2000. It included 75,990 sherds from the five 'Main sequences' and 10,797 sherds from nine 'Secondary assemblages', giving the total of 86,787 sherds mentioned above. The vast majority $(72,201)$ of these were body sherds and were counted but not further classified (with the exception of a few wares) because they proved impossible to classify reliably using the naked eye and $\mathrm{a} \times 10$ hand lens (see the discussion on methodology below). The quantitative analysis was therefore carried out only on rim-sherds, a total of 14,586 of which were recorded from the studied assemblages. These are distributed across the periods in the following way: Period 1: 5,176; Period 2: 5,424, Period 3: 1,495, Period 3-temple: 407 and Period 4: 2,084. These are all reasonably good sized assemblages, with the exception of Period 3-temple, which is too small to allow reliable quantified comparisons in some cases. Details of the assemblage are set out in Table 7.1.

The main aims of the pottery study were to set out a clearly defined classification of types and fabrics and to provide a quantified analysis of their occurrence through the stratigraphic sequence. It was hoped that such an approach would provide a means with which to link the excavated sequences from the different trenches as well as providing a tool that might be of use to researchers working at other sites in the region.

\section{Traditional methodology}

The system of pottery description and analysis that is traditionally used in the publication of excavation reports in this region of India is to divide the pottery assemblage into what are loosely called 'wares', of which there are many, for example 'Red ware', 'Coarse Red ware', 'Black and Red ware' and 'Burnished and Slipped Red ware'. The problem with this approach is that, although most experienced archaeologists working in the region believe they know roughly what these ware names refer to, the terms have never been precisely and formally defined and neither has their chronology. Because of the lack of clear definitions, the ware names often appear to be used very loosely and in many cases refer to different wares at different sites. For example at Bhokardan, the term 'Drab black' ware is used, whilst at Maheshwar and Prakash, 'Coarse Black' or 'Darkish-grey' ware is reported (Sankalia et al. 1958: 140, 149, 154, 163; Thapar 1967: 93; Deo and Gupte 1974: 91). Similarly, at Nevasa, 'Tan slipped' ware is reported, whilst at Bhokardan, the name 'Micaslipped tan ware' is used, and at Maheshwar, 'Tan' ware is reported (Sankalia et al. 1958: 87, 116, 146, 158, 164; Sankalia et al. 1960: 264, 287; Deo and Gupte 1974: 108). To give a further example of the problem, at Bhokardan, we hear of 'Mica-slipped red ware', which is not reported at Nevasa, Maheshwar or Prakash (Deo and Gupte 1974: 89, 99-100). By contrast, 'Thick coarse red' ware was found at Maheshwar but not at Bhokardan (Sankalia et al. 1958: 164). The question faced by the pottery analyst is: are the wares described by these names the same, sharing the same date and possibly even manufacturing centre? Alternatively, are they attempts by archaeologists to impose the same poorly defined classification system on to localised pottery traditions that are in reality quite different? Or are 
they simply descriptive terms that are not suitable for making inter-site comparisons? Are these apparent differences indicative of regional or chronological variations between the sites in question, or are they simply the result of the use of imprecise and poorly defined terminology? The general consensus seems to be that there are broad patterns of technological and stylistic change in pottery manufacture that encompass large areas of Early Historic and Early Medieval India, by which 'Black and Red ware' precedes a variety of Red wares and then Grey wares. This is potentially a very important issue and one that certainly requires further investigation if we are to improve our understanding of the chronology and of the production and distribution systems of these periods. But how can the question be further investigated if a precise and coherent ware terminology does not exist?

Table 7.1: Sherd numbers for the main sequences and secondary assemblages included in the final pottery study.

\begin{tabular}{lrrr}
\hline Trench & Rims & Other sherds & Totals \\
\hline Main sequences & & & \\
\hline A:TP1 & 2,874 & 18,780 & 21,654 \\
\hline B & 4,230 & 21,679 & 25,909 \\
\hline D1 & 810 & 3,287 & 4,097 \\
\hline D2 & 3,318 & 8,177 & 11,495 \\
\hline F & 2,251 & 10,584 & 12,835 \\
\hline Secondary assemblages & & & \\
\hline A:South Area & 117 & 1,604 & 1,721 \\
\hline A:South Area, TP6 & 0 & 359 & 359 \\
\hline A:TP3 & 867 & 6,351 & 7,218 \\
\hline A:TP3, TP5 & 116 & 1,277 & 1,393 \\
\hline Other (E, GG North, NWNT, & 3 & 103 & 106 \\
TP9) & & & $\mathbf{8 6 , 7 8 7}$ \\
\hline Totals & $\mathbf{1 4 , 5 8 6}$ & $\mathbf{7 2 , 2 0 1}$ & \\
\hline
\end{tabular}

The fact is that almost all of the 'wares' mentioned above and many others like them that are presented in excavation reports are loosely descriptive terms based entirely on observation of surface treatments and body colour rather than on clay fabrics, inclusions and tempers. In fact, the latter are not described to an acceptable standard in any of the excavation reports that have been examined by the present author.

It can therefore be said that the traditional system of pottery classification used in the region does not provide us with a mechanism for identifying chronological or regionalvariation between assemblages. This lack is clearly reflected in the lack of progress over the last 45 years or so towards a more precise ceramic chronology for the Early Historic period. The 300- to 400 -year-long archaeological periods that are in use today are the same as those that were set out in the late 1950s and early 1960s by Sankalia and his colleagues and there has been no perceptible progress towards refining them.

Having said this, it should also be noted that local course wares of the Early Historic and Early Medieval period in India are particularly challenging to the ceramic analyst. Clear definition of fabrics is particularly difficult given the generally low degree of standardisation and the high levels of continuity between periods. These problems are especially obvious when compared to other regions of the world such as the Mediterranean or the Near East. Such differences may be related to different structures in the organization of production and distribution but further research is needed into this question.

\section{Methodology at Paithan}

The traditional classification system discussed above was initially tried at Paithan, but it was soon abandoned because it quickly became obvious that, as has been stated above, these terms are so vague and poorly defined as to prevent the identification of patterns of change within the sequence. The fabrics of traditional 'wares' such as 'Coarse red ware', 'Burnished and slipped red ware' and 'Slipped red ware' were compared and found to be indistinguishable with the use of a $\times 10$ hand lens or the naked eye. Instead, it was clear that a number of coherent 'types' based on rim shapes were present in the sequence, some of which had discreet chronological patterns of occurrence. It was therefore decided that a formal typology based on rim forms linked to a more precise description of clay fabrics was the most promising method by which to classify the Paithan assemblage.

In developing and using this system, great care was taken to quantify the assemblage from each layer accurately. Only in this way has it been possible to gain a clear impression of the chronological life span of individual types. Quantification has also helped, at least to some degree, to overcome the perennial problem of multi-period sites, that of residuality. By quantifying 
the assemblages, it is often possible to get a reasonable sense of when a type ceased to circulate from the point at which there is a notable decline in its overall proportion of the assemblage.

So, whilst it would be wrong to suggest that the system adopted at Paithan has provided us with the final key to the pottery chronology of the Early Historic period in this part of India, it certainly does offer a more precise and reliable method with greater potential for the identification of chronological and regional patterning within and between pottery assemblages.

In this study, a distinction is made between 'fabric', 'class' and 'ware'. The 'fabric' is the clay of which the pottery is made, including the temper and other mineral inclusions (natural and deliberately added). Fabrics were identified and described with the assistance of a $\times 10$ hand lens and a Munsell soil colour chart. A 'class' is any group of pottery with consistently similar variables that allow it to be meaningfully grouped or classified together. 'Ware' has a the same meaning as 'class', although it should be noted that, in more general parlance, the use of the word 'ware' might be taken to indicate that the pottery was manufactured in the same locality or at the same kiln, whereas 'class' suggests only a working subdivision of material for the purposes of archaeological study.

It was found that the majority of the pottery at Paithan is made of a single, almost certainly local fabric (Fabric 1), or a variant thereof. It is quite variable in quality, firing and the nature of the inclusions, which probably reflects the loose organization of the manufacturing process rather than necessarily indicating the existence of distinct industries. Many of the other fabrics (e.g. Fabric 2 and 3) appear to be closely related to Fabric 1 but seem to have undergone different methods of levigation, tempering and firing. The highly variable nature of these fabrics makes it difficult, if not impossible, to identify the products of individual potters or industries consistently without the use of scientific techniques.

\section{Pottery fabrics}

Fabrics 1, 2 and 3 described below make up between 93\% at the highest (Period 1) and 62\% at the lowest (Period 4) of the pottery assemblage from each period, or $85 \%$ of the total pottery assemblage from the site. Fabrics 4 and 5 are much less common and tend to be specific to certain types and wares.

\section{Fabric 1 (local buff fabric)}

This is a coarse fabric that is quite variable in terms of the proportion of various inclusions, the firing temperature and colour, although other basic features do not change. The variability makes it difficult to define coherent sub-fabrics within the pottery using only a $\times 10$ hand lens. It is possible that more sub-fabrics may exist than those that have been defined below.

As a whole, this fabric makes up between about $50 \%$ and $80 \%$ of the total pottery assemblage from each period (see Table 7.2).

\section{Fabric 1a}

Types: 1, 1a, 1b, 2, 3, 4, 5, 8, 12, 16, 17, 18, 22, 25, 27, 30, 31, 32, 33, 34, 35, 36, 37, 40, 41, 42, 47, 50.

- Traditional classification: Depending on the surface treatment, pottery made in this fabric might traditionally have been classified as 'Red', 'Buff', 'Burnished and slipped red' or 'Tan' ware.

Table 7.2: The occurrence of the main fabrics by period, by rim-sherd count above, and by rim-sherd count as a percentage of the total period rim-sherd count below.

\begin{tabular}{lrrrrr}
\hline Fabric & $\mathbf{1}$ & $\mathbf{2}$ & $\mathbf{3}$ & 3-temple & $\mathbf{4}$ \\
\hline $\mathbf{1 a}$ & 3,790 & 4,043 & 855 & 323 & 835 \\
\hline $\mathbf{1 b}$ & 129 & 137 & 34 & 5 & 73 \\
\hline $\mathbf{1 c}$ & 3 & 53 & 1 & 0 & 161 \\
\hline $\mathbf{2}$ & 3 & 11 & 195 & 5 & 145 \\
\hline $\mathbf{3}$ & 897 & 581 & 44 & 24 & 73 \\
\hline $\mathbf{4}$ & 4 & 20 & 13 & 0 & 72 \\
\hline $\mathbf{5}$ & 0 & 0 & 0 & 0 & 67 \\
\hline Other & 350 & 579 & 353 & 50 & 658 \\
\hline Total & $\mathbf{5 , 1 7 6}$ & $\mathbf{5 , 4 2 4}$ & $\mathbf{1 , 4 9 5}$ & $\mathbf{4 0 7}$ & $\mathbf{2 , 0 8 4}$ \\
\hline
\end{tabular}

\begin{tabular}{lrrrrr} 
1a & 73.2 & 74.5 & 57.2 & 79.4 & 40.1 \\
\hline 1b & 2.5 & 2.5 & 2.3 & 1.2 & 3.5 \\
\hline 1c & 0.1 & 1.0 & 0.1 & 0.0 & 7.7 \\
\hline $\mathbf{2}$ & 0.1 & 0.2 & 13.0 & 1.2 & 7.0 \\
\hline $\mathbf{3}$ & 17.3 & 10.7 & 2.9 & 5.9 & 3.5 \\
\hline $\mathbf{4}$ & 0.1 & 0.4 & 0.9 & 0.0 & 3.5 \\
\hline $\mathbf{5}$ & 0.0 & 0.0 & 0.0 & 0.0 & 3.2 \\
\hline Other & 6.8 & 10.7 & 23.6 & 12.3 & 31.6 \\
\hline
\end{tabular}


- Occurrence: This is the most common fabric in all periods at Paithan, making up over $70 \%$ of the pottery assemblage in Periods 1 and 2 (and 3 -temple), dropping to $57 \%$ by Period 3 and $40 \%$ by Period 4.

- Description: The fabric colour varies from red through reddish yellow to very pale brown (2.5YR 6/6; 5YR 7/6; 7.5YR 6/5-7/6; 10 YR 6/4-8/4). It is normally poorly fired, very weak and breaks as easily as a stale biscuit, although there is a light snap in the better-fired examples. The fracture is very rough and the structure of the clay is notably blocky and grainy. The limited range of inclusions encompasses the following in varying proportions and amounts: (1) curved white laminar inclusions up to about $1 \mathrm{~mm}$ which appear to be the remains of seed husks; (2) small (1-2 mm) grey/white subangular or rounded inclusions; and (3) very fine sand inclusions that give the clay a grainy structure. There is considerable variation in the presence and especially proportions of these inclusions, but these variations do not appear to show any clear pattern in relation to the types that have been defined. They probably reflect an arbitrary range of clay treatments that were used by potters. An attempt was made to subdivide this fabric on the basis of the proportion of the inclusions. This might have yielded useful results with a greater investment of time than it was possible to give, but the apparently random variation that came to light suggested that this approach would not necessarily yield useful results and it was abandoned at a relatively early stage.

- Surface treatment: The core of the fabric is often a greyer colour than the surface. The surface treatments vary with type, the most common are reddish brown slips and washes that are sometimes burnished.

\section{Fabric 1b}

Types: 6, 7, 9, 43, 49.

- Description: This is the same fabric as Fabric 1a except that it has a high percentage of sand grains that are large enough to be visible to the naked eye (up to $0.3 \mathrm{~mm}$ ). Chaff temper is also less evident. The fabric has a different feel to Fabric 1a, and once familiarity has been established, the two can easily be distinguished with the naked eye.

\section{Fabric 1c}

Types: 19, 41, 48, 55.

- Description: This is again the same fabric as Fabric $1 \mathrm{a}$, but in this case, there is an absence of large inclusions and of vegetable temper, giving the fracture a slightly smoother and purer look, although the fine grainy structure is still readily visible with $\mathrm{a} \times 10$ hand lens.

\section{Fabric 2}

Types: 14, 15, 24, 26, 44, 45, 46.

- Traditional classification: Pottery made in this fabric would traditionally have been classified as 'Grey', 'Thick grey' or 'Medieval grey' ware.

- Description: This fabric is finer and better levigated than Fabric 1a and tends to have a smoother fracture as a result. The clay has a less blocky structure to it, and there are fewer large inclusions. On the whole, it is also denser, stronger and better fired. Vegetable or chaff tempering is present, but it is difficult to see in section and is normally only detectable as voids on the clay surface. Some sherds contain occasional large $(<0.75 \mathrm{~mm})$ rounded grains, that are probably quartz. This fabric is fired to between a very dark grey to an olive grey (5Y 3/1-4/1; 5Y4/2), normally being darker on the edges than at the core. There is some variation in the fabric, but this is less than for Fabric 1a. It seems quite likely that this clay came from the same source as Fabric 1 but that it was mixed and fired according to a different system.

\section{Fabric 3}

Types: 10, 11, 29, 38, 39, 58.

- Traditional classification: Pottery made in this fabric would traditionally have been classified as 'Black and red' ware or as 'Burnished black' ware depending on the colouring of the exterior.

- Description: This is a finer fabric than Fabric 1a. It breaks with a light snap and has a rough angular fracture and a very fine grainy structure due to a moderate amount of fine, badly sorted, sub-angular grey grits, the smallest of which are almost too small to see even with a $\times 10$ hand lens. There are occasional signs of chaff or other vegetable temper, but these are not very common. The fabric 
is fired to between a greyish brown and a very dark grey (2.5Y 5/2-3/1). The external surface of Types 10 and 38 is black, with the exception of the lower part of the exterior, from about $2 \mathrm{~cm}$ below the rim, where it is fired to between a yellowish red and a reddish yellow (5YR 5/6 to 7.5YR 7/6). These are the vessels that are traditionally referred to as 'Black and Red ware' (see below). Other vessels (Types $11,29,39,58$ ) are entirely black on the interior and exterior surfaces; these are the vessels that are traditionally referred to as 'Burnished black ware' (see below).

\section{Fabric 4}

Types: 20, 21.

- Traditional classification: Pottery made in this fabric would traditionally probably have been classified as 'Fine red' ware.

- Description: This fabric is weakly fired and breaks easily with hardly a snap. It is well levigated and has a smooth fracture. There are very few visible inclusions. The fabric has a fine grainy structure that is visible with $\mathrm{a} \times 10$ lens; it is caused by very dense, tiny, well-sorted grains that are almost too small to see with the $\times 10$ lens. The fabric is fired to an even reddish yellow (5YR 6/6-7.5YR 6/6). All of the sherds are small jars or bowls with quite thin walls $(<5 \mathrm{~mm})$. They are all covered with a thin mat slip/paint (on the exterior only in the case of jars), which is red to weak red in colour (2.5YR5/4-5/6).

\section{Fabric 5}

Types: 51, 52 (and White and Red Painted [WARP] class).

- Traditional classification: Unknown.

- Description: This is a fine, well-levigated fabric with a smooth fracture. It is soft to medium fired and can break with a slight snap. There are no large inclusions, but there are occasional small $(0.1 \mathrm{~mm})$ unidentified white flecks in the clay. The clay also has a very fine grainy structure caused by fine grits that are almost too small to see with a $\times 10$ lens. The fabric fires to an even reddish yellow (7.5YR 6/6-6/8).

Table 7.2 shows the occurrence of the main five fabrics through the sequence where chronological change can be noted. For example, Fabric 3 is clearly more common in Periods 1 and 2 and may have gone out of use by Period 3, the few remaining sherds being residual. Likewise, Fabric 2 seems to be datable predominantly to Period 3; the few examples from earlier layers may be misidentifications or intrusive sherds. The amount of Fabric 1a declines in Period 3 and Fabric 5 occurs only in Period 4.

\section{Pottery wares}

In addition to the typological and fabric classification, which formed the basis of the Paithan pottery study, a number of ceramic wares or classes were also identified or defined and these are described below. Some are already well known from the published literature and can be approximately dated by evidence from other sites, whilst others are defined here for the first time.

\section{Jorwe ware}

At Paithan, eight very small and heavily eroded sherds of a red, finely levigated, well-fired pottery ware came to light in the natural soil layer (777) that was excavated in the lowest levels of Trench D. These sherds seem to berelated to a type of pottery noted in Proto Historic levels at other sites in the region, which is wheel-made and has a fine, well-levigated fabric with an orangered core, thin walls and black-painted designs. This ware is variously called 'Jorwe ware', 'Jorwe Nevasa red ware', 'painted red ware b', 'painted black on red ware', 'black-painted red pottery of the Jorwe ware' or 'Jorwe Nevasa painted red ware' and has been found at Nasik, at Nevasa in Period III, at Navdatoli in Period III and at Prakash in Period Ib, amongst other sites (Sankalia and Deo 1955: 161-162; Sankalia et al. 1958: 85-86; Sankalia et al. 1960: 205-207; Thapar 1967: 36, 49-54). At Nevasa, which is close to Paithan, it made up $65 \%$ of the pottery of Period III, whilst at more distant Prakash, it made up only between 5\% and 15\% of the roughly contemporary Period $1 \mathrm{~b}$ assemblage (Sankalia et al. 1960: 205; Thapar 1967: 26). The ware is normally dated to between about 1400 and $1000 \mathrm{BC}$, with a later 'degenerate' form said to continue as late as $700 \mathrm{BC}$, although some of this dating seems to be based on uncalibrated $C^{14}$ dates (Ghosh 1989, I: 239).

As the sherds found at Paithan are very small and eroded and none of their shapes or original surface 
decorations are preserved, it is impossible to be absolutely certain of this attribution, although it seems likely to be correct given the lack of alternatives and the predominance of this ware in Proto Historic levels at nearby Nevasa. A jar that is on display in the Balasaheb Patil Government Museum at Paithan is another example of this ware that is thought to have been found at Paithan (see Fig. 11.6, 1).

\section{Northern Black Polished ware}

Northern Black Polished ware (NBP) is a well-known fine, black-slipped ware that was probably manufactured in the Ganges region (Sankalia et al. 1958: 132134; Thapar 1967: 71-75; Ghosh 1989, I: 251-257). The sherds found at Paithan have a very fine, well-levigated grey to light grey body (2.5YR 6/1-7/1) that is very strong and well fired and breaks with a snap. The fracture is conchoidal and there are not usually any visible inclusions, although in some cases, rare rounded red inclusions (grog?) are visible alongside occasional small angular air holes. The surface is covered with a highquality, thin black slip that appears almost to have vitrified in some cases to a glaze, giving off a lustrous sheen (Figs 7.1-7.2).
The presence of NBP is often used as a chronological 'marker' in excavation reports. It is found over the whole of the Ganges area and into the western Deccan as far south as Brahmapuri (e.g. Thapar 1967: fig. 21). There is some discussion over the precise chronology of its production, but this has mostly centred on the date of its introduction. Erdosy has reviewed the $\mathrm{C}^{14}$ evidence for NBP production in the Ganges area around Kausambi, Sravasti, Rajghat and Vaisali. He places its introduction in the second half of the 6th century BC - although this has been arrived at by averaging dates from a number of different sites and contexts (Erdosy 1995: 104) - and the end of its production at about $100 \mathrm{BC}$, although this is based on unspecificied associated coins, seals and sealings (Erdosy 1995: 105). It is important to note two things in relation to Erdosy's chronology: firstly that the $\mathrm{C}^{14}$ dates on which it is based are not very precise due to the nature of the calibration curve at this period, and secondly, that the dating of the end of production is largely speculative and is not well supported by evidence (Erdosy 1995: 100105). Even if Erdosy's dates are correct, they apply only to the core area of NBP production in the Ganges valley and the area immediately surrounding. It is possible - or even highly likely - that it came into use at different times in different regions (e.g. Sankalia et al. 1960: 69; Ray 1986: 47). The date at which it first began to circulate widely

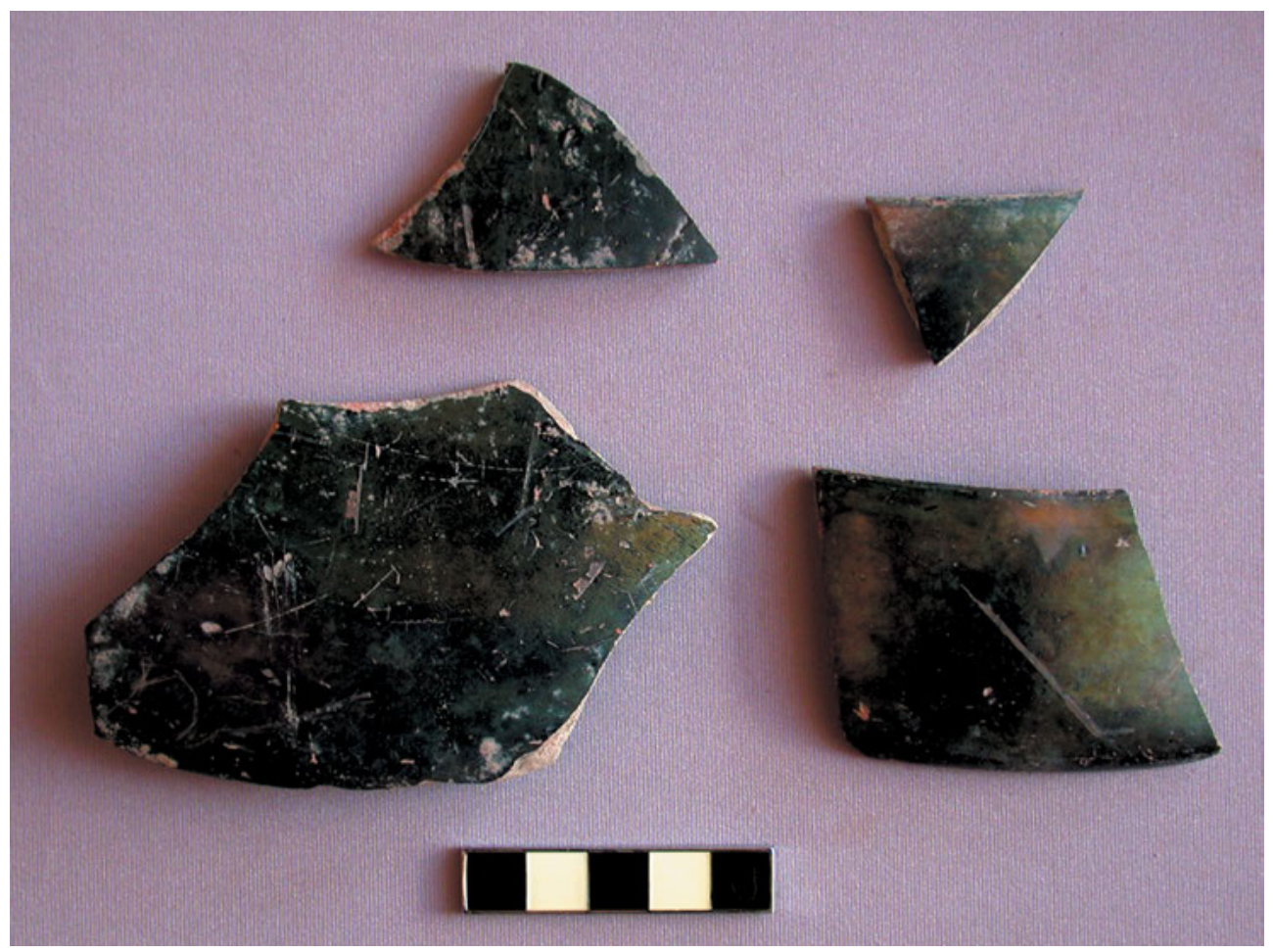

Fig. 7.1: Northern Black Polished ware sherds (NBP) (scale in $\mathrm{cm}$ ). 


\section{$1+\frac{1}{1-1}$}

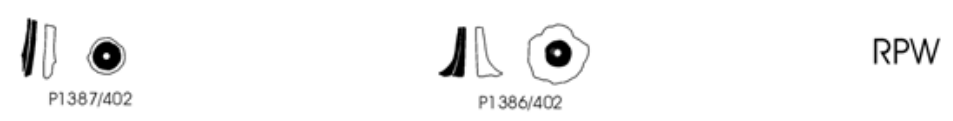

$\| \prod_{\text {P21 12/432 }}$ SLIP
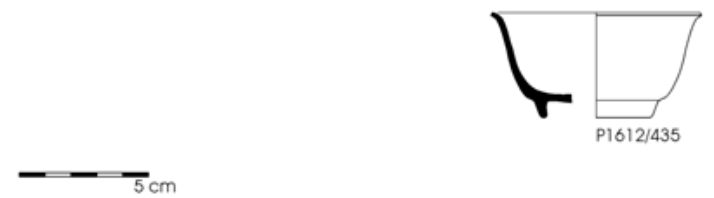

Fig. 7.2: Classes NBP, RPW, SLIP and CBW.

in the western Deccan and surrounding areas has never been accurately established, and neither has the date at which it ceased to circulate. To give some idea of the way in which NBP has been dated in this region, at Nevasa, it was dated to the 'late Mauryan period'; at Prakash, to the third/second or possibly 1st century BC; at Nasik, to 400-200 BC; at Maheshwar, 400 to $100 \mathrm{BC}$; and at Ter, between 200 вС and the 1st century вс (Sankalia and Deo 1955: 28; Sankalia et al. 1958: 19, 22; Sankalia et al. 1960: 69; Thapar 1967: 74-75; Chapekar 1969: 17). However, close inspection of these reports, as well as reports on other sites in the region where NBP has occurred, such as Brahmapuri, Mansar, Pauni and Nagara, reveals that none of these sequences contains any reliable dating evidence with which to establish the first or latest occurrence of NBP. Bearing in mind the lack of reliable evidence for the end of production in the Ganges area, this means that, at present, in the western Deccan NBP can, strictly speaking, only be used as a terminus post quem to date the layers in which it occurs to the mid-6th BC or later. Of course it is almost certain that it came into use somewhat later in the western Deccan, and, to judge from excavation reports, there was probably a period of time during which it circulated in reasonably large quantities, but, at present, the chronology of these developments is unknown. Therefore, although the circulation of NBP in the western Deccan region may one day be more accurately dated, until further evidence has come to light, any attempt to use it for more precise dating is purely speculative (Thapar 1967: 25).

Twenty-three sherds of NBP were recorded at Paithan, 22 of them in layers allocated to Period 1; the remaining sherd was found in a layer allocated to Period 2 and must therefore be residual (Tables 7.3 and 7.4).

\section{Red Polished ware}

This is another well-known ware about which much has been written (Pinto Orton 1991). It has a very fine, well-levigated, brick-red body covered by a thin orange-red slip, which is often burnished. The fracture is smooth with no visible inclusions. Mica is visible on the surface. The most common forms are a carinated pot with an almost horizontal out-turned rim that is notched on its outer face and a sprinkler (Figs 7.2-7.3).

Red Polished ware (RPW) is found over much of central and northern India, although some of it was probably produced in Gujarat, perhaps in the region around Amreli, the site which has yielded the greatest 
number of types (Rao 1966: 51-59; Pinto Orton 1991). It was first defined at Baroda and is normally dated to between the 1st and anywhere between the 3rd and the 5thcenturies AD, although sometimes as late as the late sixth (Subbarao 1953: 56-64; Sankalia et al. 1958: 161; Rao 1966: 52-53; Whitehouse and Williamson 1973: 39; Ghosh 1989, I: 259; Pinto Orton 1991: 46). The evidence for the first appearance of RPW in the western Deccan between the 1st BC and 3rd AD is demonstrated in Period V at Nevasa, where it is associated with reasonable numbers of confirmed Roman amphorae of a known date (Sankalia et al. 1960: 69, 280-281, 307; Gupta et al. 2001; Tomber 2007: table 1, 979). There are very few cases, however, where the dating evidence for its disappearance stands up to detailed critical scrutiny. For example, Rao proposes a 'lower limit' of the beginning of the 5th century based upon the fact that a coin datable to AD 380 was found in one of the layers containing RPW at Amreli (Rao 1966: 53), but thereis clearly no reason, based on this evidence, that RPW could not have continued in use much later. A more convincing case is Period III at Paunar, which is dated to the 6th century and later by coins of the Kalachuris and Vishnukundins and Vakataka-style sculpture (Deo and Dhavalikar 1968: 7). No RPW is reported from layers 4 and 5 that make up Period III, whereas 52 sherds are reported from the preceding Period IIb (Deo and Dhavalikar 1968: 47-69). Another is Prakash, where RPW occurs only in levels 28-25 (Thapar 1967: 24), below levels containing figurines and coins dated to the 4th to 8th centuries, suggesting that it was out of circulation by the $6 \mathrm{th} / 7$ th centuries. On the other hand, the evidence from the excavations at Kush in the United Arab Emirates (UAE) has suggested that RPW may have continued to circulate as late as the 8th century AD (Kennet 2004a: 65-66). It is possible that there are regional differences in the distribution of RPW and that Gujarati RPW continued to be manufactured and traded by sea later than RPW circulated in the western Deccan.

Only 10 sherds of RPW were recorded at Paithan, three occurred in Period 2, and the others occur in layers allocated to Period 3-temple, Period 4 or in layers that were not allocated a period (Tables 7.3 and 7.4).

\section{Chinese wares (CBW and other)}

All but one of the sherds of Chinese pottery are Chinese Blue and White porcelain (CBW), which is a wellknown class of porcelain, covered with a transparent glaze and decorated with under-glaze cobalt. It is possible to subdivide CBW into different styles based on the decorative scheme (e.g. Swatow and Kraak) (Figs 7.2 and 7.4).

Large-scale production and export of CBW from China did not begin until the first or second quarter of the 14th century at the earliest (Medley 1976: 176; Guy 1986: 76; 1990: 26). It started to become common in elite circles in the Near East at the end of the 14th century (Lane 1947: 27-28; Gray 1948-49: 30; Krahl 1986, II: 482), but it did not begin to be traded widely until the mid to late 15th century and probably began to arrive in India in quantity at around the same time (Krahl 1986, II: 533; 1997: 154). It continued to be exported to the western Indian Ocean and Europe until the late 18th century, when imitations began to be manufactured in Europe (Lunsingh Scheurleer 1974: 37-38).

Thirty sherds of CBW occurred at Paithan, and their presence was used to define layers of Period 4 (Tables 7.3 and 7.4). Of these, 16 sherds, including all but two of those mentioned below, come from Trench B, between layers 402 and 435. One of the youngest sherds in this sequence (P1612) comes from the earliest layer (435), indicating high levels of re-deposition. Of the Trench B sherds, there are two that might be as early as the 15th century (P1614, P2165), and there are also two sherds of 16th century Kraak porcelain (P2167, P2168). The rest of the material is datable to the 16 th/17th centuries, with the exception of two sherds (P1612, P2164) of the Kangxi period (AD 1662-1722).

In addition, there is one Chinese sherd that is not CBW, but that might conceivably be significantly older: P1613. This might possibly be a Southern Song Jingdezhen product of the 12th to 13th century, but it is probably a Ming or Qing period Fujian white ware. It was found in context 435 in Trench B associated with sherd P1612, which is 17th to 18th century in date, along with other sherds mentioned above that are datable to the 15th to 17th centuries. Sherds P2173 and P2174 (both datable to the Wanli period, AD 1573-1620) come from Trench A South Area.

\section{Blue and White Frit (PERS)}

This ware is made of a good-quality thick frit or stonepaste body; the interior and the exterior of the vessels are coated in a transparent glaze that covers underglaze painting in cobalt blue. It is often mistaken for Chinese porcelain, although the body is notably different, as are the quality of the glaze and decoration. Frit 
Table 7.3: Summary of selected ceramic classes from Paithan by period (rim-sherd counts above; percentages of total period rim-sherd assemblages below).

\begin{tabular}{|c|c|c|c|c|c|c|}
\hline Ware Period & 1 & 2 & 3 & 3-temple & 4 & Total \\
\hline Black and Red & 878 & 569 & 44 & 21 & 72 & 1,584 \\
\hline Black Burnished & 19 & 12 & & 3 & 1 & 35 \\
\hline NBP & 5 & & & & & 5 \\
\hline RPW & & 1 & & & 1 & 2 \\
\hline GREY & 3 & 11 & 195 & 5 & 144 & 358 \\
\hline PERS & & & & & 1 & 1 \\
\hline WARP & & & & & 69 & 69 \\
\hline CHIN & & & & & 12 & 12 \\
\hline Other & 4,271 & 4,831 & 1,256 & 378 & 1,784 & 12,520 \\
\hline \multirow[t]{2}{*}{ Total } & 5,176 & 5,424 & 1,495 & 407 & 2,084 & 14,586 \\
\hline & $\%$ & $\%$ & $\%$ & $\%$ & $\%$ & \\
\hline Black and Red & 16.96 & 10.49 & 2.94 & 5.16 & 3.45 & \\
\hline Black Burnished & 0.37 & 0.22 & & 0.74 & 0.05 & \\
\hline NBP & 0.10 & & & & & \\
\hline RPW & & 0.02 & & & 0.05 & \\
\hline GREY & 0.06 & 0.20 & 13.04 & 1.23 & 6.91 & \\
\hline PERS & & & & & 0.05 & \\
\hline WARP & & & & & 3.31 & \\
\hline $\mathrm{CHIN}$ & & & & & 0.58 & \\
\hline
\end{tabular}

Table 7.4: Summary of body sherd counts of by period for those wares for which body sherds were counted separately.

\begin{tabular}{|c|c|c|c|c|c|c|c|}
\hline & 1 & 2 & 3 & 3-temple & 4 & No period & Total \\
\hline Jorwe & 8 & & & & & & 8 \\
\hline NBP & 17 & 1 & & & & & 18 \\
\hline RPW & & 2 & & 2 & 3 & 1 & 8 \\
\hline CHIN & & & & & 18 & & 18 \\
\hline PERS & & & & & 3 & 1 & 4 \\
\hline SLIP & & & & & 7 & & 7 \\
\hline WARP & & & & & 6 & & 6 \\
\hline \multirow[t]{2}{*}{ Other } & 21,518 & 25,290 & 9,260 & 3,702 & 12,261 & 101 & 72,132 \\
\hline & & & & & & Total & 72,201 \\
\hline
\end{tabular}


wares were produced in the Near East from about the 12th century onwards, but this style of frit ware, which closely imitates CBW porcelain, was produced in the Near East from the 14th until about the 19th century (Soustiel 1985: 214), and this is supported by excavation data from the UAE (Kennet 2004a: FRIT.BW). Only five sherds of PERS occurred at Paithan, all in layers allocated either to Period 4 or for which it was not possible to allocate a period (Tables 7.3 and 7.4, Fig. 7.5).

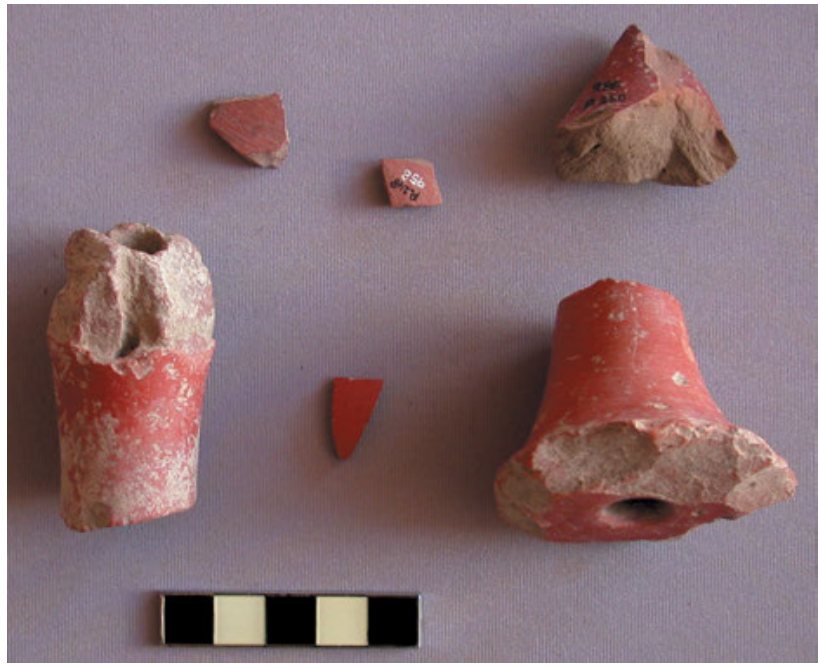

Fig. 7.3: Red Polished ware sherds (RPW).

\section{Slip-painted ware (SLIP)}

This is a glazed ware with a coarse red earthenware body that has a fine sandy texture. It has a smooth fracture and the body is fired an even red (2.5YR 5/8). The seven sherds retrieved all come from small closed vessels such as jars. They are all covered on the outside with a transparent lead glaze that contains some splashes of green. This covers decoration painted in a thick, cream yellow slip. The motives are lines and arches and foliage. There is no glazing or decoration on the interior surface or on the top of the flattened rim (Figs 7.2 and 7.6).

The date of this class is not known. Slip-painted ware first appeared in the Near East in around the 11th or 12th century AD, but these sherds are likely to be considerably later, probably datable to the 14 th century or somewhat later. At Paithan, only seven sherds were recorded, all from layers allocated to Period 4 (Table 7.4).
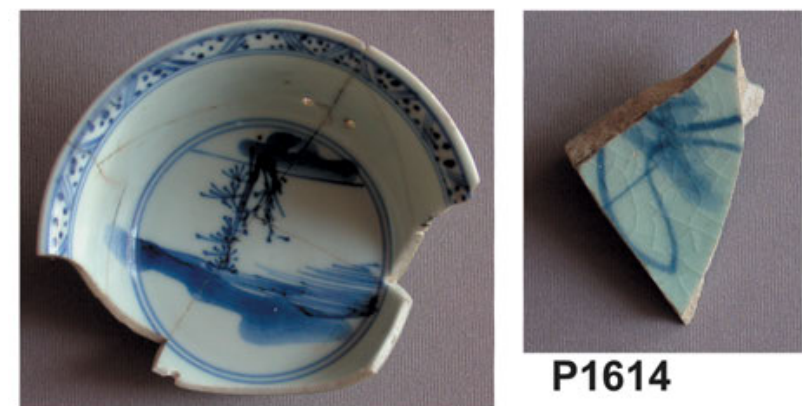

P1614

\section{P1612}
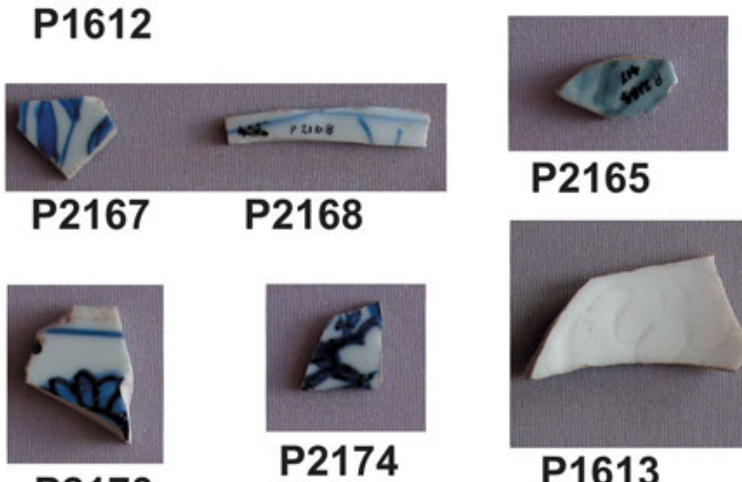

P2173
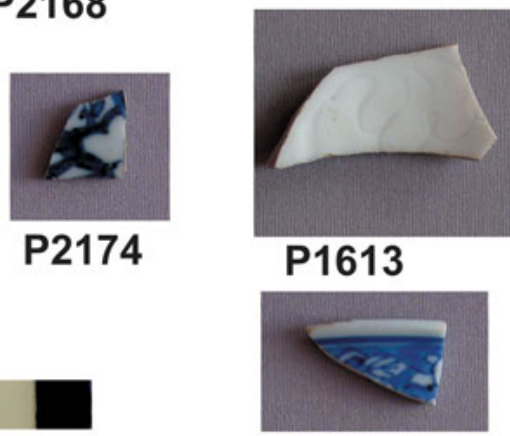

P2164

Fig. 7.4: Chinese Blue and White porcelain sherds (CBW).

\section{White and Red Painted (WARP)}

Types: 51, 52.

This is an unglazed painted earthenware that was defined by this study. It consists of small closed vessels such as jars that are made of Fabric 5 and are decorated on the outside and over the rim with a thin, white mat paint that is then decorated crudely with thin horizontal red bands of paint (Fig. 7.7).

This class includes types 51 and 52 as well as a number of unclassified body sherds. Seventy-five sherds were found at Paithan, these occurred only in layers allocated to Period 4 where it was quite common (Tables 7.3 and 7.4). The high number of rim-sherds relative to body sherds is caused by an anomalous find in context 435 of Trench B. 


\section{Thick Grey wares (GREY)}

Types 14, 15, 24, 26, 44, 45, 46.

These types make up are very distinctive class of pottery that is known from excavations elsewhere in the region. They are all made of Fabric 2 and are large, grey, sturdy, mostly thick-walled carinated jars with everted rims of a variety of shapes. Most are burnished and many are decorated with ribbing on the outside. The types defined in this ware are all highly variable, suggesting a low level of standardisation. This might reflect the relatively informal organization of the industry that produced these wares.

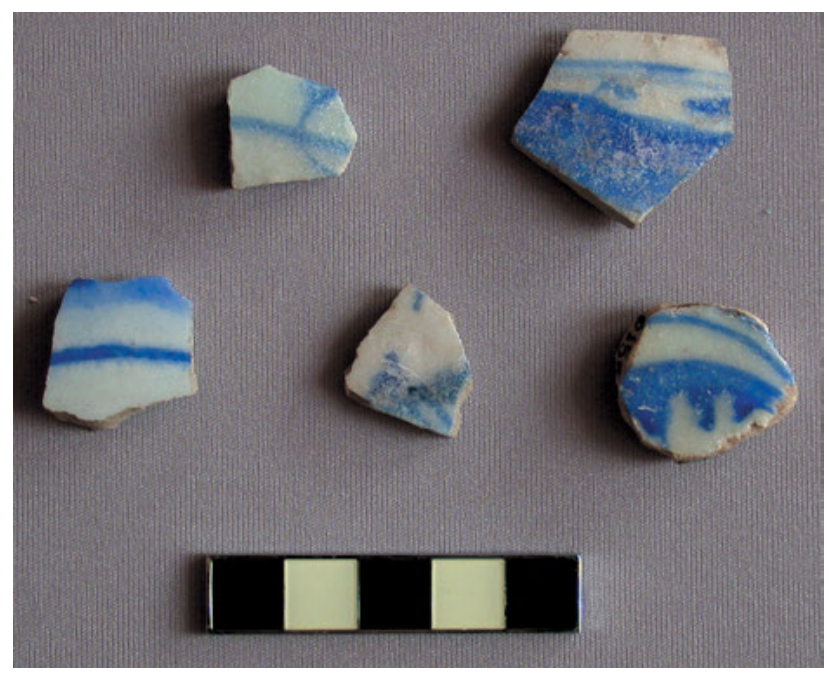

Fig. 7.5: Blue and White Frit sherds (PERS).

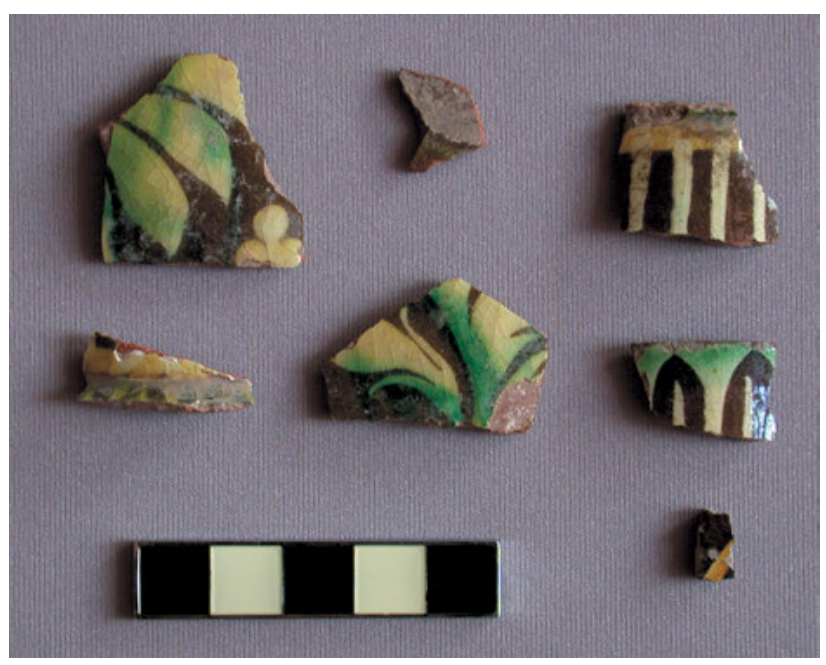

Fig. 7.6: Slip-painted ware sherds (SLIP).

At other sites in the region where they have been encountered, these types are referred to as 'Coarse Black ware', 'Black ware' (Nevasa, Maheshwar) or
'Darkish-Grey ware' (Prakash). They tend to appear in large quantities in the later Early Historic or Early Medieval layers, for example at Nevasa in Period VI (14th18th century AD), at Maheshwar in Period VI (AD 100500) and at Prakash in Period IV (6th-11th century AD), although there is no clear evidence to show precisely at which date they first began to appear; the dating of some of the periods mentioned is also in need of review (Sankalia et al. 1958: 137, 140, 150-151, 154-155, 163; Sankalia et al. 1960: 333; Thapar 1967: 15, 89, 93; see also the discussion below related to types 14 and 24). Given the obvious significance of this ware to the archaeology of the Early Medieval period, it is surprising that it is not more widely discussed in the literature (e.g. Mehta 1979: 42-49; Ghosh 1989, I: 260).

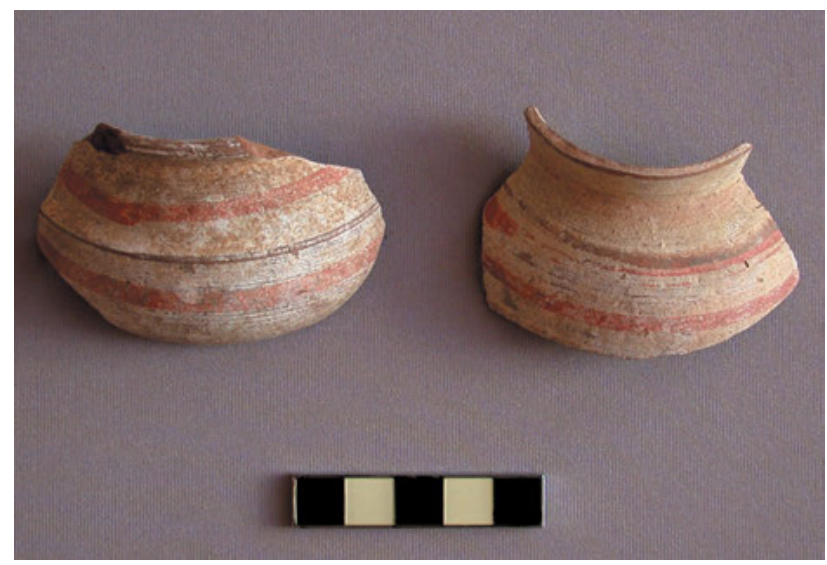

Fig. 7.7: White and Red Painted ware sherds (WARP).

At Paithan, Thick Grey ware was a very significant and obvious component of the Period 3 assemblage of which it made up over 13\% (Table 7.3). Indeed, its appearance in the sequence was used to mark Period 3. This holds true with the exception of 14 sherds, three from Period 1 and 11 from Period 2, that are considered to be intrusive, although it should be noted that at Maheshwar, it occurred in smaller quantities through the Early Historic levels (Sankalia et al. 1958: 150). This suggests that these wares may have been in existence from earlier but have become more abundant towards the end of the Early Historic period. They are potentially extremely important wares for our understanding of the Early Historic/Early Medieval transition.

If the dating of the North Temple here at Paithan is accepted, Thick Grey wares can be shown to have been in circulation by the 4th or 5th century or shortly thereafter. 


\section{Black Burnished ware (BBW)}

Types 11, 29, 39, 58.

This ware consists of sherds made of Fabric 3 that are entirely black on the interior and exterior surfaces. The surface treatment never varies, being heavily burnished in all cases. This ware is made of exactly the same fabric as Black and Red ware and, aside from the absence of 'inverted firing', shares a very similar firing technique. The forms, however, are quite different from Black and Red ware, consisting of small, closed vessels such as jugs, jars and one or two bowls, although no complete profiles came to light.

Pottery described as 'burnished black', 'black slipped' or 'black-slipped burnished ware' has been found at other sites in the region, for example Maheshwar and Nevasa (Sankalia et al. 1958: 153-154; Sankalia et al. 1960: 278, 301-306, 323). At Maheshwar, it is first mentioned in Period VI (AD 100-500) and is said to have been most common in Period VII, the socalled 'Muslim-Maratha phase' (Sankalia et al. 1958: 151), whilst at Nevasa, it first appears in Period V (50 $\mathrm{BC}-\mathrm{AD}$ 200), where it is represented by 'a few sherds', and then is said to have become the 'standard ware' of Period VI ('Muslim-Maratha'), although the report contradicts itself further on by stating that red ware was more common in Period VI (Sankalia et al. 1960: 278, 323).

At both sites, the forms present in these wares and their occurrence through the sites' sequences seem to associate them with the 'Coarse Black ware' and 'Black ware' mentioned above under Thick Grey wares, whilst at Paithan, their fabric seems to associate them with Black and Red ware (below), as does the fact that they occur predominantly in Periods 1 and 2 together with a few sherds from later layers that are probably residual (Table 7.3).

\section{Black and Red ware}

Types 10, 38.

This is a well-known ware, or perhaps 'manufacturing technique' would be a better term, that has been recorded from most Early Historic sites that have been excavated in the region as well as more widely across India (e.g. Sankalia et al. 1958: 134-135, 141-143, 144-146, 150, 152153, 162, 164; Sankalia et al. 1960: 259-263, 276, 282-286; Thapar 1967: 68-71; Deo and Gupte 1974: 91-92, 103-104, 110). The ware has a long history, possibly stretching back as early as the Harappan period in some places, but it occurs as late as the Early Historic period in a series of forms similar to those found at Paithan (Ghosh 1989, I: 94-95, 234-238).

At Paithan, it consists entirely of wheel-made, slightly closed bowls that are made of Fabric 3 and are fired black with the exception of the lower part of the exterior, from about $3 \mathrm{~cm}$ below the rim, where it is fired to between a yellowish red and a reddish yellow (5YR 5/6 to 7.5YR 7/6) due to having been fired upside down. At Paithan, the surface treatment never varies, being heavily burnished in all cases, although at other sites, for example Nevasa and Maheshwar, a few coarse and unburnished examples are also reported (Sankalia et al. 1958: 134; Sankalia et al. 1960: 259, 276).

At sites where it is recorded, Black and Red ware seems to decline in abundance from a peak in Early Historic levels, dwindling to much lower quantities by Medieval times, which is exactly the pattern observed at Paithan (see below). For example, at Maheshwar, Black and Red ware made up around c. $14.7 \%+$ of the Period IV assemblage (400-100 BC), 11.4\% of the Period V assemblage (100 BC-AD 200), 8.4\% of the Period VI assemblage (AD 200-500) and only a few sherds of the Period VII assemblage (Medieval) (Sankalia et al. 1958: 137, 143, 150, 162). At Nevasa, it was present in Period IV (150 BC-AD 150), made up a lower quantity in Period V (AD 50-200) and was not mentioned in Period VI (AD 1400+) (Sankalia et al. 1960: 259, 276, 322-324). At Prakash, in Period II (600-100 BC), Black and Red made up a total of $34.83 \%$, declining from $55.48 \%$ to 9.09\% through that period, whilst in Periods III (AD 50-200) and IV, it was not mentioned (Thapar 1967: 27, 84-93). At Bhokardan, in Period IA (early Satavahana), it made up 'much less than other wares', whilst in Period IB (late Satavahana), it made up a 'large number of sherds', and in Period II (post-Satavahana), 'less bulk' (Deo and Gupte 1974: 91-92, 103-104, 110). These figures can be compared with Paithan, where Black and Red ware made up the following proportions of the period-assemblages: $16.96 \%$ in Period 1, 10.49\% in Period 2, 2.9\% in Period 3 and 3.45\% in Period 4. It is possible to see a broadly similar decline in the circulation of this ware at all sites in the region, although there are some, for example Bhokardhan, where the pattern does not seem to hold up well, possibly due to imprecise quantification. 


\section{Other wares}

Table 7.3 shows the occurrence of each ware by period as rim-sherd counts and percentages of total period rimsherd counts. The percentages are based on the number of rims as the majority of body sherds were not classified according to ware. It should also be noted that many rim-sherds were not allocated a ware type, as has been noted above. These sherds are included in the group called 'Other' in the table. These sherds were, however, classified by type and their occurrence is shown in Table 7.5. Whilst most body sherds were not classified by ware, those belonging to particular diagnostic wares such as NBP, RPW, etc., were also recorded. These are not included in the percentage analysis in Table 7.3 as they would obviously bias the trends elucidated there, but these sherds are listed in Table 7.4 so that their occurrence through the sequence can be seen.

Table 7.3 makes clear the relative significance of different wares through the sequence. Particularly notable are the decline in Black and Red ware from Period 1 onwards and the increase in Thick Grey ware in Period 3. One very obvious absence from Table 7.3 and the discussion above is the group of wares that are normally described as 'red', or 'coarse red' or 'red slipped' wares. Such wares normally make up a large proportion of the Early Historic assemblages from sites in the region; for example in Period IV at Maheshwar, 'coarse red' and 'red slipped' made up $47.4 \%$ and $29.3 \%$, respectively, of the assemblage, whilst in Period IV at Nevasa, a 'wide range of shapes' are recorded in coarse and slipped red pottery, whilst 'coarse red ware' is reported as being the most common ware in Period V (Sankalia et al. 1958: 137; Sankalia et al. 1960: 256, 277). The same is true at Prakash, where red ware is reported as making up most of the 'other wares' that themselves make up almost $65 \%$ of the Period II assemblage, whilst the Period III assemblage is described as being 'wholly of monochrome red ware' (Thapar 1967: 27, 75, 84). As can be seen in Table 7.2, at Paithan, rim-sherds that traditionally would have been defined as 'red wares' (e.g. Fabrics $1 \mathrm{a}, 1 \mathrm{~b}$ and $1 \mathrm{c}-$ which include at least five different combinations of slipping and burnishing) made up roughly $76 \%$ of Period $1,78 \%$ of Period 2, $60 \%$ of Period 3 and $51 \%$ of Period 4 rim assemblages. Although the 'Red ware' category was not used at Paithan because it is too broad and poorly defined to be reliable, these approximate figures are given here to allow rough comparisons to be made with other sites.

However, in most of these cases, 'red ware' is little more than a crude description of clay colour. In reality, there are marked variations in colour, fabric, surface treatment, form and manufacture amongst these materials, and for this reason, 'red ware' was not further used as a category in this study. This presented the problem of how to classify the remaining $80 \%$ to $90 \%$ of the 'red', 'buff' and 'tan' coloured rim-sherd assemblage that remained after the wares that have been defined above had been removed. As explained above, after a considerable amount of trial and error, it was decided that it was not possible, using the human eye and $\mathrm{a} \times 10$ hand lens, to define wares within this material with characteristics that were consistent, coherent and usable. At the same time, it was noted that it was possible to subdivide the forms and shapes of the vessels into consistent and easily recognizable types. It was therefore decided that a form- and typebased approach was the most effective method of classifying the rim-sherd assemblage from the excavations. The resulting typology is presented below.

\section{Typology}

Fifty-six separate types were defined, all of which are based on rim forms. Each type is described below and reference is given to illustrations in Figs 7.8 to 7.18. A small graph is included at the end of the chapter showing the 'occurrence profile', or the percentage each type makes up of the period rim assemblages through the sequence. The data upon which these graphs are based are presented in Table 7.5. Tables 7.6 to 7.11 also show the occurrence of types through the sequences of each of the main trenches, context by context.

In order to avoid repetition, where types are made of Fabrics 1 to 5, which have been described above, this is simply indicated. Where the fabric is unique to the type, then a full description is given below, with the type description. It should be noted that all vessels are wheel-made unless otherwise stated.

It is acknowledged that the approach adopted here is at variance with that generally taken in the study of Early Historic pottery in India. For this reason, an attempt has been made to suggest what nomenclature might have been used for each type in the more commonly used classification system, for example 'coarse red ware', 'slipped red ware', etc. This is intended to provide a link if it should be needed; it should be stressed that such terms are only for rough guidance and are not precisely defined. 
Table 7.5: Types by period based on rim-sherd count (left) and percentages of total rim-sherd count (right). 'UNIQ' means unique sherd; the most important of these are described in Table 7.15.

\begin{tabular}{|c|c|c|c|c|c|c|}
\hline \multirow{2}{*}{$\frac{\text { Type }}{1}$} & \multirow{2}{*}{$\begin{array}{r}1 \\
2,005\end{array}$} & \multirow{2}{*}{$\begin{array}{r}2 \\
708\end{array}$} & \multicolumn{2}{|c|}{3 3-temple } & \multirow{2}{*}{$\begin{array}{r}4 \\
516\end{array}$} & \multirow{2}{*}{$\begin{array}{r}\text { Tota } \\
3,968\end{array}$} \\
\hline & & & 440 & 299 & & \\
\hline 10 & 853 & 569 & 44 & 21 & 72 & 1,559 \\
\hline $1 \mathrm{~A}$ & 625 & 1,503 & 82 & 4 & & 2,214 \\
\hline $1 \mathrm{~B}$ & 314 & 1,002 & 160 & 3 & & 1,479 \\
\hline$\underline{2}$ & 212 & 21 & 5 & & 30 & 268 \\
\hline 4 & 175 & 174 & 15 & 3 & 57 & 424 \\
\hline 8 & 115 & 84 & 5 & & 21 & 225 \\
\hline 3 & 110 & 159 & 18 & & 30 & 317 \\
\hline 16 & 105 & 171 & 36 & 9 & 73 & 394 \\
\hline 9 & 63 & 75 & 9 & & & 147 \\
\hline 5 & 46 & 52 & 10 & & 15 & 123 \\
\hline 43 & 45 & 20 & 19 & 3 & 11 & 98 \\
\hline 30 & 27 & 13 & & & 2 & 42 \\
\hline 38 & 25 & & & & & 25 \\
\hline 6 & 21 & 16 & & 1 & 23 & 61 \\
\hline 33 & 16 & 39 & 8 & 1 & 11 & 75 \\
\hline 36 & 12 & 6 & & & & 18 \\
\hline 40 & 12 & 10 & & & 3 & 25 \\
\hline 42 & 9 & 4 & & & & 13 \\
\hline 58 & 9 & 1 & & & & 10 \\
\hline 29 & 7 & 11 & - & 3 & 1 & 22 \\
\hline NBP & 5 & & & & & 5 \\
\hline 20 & 4 & 20 & 13 & & 72 & 109 \\
\hline 25 & 4 & 10 & 19 & & 13 & 46 \\
\hline 24 & 3 & 8 & 153 & 1 & 4 & 169 \\
\hline 39 & 3 & & & & & 3 \\
\hline 41 & 3 & 39 & & & 36 & 78 \\
\hline 35 & 2 & 5 & 3 & & & 10 \\
\hline 18 & 1 & 4 & 2 & & 1 & 8 \\
\hline 55 & 1 & & & & 24 & 25 \\
\hline 57 & 1 & & & & 15 & 16 \\
\hline 32 & & 41 & 8 & 2 & 9 & 60 \\
\hline 7 & & 26 & 6 & 1 & 23 & 56 \\
\hline 31 & & 15 & 4 & & & 19 \\
\hline 19 & & 14 & & & & 14 \\
\hline 37 & & 13 & & & & 13 \\
\hline 34 & & 5 & 3 & & & 8 \\
\hline 12 & & 2 & 4 & & 10 & 16 \\
\hline 26 & & 2 & 27 & 4 & & 33 \\
\hline 14 & & 1 & 10 & & 19 & 30 \\
\hline 22 & & 1 & 2 & 1 & 2 & 6 \\
\hline 27 & & 1 & 19 & 1 & 3 & 24 \\
\hline RPW & & 1 & & & 1 & 2 \\
\hline 50 & & & 7 & & 5 & 12 \\
\hline 44 & & & 5 & & 65 & 70 \\
\hline 47 & & & 5 & & 34 & 39 \\
\hline 48 & & & 1 & & 125 & 126 \\
\hline 51 & & & & & 62 & 62 \\
\hline 46 & & & & & 31 & 31 \\
\hline 13 & & & & & 30 & 30 \\
\hline 45 & & & & & 19 & 19 \\
\hline 49 & & & & & 16 & 16 \\
\hline 53 & & & & & 15 & 15 \\
\hline
\end{tabular}

\begin{tabular}{|c|c|c|c|c|c|}
\hline Type & 1 & 2 & 3 & 3-temple & 4 \\
\hline 1 & 38.74 & 13.05 & 29.43 & 73.46 & 24.76 \\
\hline 10 & 16.48 & 10.49 & 2.94 & 5.16 & 3.45 \\
\hline $1 \mathrm{~A}$ & 12.07 & 27.71 & 5.48 & 0.98 & \\
\hline $1 \mathrm{~B}$ & 6.07 & 18.47 & 10.70 & 0.74 & \\
\hline$\underline{2}$ & 4.10 & 0.39 & 0.33 & & 1.44 \\
\hline 4 & 3.38 & 3.21 & 1.00 & 0.74 & 2.74 \\
\hline 8 & 2.22 & 1.55 & 0.33 & & 1.01 \\
\hline 3 & 2.13 & 2.93 & 1.20 & & 1.44 \\
\hline 16 & 2.03 & 3.15 & 2.41 & 2.21 & 3.50 \\
\hline 9 & 1.22 & 1.38 & 0.60 & & \\
\hline 5 & 0.89 & 0.96 & 0.67 & & 0.72 \\
\hline 43 & 0.87 & 0.37 & 1.27 & 0.74 & 0.53 \\
\hline 30 & 0.52 & 0.24 & & & 0.10 \\
\hline 38 & 0.48 & & & & \\
\hline 6 & 0.41 & 0.29 & & 0.25 & 1.10 \\
\hline 33 & 0.31 & 0.72 & 0.54 & 0.25 & 0.53 \\
\hline 36 & 0.23 & 0.11 & & & \\
\hline 40 & 0.23 & 0.18 & & & 0.14 \\
\hline 42 & 0.17 & 0.07 & & & \\
\hline 58 & 0.17 & 0.02 & & & \\
\hline 29 & 0.14 & 0.20 & & 0.74 & 0.05 \\
\hline NBP & 0.10 & & & & \\
\hline 20 & 0.08 & 0.37 & 0.87 & & 3.45 \\
\hline 25 & 0.08 & 0.18 & 1.27 & & 0.62 \\
\hline 24 & 0.06 & 0.15 & 10.23 & 0.25 & 0.19 \\
\hline 39 & 0.06 & & & & \\
\hline 41 & 0.06 & 0.72 & & & 1.73 \\
\hline 35 & 0.04 & 0.09 & 0.20 & & \\
\hline 18 & 0.02 & 0.07 & 0.13 & & 0.05 \\
\hline 55 & 0.02 & & & & 1.15 \\
\hline 57 & 0.02 & & & & 0.72 \\
\hline 32 & & 0.76 & 0.54 & 0.49 & 0.43 \\
\hline 7 & & 0.48 & 0.40 & 0.25 & 1.10 \\
\hline 31 & & 0.28 & 0.27 & & \\
\hline 19 & & 0.26 & & & \\
\hline 37 & & 0.24 & & & \\
\hline 34 & & 0.09 & 0.20 & & \\
\hline 12 & & 0.04 & 0.27 & & 0.48 \\
\hline 26 & & 0.04 & 1.81 & 0.98 & \\
\hline 14 & & 0.02 & 0.67 & & 0.91 \\
\hline 22 & & 0.02 & 0.13 & 0.25 & 0.10 \\
\hline 27 & & 0.02 & 1.27 & 0.25 & 0.14 \\
\hline RPW & & 0.02 & & & 0.05 \\
\hline 50 & & & 0.47 & & 0.24 \\
\hline 44 & & & 0.33 & & 3.12 \\
\hline 47 & & & 0.33 & & 1.63 \\
\hline 48 & & & 0.07 & & 6.00 \\
\hline 51 & & & & & 2.98 \\
\hline 46 & & & & & 1.49 \\
\hline 13 & & & & & 1.44 \\
\hline 45 & & & & & 0.91 \\
\hline 49 & & & & & 0.77 \\
\hline 53 & & & & & 0.72 \\
\hline
\end{tabular}




\begin{tabular}{|c|c|c|c|c|c|c|}
\hline Type & 1 & 2 & \multicolumn{2}{|c|}{3 3-temple } & 4 & Total \\
\hline CHIN & & & & & 12 & 12 \\
\hline 54 & & & & & 11 & 11 \\
\hline 23 & & & & & 8 & 8 \\
\hline 15 & & & & & 7 & 7 \\
\hline 56 & & & & & 7 & 7 \\
\hline 52 & & & & & 5 & 5 \\
\hline PERS & & & & & 1 & 1 \\
\hline UNIQ & 8 & 21 & 23 & & 30 & 82 \\
\hline NON & 335 & 557 & 330 & 50 & 504 & 1,776 \\
\hline Total & 5,176 & 5,424 & 1,495 & 407 & 2,084 & 14,586 \\
\hline
\end{tabular}

Throughout the description of types below, reference is occasionally made to whether the absence of a particular type is 'significant' or not. In this context, 'significant' means that three sherds or more of the type would have been expected in the period assemblage concerned, given the size of that assemblage and the proportion that the type makes up of other periodassemblages where it is found.

\section{Type: 1}

\section{Traditional ware name: Coarse red ware}

- Description: This is a very common, coarseware bowl with nearly straightsides and a simple pointed rim that is sometimes slightly thickened and upturned. The diameter is normally $10-12 \mathrm{~cm}$, although up to $18 \mathrm{~cm}$ has been observed. The bowl has a flat, string-cut base. Type 1 was subdivided into two subtypes, Types $1 \mathrm{a}$ and $1 \mathrm{~b}$, based on size (see below).

- Ware: Fabric 1a.

- Illustration: Fig. 7.8.

- Subtypes: Type 1a is a small version with a maximum wall thickness of $5.5 \mathrm{~mm}$ and a rim diameter of $7-12 \mathrm{~cm}$. Type $1 \mathrm{~b}$ is a large version with a minimum wall thickness of $5.5 \mathrm{~mm}$ and a rim diameter of 12-20 cm, averaging about $17 \mathrm{~cm}$.

- Internal dating evidence: Fig. 7.23 shows the occurrence of Types 1a and $1 \mathrm{~b}$ as well as the total for all Type 1. Type 1 is the most common type recorded in the assemblage, making up between $50 \%$ and $60 \%$ of the rim assemblage in Periods 1 and 2, with a decline to $45 \%$ and $25 \%$ in Periods 3 and 4, respectively. The very high percentage in Period 3-temple

\begin{tabular}{|c|c|c|c|c|c|}
\hline Type & 1 & 2 & \multicolumn{2}{|c|}{3 3-temple } & 4 \\
\hline CHIN & & & & & 0.58 \\
\hline 54 & & & & & 0.53 \\
\hline$\underline{23}$ & & & & & 0.38 \\
\hline 15 & & & & & 0.34 \\
\hline 56 & & & & & 0.34 \\
\hline 52 & & & & & 0.24 \\
\hline PERS & & & & & 0.05 \\
\hline UNIQ & 0.15 & 0.39 & 1.54 & & 1.44 \\
\hline NON & 6.47 & 10.27 & 22.07 & 12.29 & 24.18 \\
\hline
\end{tabular}

is probably anomalous due to the small size of the assemblage in that period. There is a marked decline in Period 4, many of the sherds from which may be residual, although it seems unlikely that the type ever went completely out of use. The smaller version (Type 1a) is more common in Periods 1 and 2, but this changes in Period 3, where the larger version (Type $1 \mathrm{~b}$ ) becomes more common.

- External parallels: Given the frequency of Type 1 at Paithan, it is surprising that it does not receive greater mention in the published pottery reports from other sites in the region. This may be because it is a ubiquitous, rather simple, shape with a broad chronological range, but it may also be the case that this type is particularly common at Paithan. It is frequently found at Brahmapuri (Sankalia and Dikshit 1952: fig. 18, type 52), whereas at other sites, there is usually no indication of how common this type is, and some of the illustrated types may have been single examples. For example in Period V at Nevasa, there are two types (76 and 97) that are broadly comparable in terms of shape, although the size of 76 is different, as is the fact that it is red slipped (Sankalia et al. 1960: figs 129 and 138). At Nasik, which is considerably further distant than Nevasa, better parallels can be found in Period IIA in types 13,13a and 13b, and also types 62 and 64 in Period IV (Sankalia and Deo 1955: figs 16 and 31). At Bhokardan, parallels can be found in Periods IA and IB (Deo and Gupte 1974: fig. 5 type 1 and 1a, fig. 11 type 63), at Ter in Periods I and II (Chapekar 1969: fig. 7 type 11b, fig. 15 type 33), at Prakash in Periods II and IV (Thapar 1967: fig. 23 type 1 and 1a, fig. 29 type 1) and at Maheshwar in Period IV (Sankalia et al. 1958: fig. 60 type 82). 
Type: 2

\section{Traditional ware name: Coarse red ware}

- Description: This is a small jar with an everted, slightly thickened rim above a short neck. There is some variation in the shape of the rim. The diameter is about $10 \mathrm{~cm}$.

- Ware: Fabric 1a.

- Illustration: Fig. 7.8.

- Internal dating evidence: This type was very common in Period 1 but shows a marked decline after that time. It seems likely that it only occurred in Period 1 and that the few sherds from later periods are residual (Fig. 7.23).

- External parallels: This is a reasonably common type in Period 1 at Paithan, but it is not possible to find reliable parallels in other published assemblages in the region. This may be because this type is not particularly distinctive and is difficult to identify with certainty in published drawings.

Type: 3

Traditional ware name: Burnished and slipped red ware

- Description: This is a large jar with a thick, everted rim (diameter 14-16 cm), normally rounded but also occasionally squared or triangular. There is always a distinctive notch on the inside just below the top of the rim. In this respect, it is similar to Type 4. All examples have a thick, polished, red slip/paint on the interior and exterior surfaces. There is also occasionally some light ribbing on the outside. The size seems to vary considerably. There are also similarities with Types 7,13 and 25 .

- Ware: Fabric 1a.

- Illustration: Fig. 7.8.

- Internal dating evidence: This type makes up between $2 \%$ and $3 \%$ of the assemblage in Periods 1 and 2, but there is a sharp decline in the quantity of this type after Period 2, suggesting that the type may have gone out of circulation at that time. The sherds from Periods 3 and 4 are probably residual (Fig. 7.23).

- External parallels: This is a distinctive and common type at Paithan, so it is no surprise that parallels can be found at other sites in the region, for example in Period IIa at Nasik, Period IV at Nevasa, Periods 1A and 1B at Bhokardan, Periods I and II at Ter, Period III at Prakash and Period V at Maheshwar (Sankalia and Deo 1955: fig. 9 type 3a and c, fig. 10 type 4c, fig. 11 type 5 and fig. 12. type 6c; Sankalia et al. 1958: fig. 74 type 103; Sankalia et al. 1960: fig. 118 types 46 and 47; Thapar 1967: fig. 28 type 19a; Chapekar 1969: fig. 4 types 2d and 3a, fig. 15 type 30f; Deo and Gupte 1974: fig. 5 type 7b, fig. 6 type 17b, fig. 7 types 24, 24a and 24b, fig. 12 type $71 \mathrm{~b})$. The fact that this type was found only in the later periods at Maheshwar and Prakash seems to go against the evidence for it being a predominantly early type at Paithan.

\section{Type: 4}

\section{Traditional ware name: Slipped red ware}

- Description: This is a small jar with a thickened, outward-curving rim marked by a distinctive notch on the interior. The diameter is normally about $12-15 \mathrm{~cm}$. The surface is covered with a thin red slip/wash, which is more evident on the exterior. There are marks of wet clay on the surface. This type is often very similar to Type 16 .

- Ware: Fabric 1a.

- Illustration: Fig. 7.8.

- Internal dating evidence: This type has a strange occurrence profile: it was abundant in Periods 1 and 2 but appears to have ceased circulating after that time, although a significant number of sherds was also found in Period 4 layers. These are probably residual and reflect the high levels of residuality noted in that period (Fig. 7.23).

- Comments: One fragment of Type 4 comes from context 738 , low down in the Trench D2 sequence. This is unusual, being thinner than normal and having a polished red slip, which Type 4 never normally has meaning that it is probably a mis-identification.

\section{Type: 5}

\section{Traditional ware name: Slipped red ware}

- Description: This is a lid with a pinched edge and high ridge. The diameter of the widest part is about $14 \mathrm{~cm}$. It is coated with a fine, matt red slip/wash on both the interior and exterior.

- Ware: Fabric 1a.

- Illustration: Fig. 7.8.

- Internal dating evidence: The percentage of this type declined after Period 2, but it is not possible to be certain whether sherds from Periods 3 and 4 are 
Chapter 7 The Pottery $\quad 117$

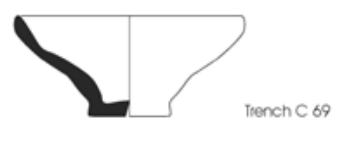

Type 1
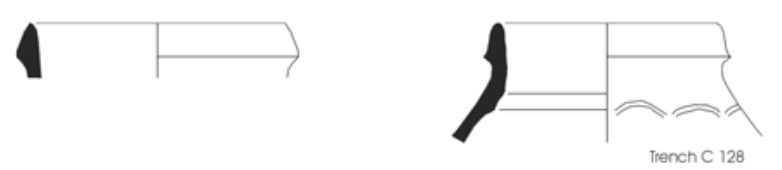

Type 2
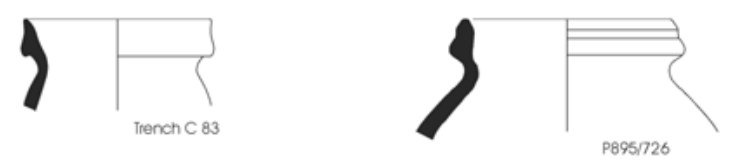

Type 3

Trench C BAA
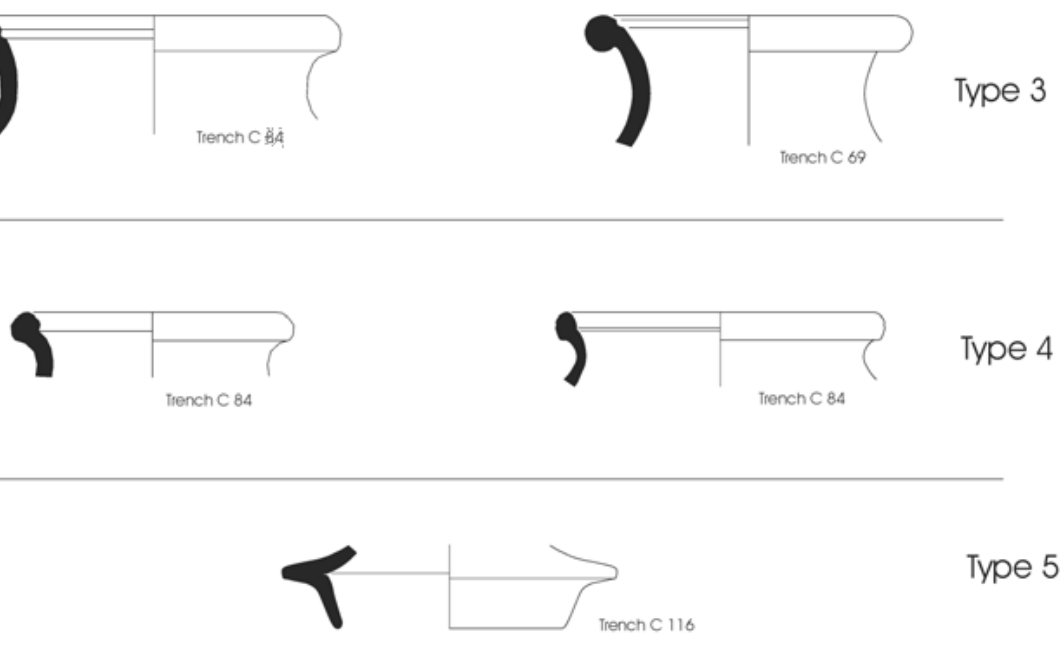

Type 5

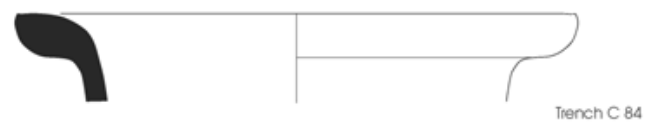

Type 6
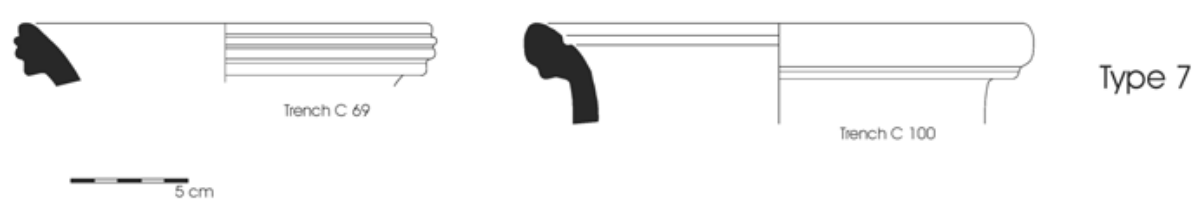

Fig. 7.8: Types 1 to 7. 
residual or not. They are quite abundant, probably indicating that the type had a very long life span extending right into Period 4. The type's absence from Period 3-temple is to be explained by the small size of the assemblage in that period.

- External parallels: Parallels can be found at most sites in the region, for example at Brahmapuri in 'late Satavahana' and 'Brahmani' levels, at Bhokardan in Periods IA and 1B, at Nasik in Periods IIA and IV, at Ter in Periods I and II, at Prakash in Periods II and III and at Maheshwar in Period V (Sankalia and Dikshit 1952: fig. 18 type 56; Sankalia et al. 1958: fig. 71 type 98; Sankalia and Deo 1955: fig. 20 types 21-24, fig. 33 types 73-80; Thapar 1967: fig. 23 type 8, fig. 27 type 1; Chapekar 1969: fig. 6 type 5, fig. 13 type 26, fig. 17 type 34; Deo and Gupte 1974: fig. 6 type 10, fig. 12 type 73 ).

\section{Type: 6}

\section{Traditional ware name: Burnished and slipped red ware}

- Description: This is a large jar or vase with a thick wall and a very heavy, thick everted rim with a diameter of about $24 \mathrm{~cm}$. Internal and external surfaces are both coated with a thick polished red slip/ paint, which is often quite well preserved.

- Ware: Fabric $1 \mathrm{~b}$.

- Illustration: Fig. 7.8.

- Internal dating evidence: This type has a problematic occurrence profile. It certainly circulated during Periods 1 and 2 and then seems to have disappeared in Period 3. Period 4, however, yielded a higher percentage of this type than either Period 1 or 2. This is difficult to account for; it may be explained by the generally high levels of residuality in Period 4 or it may be related to problems identifying this type in some cases.

- Comments: The distinction between this type and Type 9 is not always clear.

- External parallels: Parallels for this type are not common; roughly similar types have been published from Ter in Period II and at Prakash in Period II (Thapar 1967: fig. 25 type 25; Chapekar 1969: fig. 10 type 20e).
Type: 7

Traditional ware name: Burnished and slipped red ware

- Description: This is a relatively rare but very distinctive jar with an everted, thickened rim, the external vertical face of which is marked with two or three deep horizontal notches. The diameter is $12-20 \mathrm{~cm}$. The vessel is covered with a thick polished red paint/slip on both surfaces.

- Ware: Fabric $1 \mathrm{~b}$.

- Illustration: Fig. 7.8.

- Internal dating evidence: This form only occurs from Period 2 onwards and is very abundant in Period 4, which may be linked to the high levels of residuality in that period. This type's clearly significant absence from Period 1 makes it a useful chronological marker at Paithan (Fig. 7.23).

- Comments: The presence of this form was used to make the distinction between levels of Period 1 and Period 2 when the sequence was periodised (see Chapter 6).

- External parallels: This type also occurs at Nevasa in Period IV, at Bhokardan in period 1A, at Nasik in Periods IIA and IV, at Ter in Period I and at Prakash in Period II (Sankalia and Deo 1955: fig. 9 type 3e-h, fig. 21 types 26a and b, fig. 35 type 94; Sankalia et al. 1960: fig. 118 type 46c; Deo and Gupte 1974: fig. 6 type 18, fig. 8 type 41a; Thapar 1967: fig. 25 type 30; Chapekar 1969: fig. 6 type 6a-c).

\section{Type: 8}

\section{Traditional ware name: Slipped red ware}

- Description: This is a wide bowl with an almost vertical, in-turned rim that is carinated and slightly thickened on the carination, sometimes enough to make the profile almost triangular. The rim diameter is around $28 \mathrm{~cm}$. The vessel is often covered with a thin, matt slip similar to Type 5, but this is never polished.

- Ware: Fabric 1a.

- Illustration: Fig. 7.9.

- Internal dating evidence: The occurrence profile of this type shows a clear and marked decline in abundance from Period 1 onwards, with a slight increase in Period 4 that is probably due to the high levels of residuality in that period. Fig. 7.23 shows a histogram of the occurrence of this type through the sequence. 
- External parallels: It is not always possible to be certain of identifications of this type made from published drawings. Probable parallels have been found at Nevasa in Period IV, Nasik in Periods IIA and IV, Ter in Period II, Prakash in Period III and Maheshwar in Period V (Sankalia and Deo 1955: figs 17 and 17 a types $17 \mathrm{~d}-\mathrm{j}$, figs $18-19$ types 18 and 19; Sankalia et al. 1958: fig. 72 type 99, fig. 73 type 100; Sankalia et al. 1960: fig. 119 type 49; Thapar 1967: fig. 27 type 4; Chapekar 1969: fig. 12 type 23d).

\section{Type: 9}

\section{Traditional ware name: Burnished and slipped red ware}

- Description: This is a bowl with tightly curved sides and a thick, broad, everted rim that is slightly thickened and rounded at the end and with a diameter of $16 \mathrm{~cm}$ or more in some cases. The surface is sometimes covered with a polished red slip/wash.

- Ware: Fabric 1b.

- Illustration: Fig. 7.9.

- Internal dating evidence: Type 9 almost certainly ceased to circulate after Period 2 or early in Period 3. The few sherds found in Period 3 levels are probably residual (Fig. 7.24).

- Comments: During the course of the pottery study, it became clear that Types 6 and 9 are probably different sizes of the same type, Type 9 being the smaller of the two.

- External parallels: Similar types are reported from Nevasa Period V, Nasik Period IIA, Ter Period II and Maheshwar Period IV (Sankalia andDeo 1955: fig. 15 type 10c; Sankalia et al. 1958: fig. 60 type 83; Sankalia et al. 1960: fig. 129 type 74, fig. 135 type 86; Chapekar 1969: fig. 16 type 32g).

\section{Type: 10}

\section{(Black and Red ware) Traditional ware name: Black and} Red ware

- Description: This is the more common of the two Black and Red ware forms. It is a simple, almost vertically sided bowl/cooking pot. It is thin-walled (up to $5 \mathrm{~mm}$ ) with a heavily burnished gloss over the slip both inside and out. The rim diameter is normally between 17 and $20 \mathrm{~cm}$ but can be smaller.

- Ware: Fabric 3.

- Illustration: Fig. 7.9.
- Internal dating evidence: This type declines very markedly after Period 1. It probably went out of use during the course of Period 2 and the sherds from Periods 3 and 4 are probably residual (Fig. 7.24).

- External parallels: This is an extremely common type and has been found at all sites in the region where Black and Red ware has been encountered, for example Nevasa Periods IV and V, Bhokardan Periods IA, IB and II, Nasik Period IIA, Ter Period I, Prakash Period II and Maheshwar Period IV (Sankalia and Deo 1955: figs 26 and 37; Thapar 1967: fig. 20; Sankalia et al. 1958: fig. 63 type 89; Sankalia et al. 1960: fig. 115 type 28e-i, fig. 124 fig. 59a and b; Chapekar 1969: fig. 6 type 15; Deo and Gupte 1974: fig. 9 types 50-51, fig. 15 types 115-116, fig. 17 type 138).

- Note: Two of the illustrated sherds (1766 and 863) have crude incised symbols on their exteriors just below the rim. This arrow-like symbol is known from other sites in the region; for example at Prakash, it was found in Period I on a sherd of Jorwe ware (Thapar 1967: 67, fig. 19 8), whilst at Nasik, it was found on a sherd of red ware whose period is not reported (Sankalia and Deo 1955: 84, fig. 8a 1).

\section{Type: 11}

\section{(Black Burnished ware) Traditional ware name:}

\section{Burnished black ware}

- Description: This is a small jar with a small everted triangular rim, the diameter of which is about 12 $\mathrm{cm}$. The surface is heavily burnished. The type is represented only by three small sherds.

- Ware: Fabric 3.

- Illustration: Fig. 7.9.

- Internal dating evidence: No examples of this type were found in the stratified sequence (the illustrated example is from an unstratified layer). 

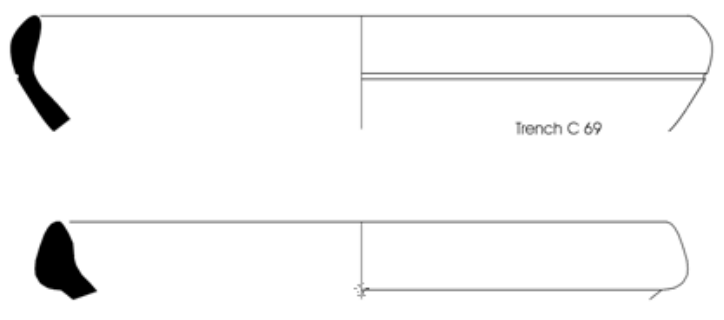

Type 8

Irench C 87
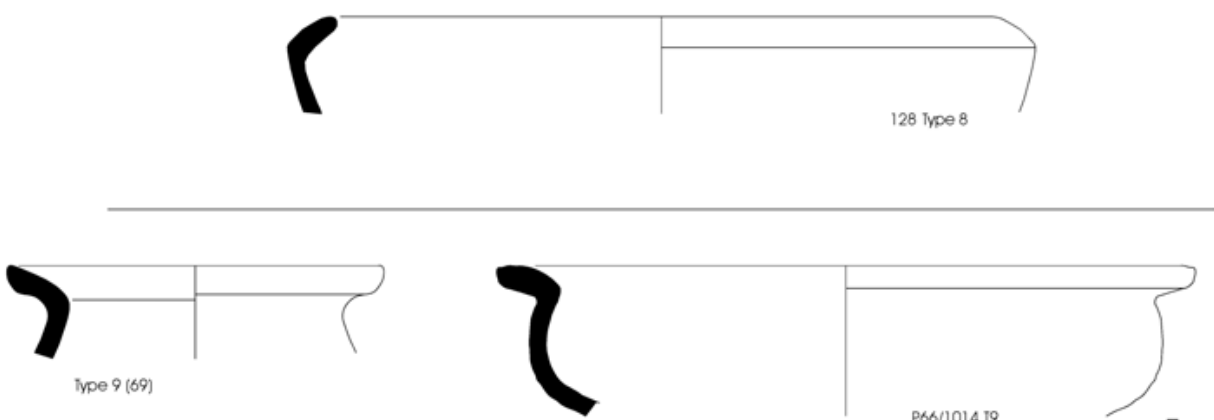

P66/1014 19

Type 9
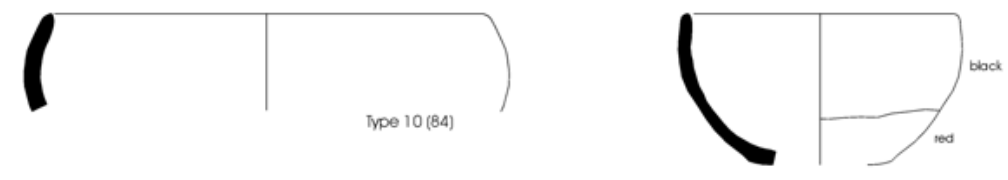

100 iype 10

Type 10

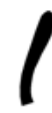
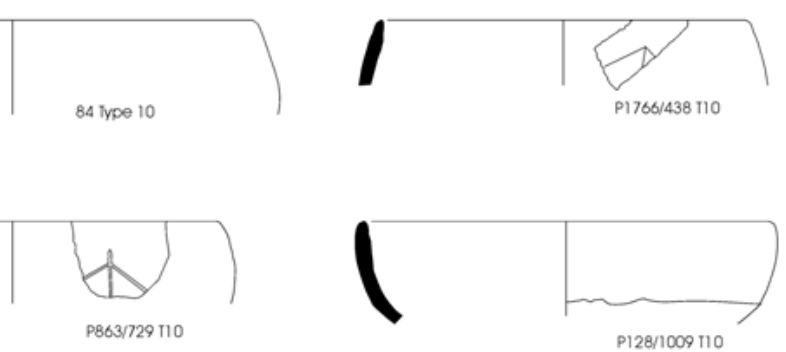

1

Type 11 (83)

Type 11

$-5 \mathrm{~cm}$

Fig. 7.9: Types 8 to 11. 


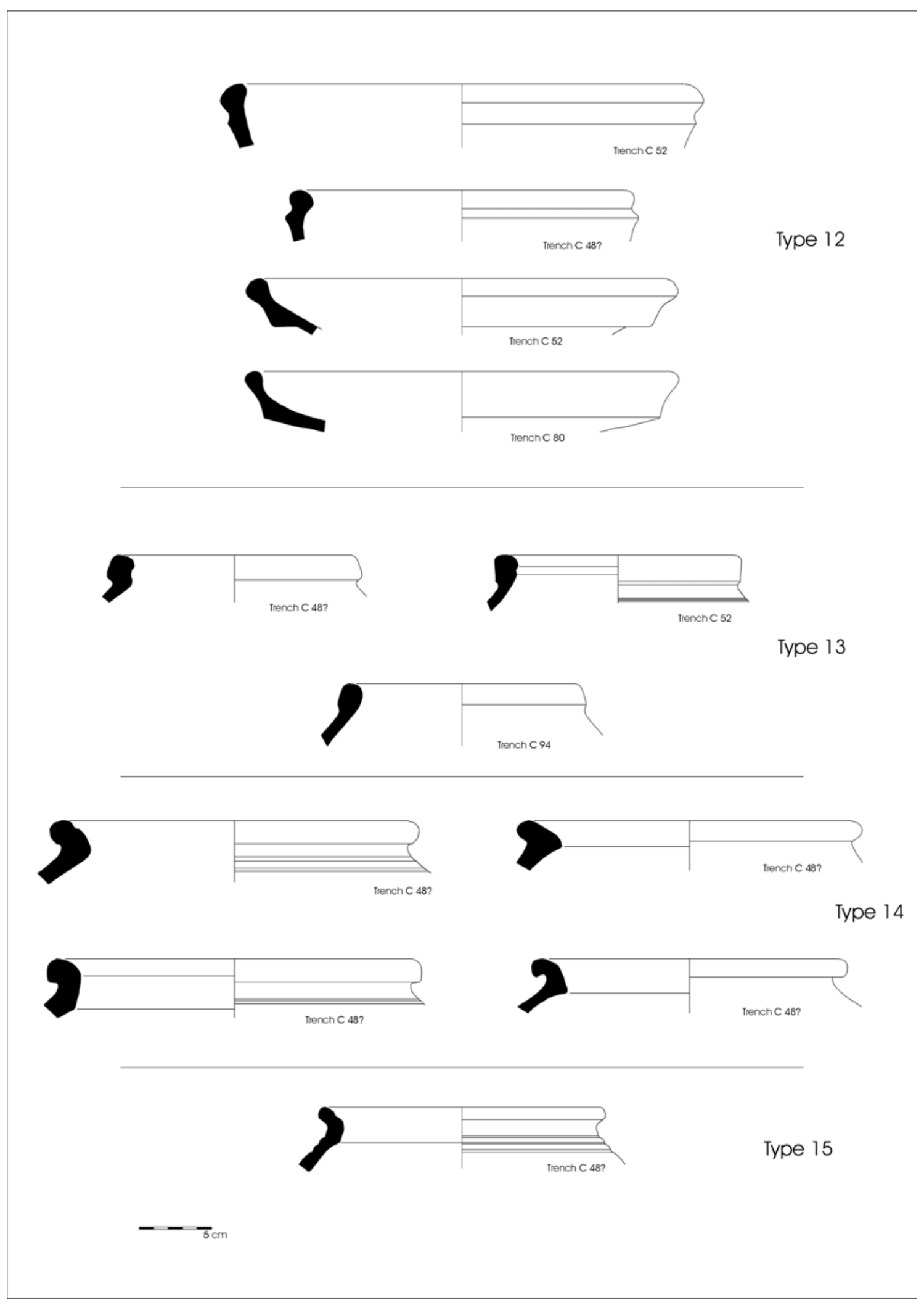

Fig. 7.10: Types 12 to 15. 


\section{Type: 12}

\section{Traditional ware name: Coarse red ware}

- Description: This is a large carinated bowl with a distinctive rounded and thickened rim that flares outwards above the carination. It is a coarse, thickwalled vessel. The diameter is $25-30 \mathrm{~cm}$. It is fired to a dark grey/black red. Traces of a surface wash are only occasionally seen. This is quite a variable type.

- Ware: Fabric 1a.

- Illustration: Fig. 7.10.

- Internal dating evidence: This is not a common type. There are two sherds from Period 2 but it is mostly restricted to Periods 3 and 4, particularly the latter. Because the type is so rare, it is possible that its absence from Period 1 is due to chance. It may have been in circulation at that time (Fig. 7.24).

\section{Type: 13}

\section{Traditional ware name: none}

- Description: This is a large, broad-mouthed jar with a squared, thickened, vertical rim. There is a notch or indent on the interior and incised lines on some examples below the rim. The diameter is about $17-18 \mathrm{~cm}$. The burnished surface is preserved on a number of examples, one or two are also red slipped/washed.

- Ware: This is a type-specific fabric. It is a coarse grey ware with occasional very small grit inclusions. The dense fabric is medium to soft-fired with a smooth fracture and black body (7.5YR 2.5/1). One example contains vegetable temper, and the fracture shows a more laminar structure. This example is partly fired to a reddish yellow (7.5YR 6/6). This fabric appears to be a slightly better levigated and fired version of Fabric 1a.

- Illustration: Fig. 7.10.

- Internal dating evidence: This type occurs only in Period 4.

\section{Type: 14}

\section{(Thick Grey ware) Traditional ware name: Grey ware}

- Description: This is a Thick Grey ware jar or cooking pot with a heavy, everted rim and thick walls. The diameter is about $25-30 \mathrm{~cm}$. The exterior is normally burnished and decorated with incised lines.

- Ware: Fabric 2.
- Illustration: Fig. 7.10.

- Internal dating evidence: Apart from one sherd in Period 2, this type occurs only in Periods 3 and 4. Its absence from Period 3-temple is probably due to the small size of that assemblage. Given that ten sherds were found in Period 3, it is likely that its absence from Period 1 and limited presence in Period 2 are an accurate reflection of its dating (Fig. 7.24); see the discussion under 'Thick Grey ware' above.

- External parallels: As with Thick Grey wares, this type tends to be more common in the later levels at excavated sites, for example at Nevasa in Period IV, at Nasik in Period IV and at Ter in Period II (Sankalia et al. 1960: fig. 118 types 48 and 48a; Sankalia and Deo 1955: fig. 39 types 118-119; Sankalia et al. 1960: fig. 118 types 48 and 48a; Chapekar 1969: fig. 21 types 41-42).

\section{Type: 15}

\section{(Thick Grey ware) Traditional ware name: Grey ware}

- Description: This is a Thick Grey ware jar with an everted rim and ribbing below the rim on the exterior. The walls of the vessel around the rim tend to be rather thinner than in Type 14. The diameter is about $18 \mathrm{~cm}$. This type does also occur occasionally in red-washed ware.

- Ware: Fabric 2.

- Illustration: Fig. 7.10.

- Internal dating evidence: This type occurs only in Period 4.

\section{Type: 16}

\section{Traditional ware name: Coarse red ware}

- Description: This is a simple jar, the rim form is similar to Type 4, the rim being smaller, more everted and lacking the distinctive notch on the inside. The rim is quite variable, it is thickened, rounded and slightly triangular, even slightly overhanging. The diameter is about $13 \mathrm{~cm}$. It is not slipped or washed in most cases.

- Ware: Fabric 1a.

- Illustration: Fig. 7.11.

- Internal dating evidence: This type occurs in all periods and there is no obvious chronological pattern (Fig. 7.24).

- Comments: It was noted during the study that this form appears to become finer in the later levels 


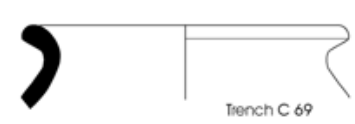

)

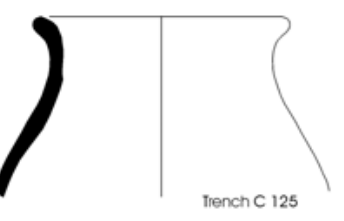

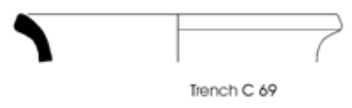

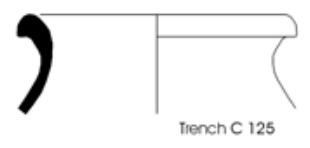

Type 16

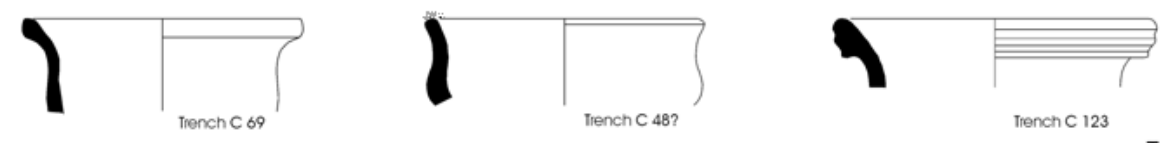

Type 17

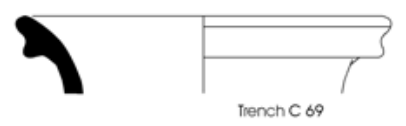

Type 18

Type 19

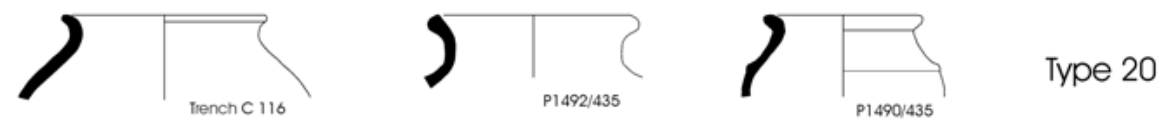

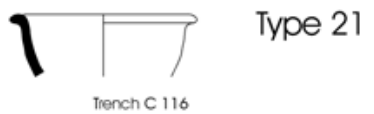

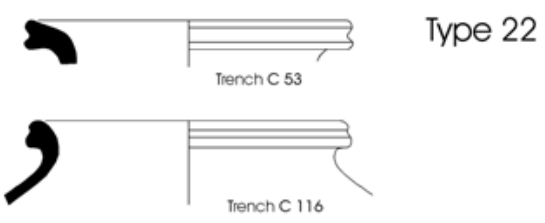

$--\overline{5} \mathrm{~cm}$

Fig. 7.11: Types 16 to 22 . 
of Trench B, where the surface is more commonly either burnished or slipped.

\section{Type: 17}

\section{Traditional ware name: Coarse red ware}

- Description: This is an almost vertically sided beaker or small jar with a slightly everted rim and slightly curved sides. It is possibly a variation on Type 16 . The diameter is about 12 to $14 \mathrm{~cm}$.

- Ware: Fabric 1a.

- Illustration: Fig. 7.11.

- Internal dating evidence: The rarity of this type makes it impossible to gain an accurate idea of its occurrence through the sequence.

\section{Type: 18}

Traditional ware name: Burnished and slipped red ware

- Description: This is a red or black ware jar with a bifoliate everted rim. There is often an incised notch on the interior. The diameter is about $14 \mathrm{~cm}$. It is covered with a thick polished red slip/wash.

- Ware: Fabric 1a. This type is also occasionally fired black.

- Illustration: Fig. 7.11.

- Internal dating evidence: Only a few examples of this type were found; they become increasingly common from Period 1 to 3, after which time the type ceased to circulate. The few sherds found in Period 4 are almost certainly residual.

- External parallels: A similar type is reported from Nevasa in Period V (Sankalia et al. 1960: fig. 130 type 75, fig. 131 type 77 ).

\section{Type: 19}

\section{Traditional ware name: Slipped red ware}

- Description: This is a large plate with a slightly raised, flattened rim. The diameter is about $24 \mathrm{~cm}$. There is a very thin matt red wash on the interior which gives a distinctive appearance.

- Ware: Fabric 1c.

- Illustration: Fig. 7.11.

- Internal dating evidence: The presence of this form was used to make the distinction between Period 1 and Period 2 when the sequence was periodised (see Chapter 6). It occurs only in Period 2. The type is wholly absent from Trench B, which is puzzling, but must simply be due to chance.

- External dating evidence: A roughly similar type is published from Brahmapuri in levels reported to date to the 'late Satavahana' period (Sankalia and Dikshit 1952: fig. 15 types 9 and 10).

\section{Type: 20}

\section{Traditional ware name: none}

- Description: This is a small, thin-walled jar with a finely shaped, everted rim. There is a carination on the body in some examples. The diameter is normally $8-10 \mathrm{~cm}$. It is fine-walled with a red wash on the smoothed exterior.

- Ware: Fabric 4.

- Illustration: Fig. 7.11.

- Internal dating evidence: This type occurs in all periods, but it is very rare in Period 1 and only becomes common in Period 4 (Fig. 7.24).

\section{Type: $\mathbf{2 1}$}

Traditional ware name: none

- Description: This is a small beaker with a fine everted rim and curved sides. The diameter is $6-8$ $\mathrm{cm}$. It has a thin body and a distinctive red slip/ wash.

- Ware: Fabric 4.

- Illustration: Fig. 7.11.

- Internal dating evidence: No examples of this type occurred in the quantified sequence (the illustrated example is from an unstratified layer).

\section{Type: 22}

\section{Traditional ware name: Coarse red ware}

- Description: This is a small jar with an almost horizontally everted, bifoliate rim. The diameter is about 12-13 cm.

- Ware: Fabric 1a. There is a slight snap to the break with a smooth to hackly fracture and no vegetable temper.

- Illustration: Fig. 7.11.

- Internal dating evidence: Very few sherds of this type came to light. There is only one sherd in Period 2 and two in Periods 3 and 4. Because this type is so rare, its absence from Period 1 cannot be 
taken as an indication that it was not in circulation at that time.

- External parallels: A similar type is reported from Bhokardan Period IB (Deo and Gupte 1974: fig. 13 types $81 \mathrm{a}-\mathrm{c}$ ).

\section{Type: 23}

\section{Traditional ware name: none}

- Description: This is a broad-mouthed jar with an everted, rounded rim with a slight notch on the interior. The diameter is about $18 \mathrm{~cm}$. The surface is smoothed with a thin wash.

- Ware: This is a type-specific fabric. It is a dense, well-levigated fabric with a smooth, almost subconchoidal fracture. The body breaks with a slight snap and appears to be only medium fired. The clay has few inclusions apart from occasional laminar particles of chaff or other vegetable temper and a very fine gritty structure that is caused by fine grains that are almost invisible even with $\mathrm{a} \times 10$ hand lens. The body is an even reddish yellow (7.5YR 7/8).

- Illustration: Fig. 7.12.

- Internal dating evidence: Eight sherds of this type occur in Period 4.

\section{Type: 24}

\section{(Thick Grey ware) Traditional ware name: Grey ware}

- Description: This is an extremely variable type. It is a jar with an everted rim that is rounded and slightly thickened at the end. The outward turn of the rim is marked by a sharp carination on the interior. The rim diameter is between 16 and $25 \mathrm{~cm}$, and the wall thickness is between 6 and $7 \mathrm{~mm}$. The jar was also sharply carinated around the middle of the body. The surface is burnished to a high polish which looks like a slip. Turning marks are visible on the surface. Although the basic concept of the jar is the same, there is a high degree of variability in the details of the form and the shape of the rim.

- Ware: Fabric 2.

- Illustration: Fig. 7.12.

- Internal dating evidence: Small quantities of this type occur in all periods, but it is very abundant in Period 3 (Fig. 7.24; see the discussion under 'Thick Grey ware' above).
- External parallels: Parallels to this type are most commonly found in the later levels at excavated sites, for example at Nevasa in Periods V and VI, at Brahmapuri in levels dated 'late Satavahana' or 'Brahmani', at Bhokardan in Periods IA, IB and II, at Nasik in Periods IIA and IV, at Ter in Period II and at Maheshwar in Period VI (Sankalia and Dikshit 1952: fig. 17 type 37a, fig. 19 types 65-66; Sankalia and Deo 1955: fig. 27 type 40, fig. 39 types 120-121; Sankalia et al. 1958: fig. 78 type 119, fig. 79 types 120-122; Sankalia et al. 1960: fig. 140 type 104, fig. 157 type 127, fig. 158 type 129; Chapekar 1969: fig. 17 type 40; Deo and Gupte 1974: fig. 9 types 46-48, fig. 15 types 112-114, fig. 17 type 133).

\section{Type: 25}

\section{Traditional ware name: Burnished and slipped red ware}

- Description: This is very similar to Type 3 in almost all respects, but it does not have an interior niche on the rim. The diameter is around $14 \mathrm{~cm}$.

- Ware: Fabric 1a.

- Illustration: Fig. 7.12.

- Internal dating evidence: This type occurs in all periods but is most common in Period 3. Some of the Period 4 sherds might be residual (Fig. 7.24).

Type: 26

(Thick Grey ware) Traditional ware name: Grey ware

- Description: This type was used as a catch-all for very fragmentary rim sherds of thick grey polished ware with a fairly heavy rolled rim. Some of these may in fact be Type 24, but they are too fragmentary to be certain. The diameter is normally about $20 \mathrm{~cm}$.

- Ware: Fabric 2.

- Illustration: Fig. 7.12.

- Internal dating evidence: Apart from two sherds in Period 2, which may be intrusive, this type is found almost entirely in Period 3 and Period 3-temple. As the type is represented by 27 sherds in Period 3, it seems certain that its absence from Period 1 is an indication that it was not in circulation at that time (Fig. 7.25; see also the discussion under 'Thick Grey ware' above). 


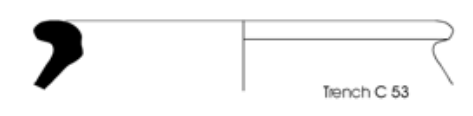

Type 23

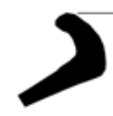

P80/312
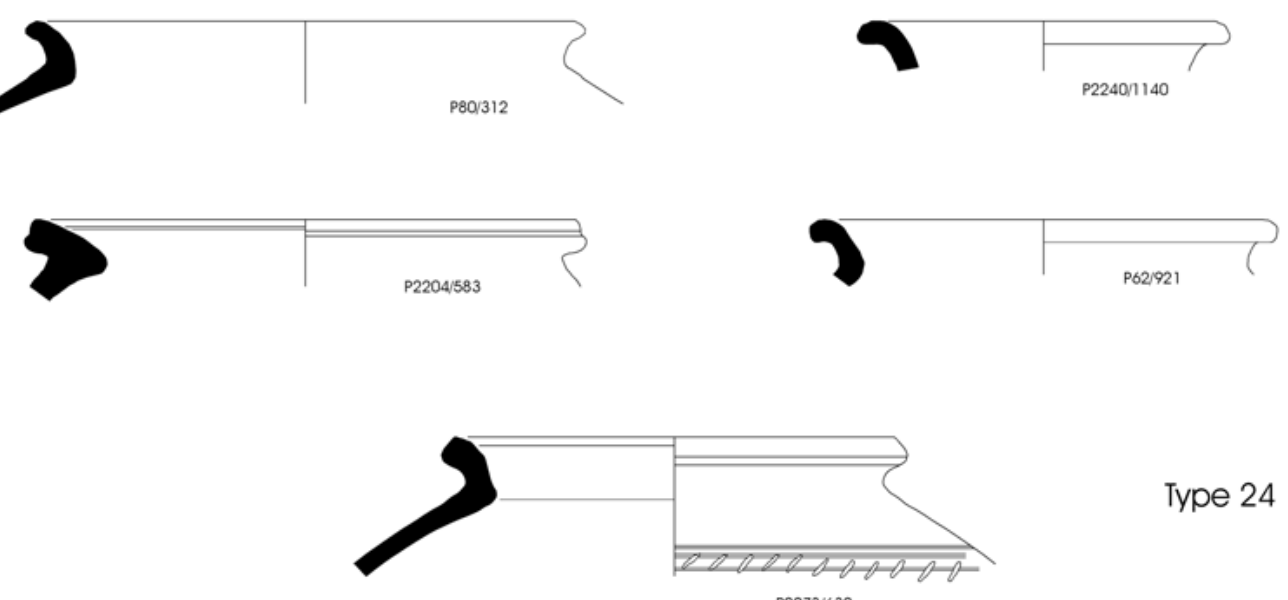

Type 24

P2273/ه32

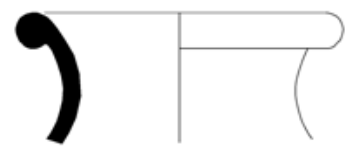

Type 25
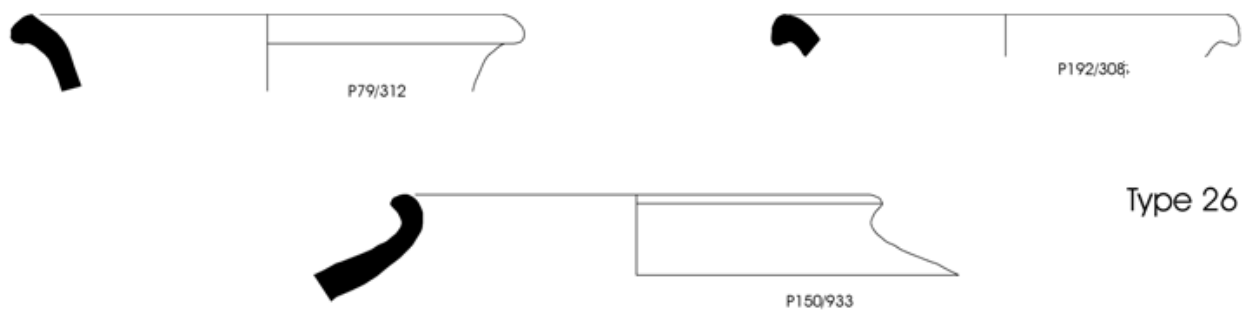

Type 26
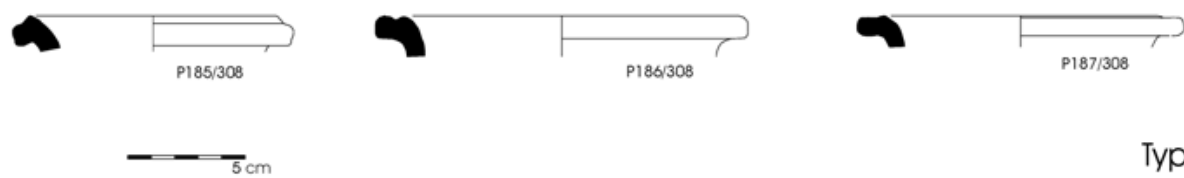

Type 27

Fig. 7.12: Types 23 to 27. 


\section{Type: 27}

\section{Traditional ware name: Burnished and slipped red ware}

- Description: This type has a slightly complex everted rim with a niche on the upper surface. The width of the everted part of the rim is somewhat variable, but the concept is the same. The diameter is $12-14 \mathrm{~cm}$. The surface of these sherdshas a fine red polished slip on the interior and exterior.

- Ware: Fabric 1a.

- Illustration: Fig. 7.12.

- Internal dating evidence: Apart from a single sherd in Period 2, and a few residual sherds in Period 4, this type is found exclusively in Period 3. As the type is represented by 19 sherds in Period 3, it seems certain that its absence from Period 1 is an indication that it was not in circulation at that time (Fig. 7.25).

\section{Type: 28}

Traditional ware name: none

- Description: This type number was not used.

\section{Type: 29}

(Black Burnished ware) Traditional ware name:

\section{Burnished black ware}

- Description: This is a simple, almost vertically sided bowl/cooking pot with a widely flaring rim. It is thin walled (up to $5 \mathrm{~mm}$ ) with a heavy burnish both inside and out. The rim diameter is $10-20 \mathrm{~cm}$. The body is black and the surfaces are heavily burnished.

- Ware: Fabric 3.

- Illustration: Fig. 7.13.

- Internal dating evidence: The percentage of this type appears to increase from Period 1 to Period 2, after which time it must have died out, the sherds in Period 3-temple and Period 4 are probably residual.

\section{Type: 30}

\section{Traditional ware name: Slipped red ware}

- Description: This is a small, gently carinated bowl with a rounded rim and a distinct mat red wash inter- nally and externally. The diameter is about $15 \mathrm{~cm}$. The surface is covered with an unpolished red slip.

- Ware: Fabric 1a.

- Illustration: Fig. 7.13.

- Internal dating evidence: This type was very abundant in Period 1, but it declined in Period 2 and had completely disappeared from circulation by Period 3. The two sherds in Period 4 are probably residual (Fig. 7.25).

\section{Type: 31}

Traditional ware name: Slipped red ware

- Description: This is a somewhat enigmatic type, consisting of a bowl with flaring sides and a slightly incurving, almost vertical rim. It commonly has an unpolished red wash or slip on the surface. The diameter is between 15 and $20 \mathrm{~cm}$.

- Ware: Fabric 1a.

- Illustration: Fig. 7.13.

- Internal dating evidence: This type is found only in Periods 2 and 3. It is abundant enough for its absence from Period 1 to be significant.

\section{Type: 32}

Traditional ware name: Slipped red ware

- Description: This is a rolled rim of a large storage vessel. The width of the rolled rim itself is between 3.5 and $5.5 \mathrm{~cm}$ and the diameter is a minimum of $35-40 \mathrm{~cm}$. The vessel walls are a minimum of 1.75 $\mathrm{cm}$ in thickness. This is a really large storage vessel of the type that would not have been moved around once installed. The surface is lighter than the core of the fabric, and it is smoothed and covered with a mat red slip.

- Ware: Fabric 1a. This type tends to be rather weakly fired and breaks easily with no snap.

- Illustration: Fig. 7.13.

- Internal dating evidence: This type does not occur in Period 1 and its presence was used to make the distinction between Periods 1 and 2. It was most abundant in Period 2, after which time it slowly declined. It is abundant enough for its absence from Period 1 to be significant (Fig. 7.25).

- Comments: The presence of this form was used to make the distinction between levels of Periods 1 and 2 when the sequence was periodised (see Chapter 6). 

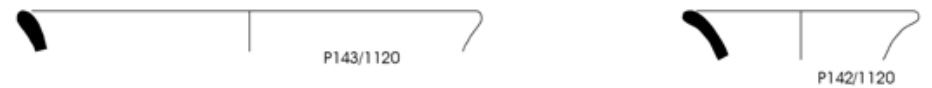

Type 29
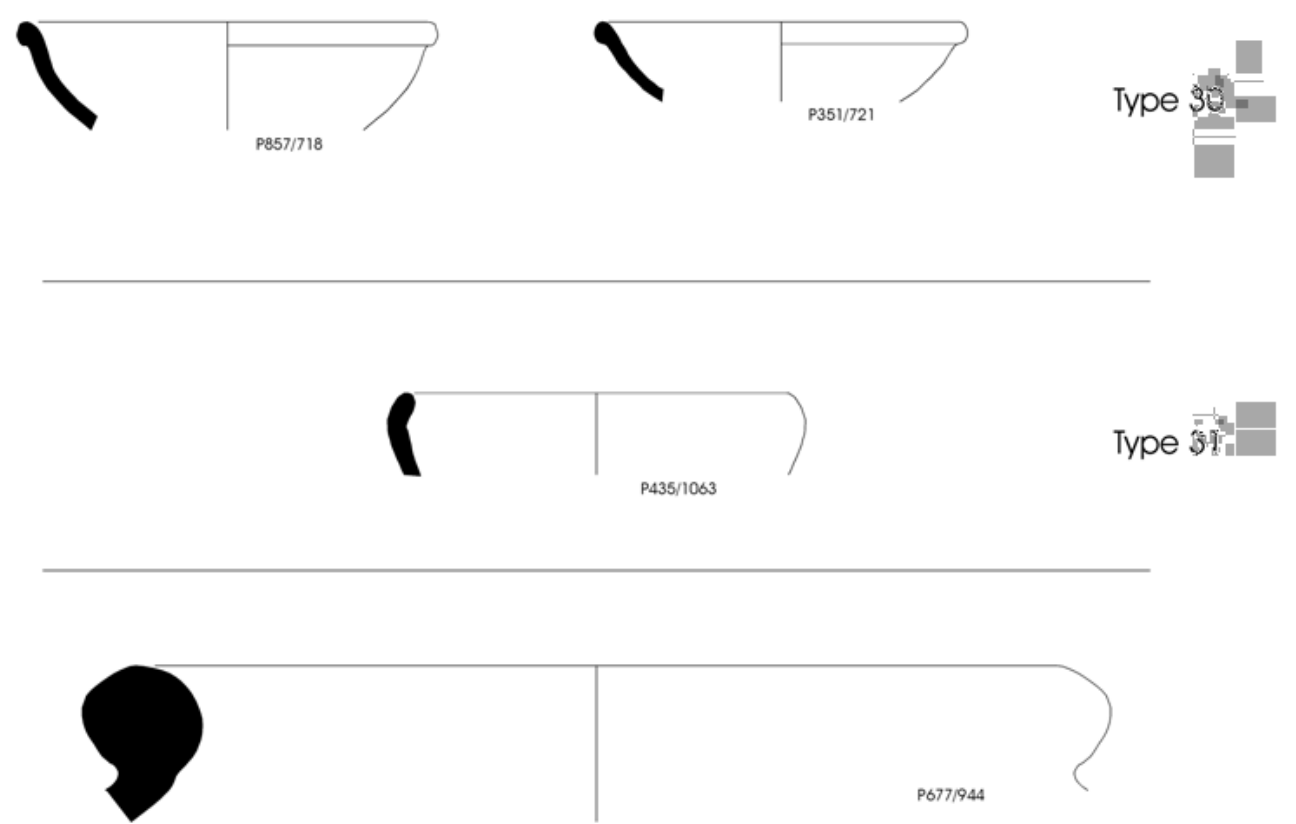

Type 32

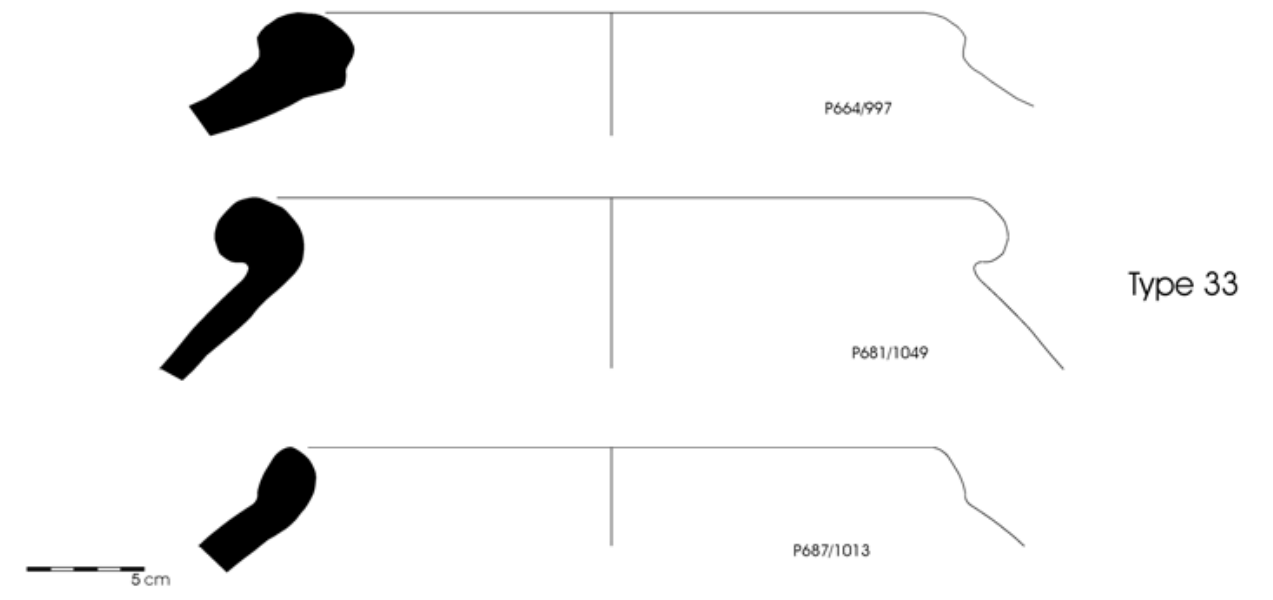

Fig. 7.13: Types 29 to 33. 
- External parallels: The introduction of these very distinctive large storage jars appears to have happened relatively late at some sites, such as Nevasa where they first appear in Period IV and at Maheshwar where they occur in Periods V and VI. They do occur, however, in earlier levels at other sites in the region such as Bhokardan Period IA and Ter Period II (Sankalia et al. 1958: fig. 76 type 111, fig. 91 type 162; Sankalia et al. 1960: fig. 120 type 55; Chapekar 1969: fig. 19 type 35; Deo and Gupte 1974: fig. 9 types 53 and 53a).

Type: 33

Traditional ware name: Slipped red ware

- Description: This is a smaller version of Type 32, a large storage vessel with a large rounded or everted rim, of variable shape. The diameter is 24-30 cm. The type is most often smoothed and covered with a matt red wash. One or two examples are fired grey.

- Ware: Fabric 1a.

- Illustration: Fig. 7.13.

- Internal dating evidence: This type occurs in all periods but is most common in Period 2 (Fig. 7.25).

- External parallels: A similar type was found at Bhokardan in Period IA (Deo and Gupte 1974: fig. 7 types 27 and 27a).

\section{Type: 34}

\section{Traditional ware name: Coarse red ware}

- Description: This is a bowl with flaring sides and an everted, thickened rim with a deep notch just below the rim on the inside where it has been rolled over. The diameter is $15-20 \mathrm{~cm}$. The surface of the vessel is smoothed and a lighter colour than the body internally and externally.

- Ware: Fabric 1a. This form is slightly higher fired than others in this fabric.

- Illustration: Fig. 7.14.

- Internal dating evidence: Only eight examples of this form were recorded, so it is difficult to be certain of the reliability of its occurrence through the sequence. It occurs only in Periods 2 and 3, most commonly in Period 2. As it is not very common, it is possible that its absence from the Period 1 assemblage is due to chance.

\section{Type: 35}

Traditional ware name: Slipped red ware

- Description: This is a large, slightly closed basin, with a thickened, rolled rim with an almost triangular profile. The diameter is between 30 and $35 \mathrm{~cm}$. The surface of the vessel is covered with a thick matt red slip which has fired grey in some cases.

- Ware: Fabric 1a.

- Illustration: Fig. 7.14.

- Internal dating evidence: This type occurs in Periods 1 to 3 , in increasing quantities, although numbers are very small. There are no residual sherds from Period 4. The reason for the absence of this type from Period 3-temple is probably due to the small size of that assemblage.

Type: 36

Traditional ware name: Coarse red ware

- Description: This is an angular form of Type 2 that is found in only a few layers in Trench D2. It is unslipped and unburnished. The diameter is about $15 \mathrm{~cm}$.

- Ware: Fabric 1a.

- Illustration: Fig. 7.14.

- Internal dating evidence: This type occurs only in Periods 1 and 2, but its absence from later assemblages may be due to chance, given the small numbers concerned.

\section{Type: 37}

Traditional ware name: Burnished and slipped red ware

- Description: This is a medium-sized jar with an everted, slightly thickened rim. It is very similar to Type 3 except that it lacks the distinctive notch on the interior. The diameter is around $15-17 \mathrm{~cm}$. The type is normally coated in a polished red slip.

- Ware: Fabric 1a.

- Illustration: Fig. 7.14.

- Internal dating evidence: Only 13 examples of this type were recorded, all from Period 2. Its presence was used to help define Period 2 from Period 1. It occurs in the lower part of Trench A:TP1 and once in the upper part of D2. Its absence from Trench B is perhaps to be explained by chance.

- Comments: The presence of this form was used to make the distinction between levels of Period 1 and 

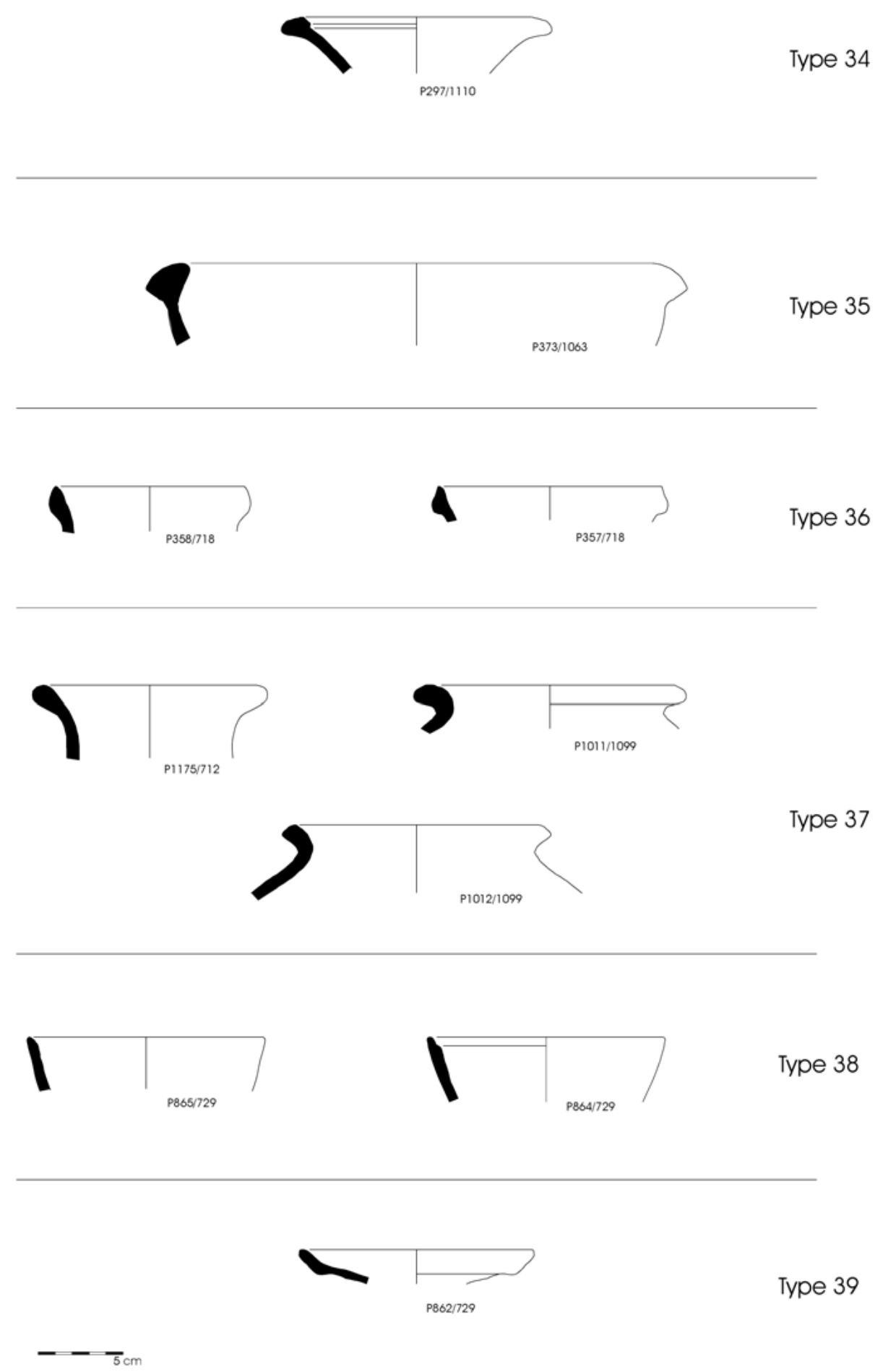

Fig. 7.14: Types 34 to 39. 
Period 2 when the sequence was periodised (see Chapter 6).

\section{Type: 38}

(Black and Red ware) Traditional ware name: Black and

\section{Red ware}

- Description: This is a simple, straight-sided bowl with a vertical pointed rim that is marked by having the top $8 \mathrm{~mm}$ or so of its inner edge shaved steeply to a triangular point. The diameter is about $12 \mathrm{~cm}$. The surface is slipped and heavily burnished.

- Ware: Fabric 3.

- Illustration: Fig. 7.14.

- Internal dating evidence: This type occurs only in Period 1 (Fig. 7.25).

- Comments: Only 25 sherds of this type were recorded; it was used as a marker of the Period 1 assemblage.

- External parallels: Roughly similar types are reported from Nevasa Period IV and Maheshwar Period V, although no precise parallels to this type could be found amongst the Black and Red ware from early layers at the published sites in the region (Sankalia et al. 1958: fig. 69 type 92; Sankalia et al. 1960: fig. 116 type 29).

\section{Type: 39}

\section{(Black Burnished ware) Traditional ware name:}

\section{Burnished black ware}

- Description: This is a plate or a very shallow bowl with flat sides and a carinated rim of about $15 \mathrm{~mm}$ height. The diameter is 13 or $14 \mathrm{~cm}$. The vessels are black-bodied and are heavily burnished on the exterior.

- Ware: Fabric 3.

- Illustration: Fig. 7.14.

- Internal dating evidence: Only three sherds of this type were recorded, and they are all from Period 1.

Type: 40

Traditional ware name: Burnished and slipped red ware

- Description: This is a large 'nailhead' jar with an everted thickened rim with a triangular profile and a deep indent behind it on the interior. The diam- eter is around $20 \mathrm{~cm}$. The surface is coated with a polished red slip on the interior and exterior.

- Ware: Fabric 1a.

- Illustration: Fig. 7.15.

- Internal dating evidence: This type occurs in Periods 1 and 2. There are no examples from Period 3 or 3-temple, suggesting that it had ceased to be used by that time. The sherds from Period 4 are probably residual.

\section{Type: 41}

Traditional ware name: Slipped red ware

- Description: This is a simple bowl with gently curving sides and a straight, pointed rim. The diameter is up to about $26 \mathrm{~cm}$. In some cases, the surface is smoothed and it is coated with a thin mat wash on the interior and over the rim.

- Ware: Fabric 1a and occasionally Fabric 1c.

- Illustration: Fig. 7.15.

- Internal dating evidence: This type has a strange occurrence profile; it is present in Period 1 in very small quantities, it is more common in Period 2, totally absent from Period 3 and 3-temple and appears to have been quite abundant in Period 4 (Fig. 7.25).

Type: 42

Traditional ware name: Burnished and slipped red ware

- Description: This is a small jar with a thin body, a short neck and a slightly flaring rim with a small rounded thickening on the end. The diameter is about $12 \mathrm{~cm}$. The interior and exterior surfaces are covered with a thin mat or polished red or redbrown slip. This type is quite similar to Type 20, but it has a more pronounced neck.

- Ware: Fabric 1a. This type is harder fired than others in this fabric.

- Illustration: Fig. 7.15.

- Internal dating evidence: This type was present in Period 1, it then declined in Period 2 and does not occur in any later levels. 


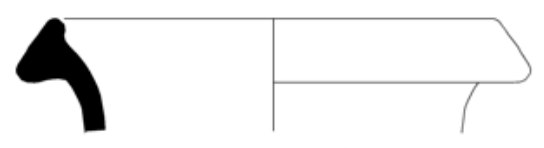

Type 40

P1 104/715
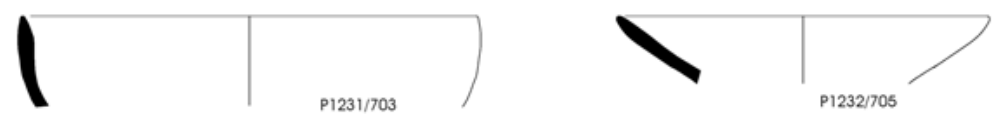

Type 41

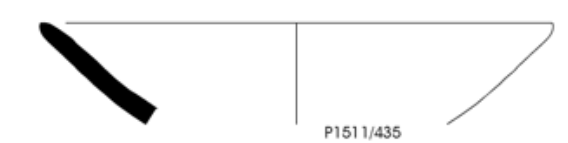

P151 1/435

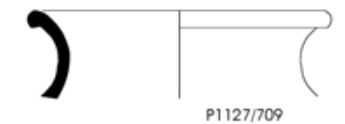

Type 42

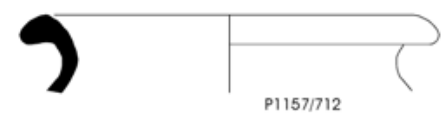

Type 43
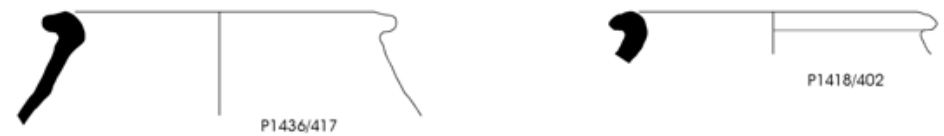

P1436/417
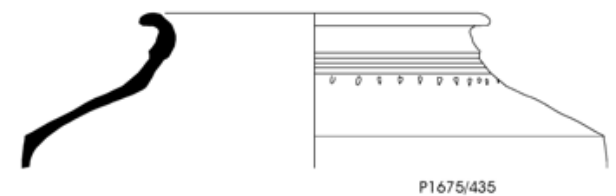

Type 44

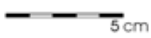

Fig. 7.15: Types 40 to 44 . 
Type: 43

Traditional ware name: Burnished and slipped red ware

- Description: This is a jar with a short neck and a simple out-turned flaring rim similar but less distinctive than Type 9. The diameter is about $18 \mathrm{~cm}$. The surface is burnished and may have had a thin brown slip.

- Ware: Fabric 1b.

- Illustration: Fig. 7.15.

- Internal dating evidence: This type occurs in all periods in reasonable quantities with no obvious chronological pattern.

\section{Type: 44}

\section{(Thick Grey ware) Traditional ware name: Grey ware}

- Description: This is a jar with a carinated body, a short neck and an everted rim that is partly rolled back on itself. There is a good deal of variability in the precise form. There are often shallow incised decorative bands around the exterior of the jar below the rim together with rows of incised slits. The diameter is normally about $14 \mathrm{~cm}$. The surface is often smoothed and burnished and is a lighter colour than the body. The body walls are notably thinner than Type 15; in this case, they are about 4 mm thick in the middle of the vessel.

- Ware: Fabric 2.

- Illustration: Fig. 7.15.

- Internal dating evidence: This type occurs from Period 3 in small quantities but was most abundant in Period 4. It is common enough for its absence from Periods 1 and 2 to be significant.

\section{Type: 45}

\section{(Thick Grey ware) Traditional ware name: Grey ware}

- Description: This is a low, flat grey ware bowl or dish with a flat base that is deliberately impregnated with coarse grit. It has a low, steeply sloping side and a slightly everted rim. The diameter is about $25 \mathrm{~cm}$. The exterior surface is untreated but the interior is burnished.

- Ware: Fabric 2.

- Illustration: Fig. 7.16.

- Internal dating evidence: This type occurs only in Period 4. It is common enough for its absence from Period 3 to be significant.
Type: 46

(Thick Grey ware) Traditional ware name: Grey ware

- Description: This is a very crude grey-ware plate or very shallow bowl with a slightly raised, carinated rim. The diameter is about $28 \mathrm{~cm}$. The base has been deliberately impregnated with coarse grits, but the outside above the carination and the interior are both smoothed, although not burnished.

- Ware: Fabric 2.

- Illustration: Fig. 7.16.

- Internal dating evidence: This type occurs only in Period 4 but it is common enough for its absence from Period 3 and earlier assemblages to be significant.

\section{Type: 47}

Traditional ware name: Slipped red ware

- Description: This is a small jar with a short neck and a slightly thickened rim with a shallow notch on the outermost face. The diameter is about 10 $\mathrm{cm}$. The surface is coated with a thin brown slip or wash that is not burnished.

- Ware: Fabric 1a.

- Illustration: Fig. 7.16.

- Internal dating evidence: A small quantity of this type occurs in Period 3, but it was most abundant in Period 4. It is common enough to suggest that its absence from Period 2 and earlier assemblages is significant.

- External parallels: Rough parallels to this form can be found at Nasik in Period IIA and at Prakash in Period II (Sankalia and Deo 1955: fig. 21 type 26; Thapar 1967: fig. 25 type 37), but it is difficult to be certain of identifying this form in published drawings.

Type: 48

Traditional ware name: Coarse red ware

- Description: This is a small, crude, hand-made bowl with very low sides and a flat base. The diameter is between 6 and $12 \mathrm{~cm}$. There is no evidence of deliberate surface treatment.

- Ware: Fabric 1c.

- Illustration: Fig. 7.16.

- Internal dating evidence: This type has a very similar occurrence profile to Type 47; it occurs 


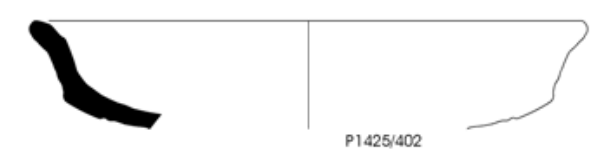

Type 45
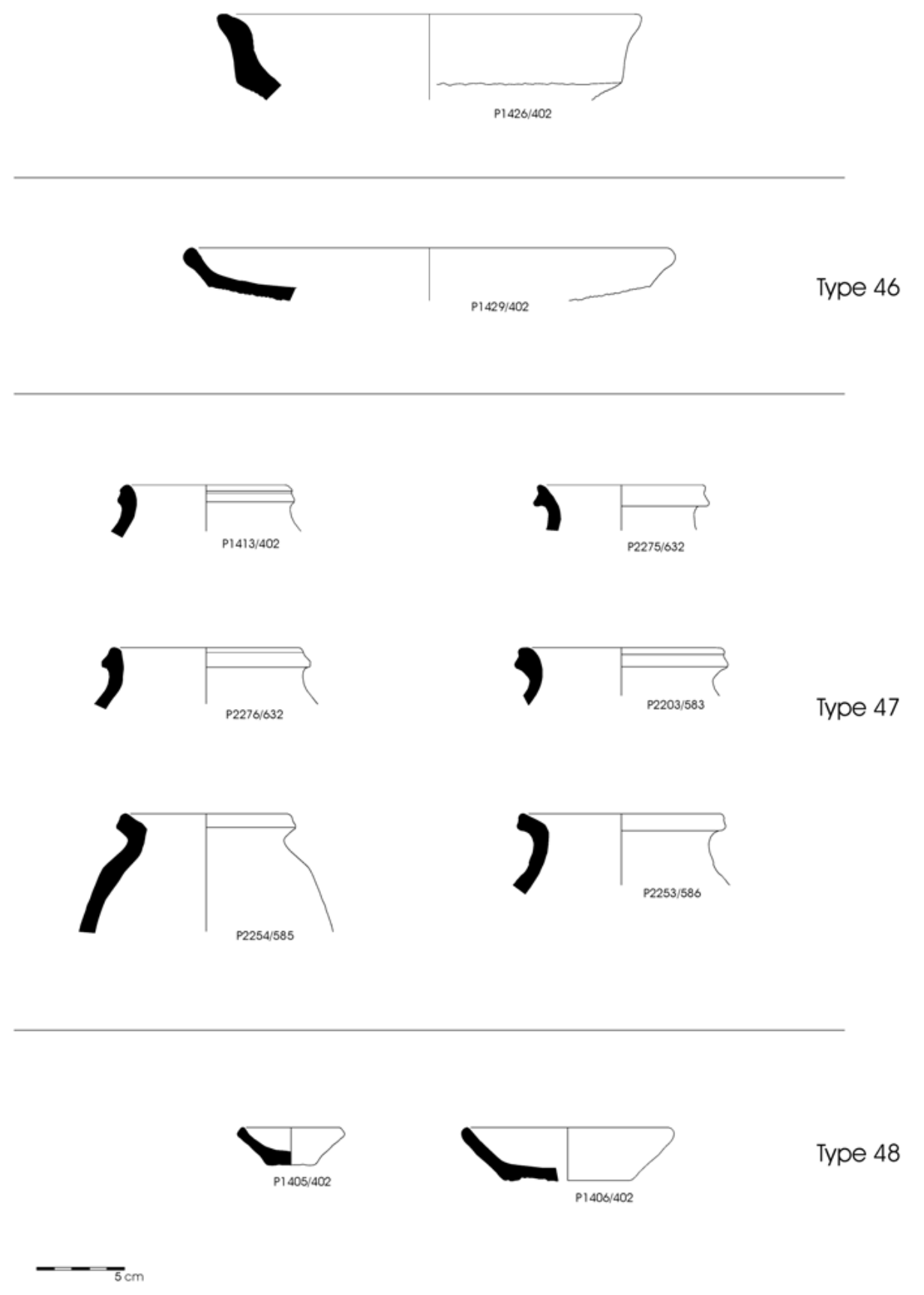

Fig. 7.16: Types 45 to 48 . 

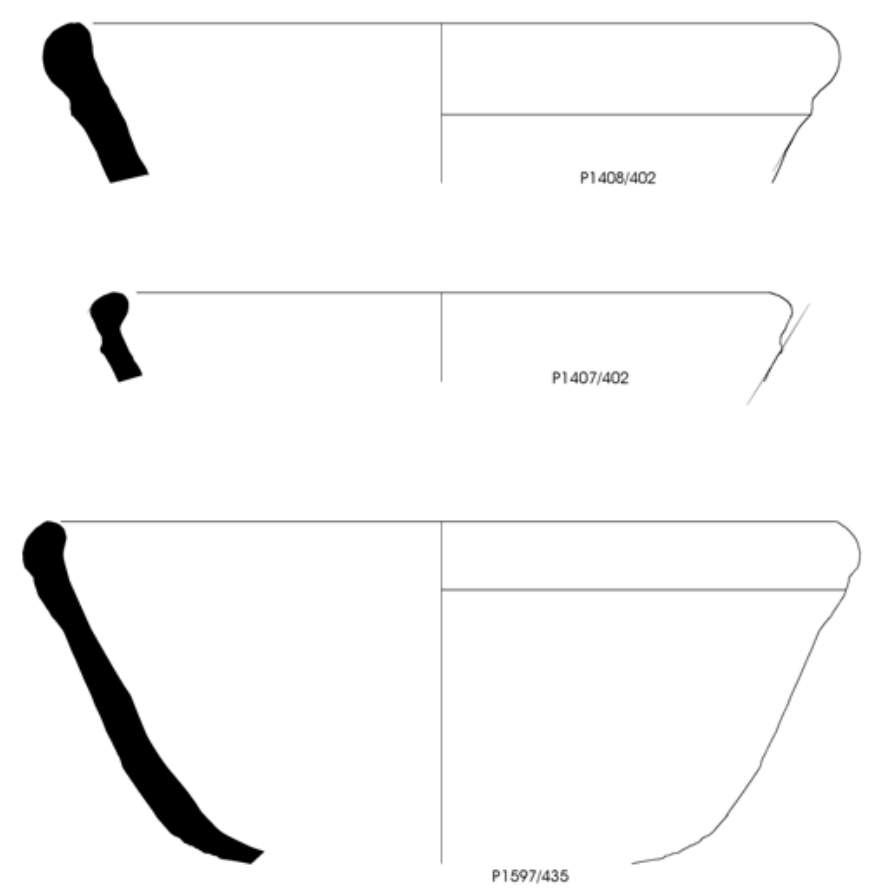

Type 49
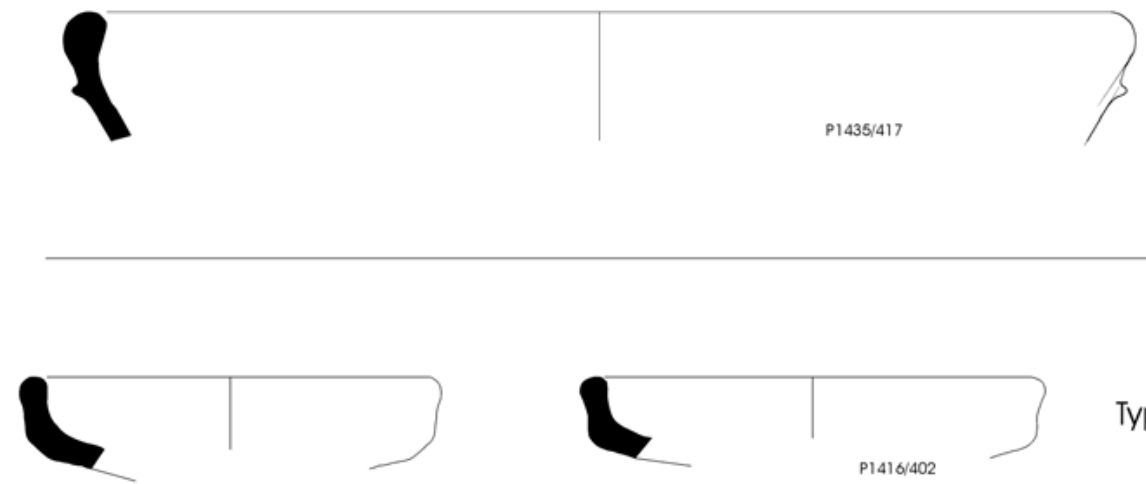

Type $\$ b$

P1415/402

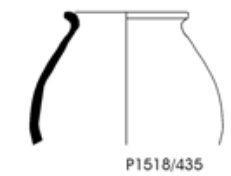

(

Y

Type sith

$--\overline{\mathrm{cm}}$

Fig. 7.17: Types 49 to 51. 
in Period 3 in small numbers, but only became common in Period 4. It is just about common enough to suggest that its absence from the Period 1 and 2 assemblages is significant.

\section{Type: 49}

\section{Traditional ware name: none}

- Description: This is a large bowl or basin with a flat base and straight flaring sides with a very slightly incurved rim with a finger-wide grove on the outside. The walls are very thick $(9-10 \mathrm{~mm})$ and the diameter is between 30 and $45 \mathrm{~cm}$. There is no evidence of any surface treatment beyond a smoothing.

- Ware: Fabric $1 \mathrm{~b}$. This type tends to be made of a denser than average Fabric $1 \mathrm{~b}$.

- Illustration: Fig. 7.17.

- Internal dating evidence: This type occurs only in Period 4. Its absence from earlier assemblages does seem to be significant.

- External parallels: Parallels to this type can be found at Maheshwar in Periods V and VI (Sankalia et al. 1958: fig. 73 type 100, fig. 84 type 140).

\section{Type: 50}

\section{Traditional ware name: Coarse red ware}

- Description: This is a crude, thick-walled, carinated bowl with a simple, almost vertical, rounded rim. The walls are about $10 \mathrm{~mm}$ in thickness, and the diameter is between 16 and $20 \mathrm{~cm}$.

- Ware: Fabric 1a. This type has a sandier fabric than usual.

- Illustration: Fig. 7.17.

- Internal dating evidence: This type occurs in Period 3 and 4. The reason for its absence from Period 3-temple is probably due to the small size of that assemblage, but its absence from the Period 1 and 2 assemblages does seem to be significant.

\section{Type: 51}

(White and Red Painted ware) Traditional ware name: none

- Description: This is a small, very fine-walled, globular jar with an everted rim. The walls are 3 or $4 \mathrm{~mm}$ thick and the diameter is between 5 and $6 \mathrm{~cm}$. The exterior is covered in white paint decorated with horizontal red painted bands around the body.

- Ware: Fabric 5, WARP.

- Illustration: Fig. 7.17.

- Internal dating evidence: This type occurs only in Period 4 and its absence from earlier assemblages does seem to be significant (Fig. 7.25).

\section{Type: 52}

\section{(White and Red Painted ware) Traditional ware name:} none

- Description: This is a small globular jar with no neck and a slightly thickened rim that has been folded back on itself. The walls are very thin (3-4 $\mathrm{mm}$ ) and the diameter is about $6 \mathrm{~cm}$. The exterior and at least a part of the interior are painted with a thin white paint.

- Ware: Fabric 5, WARP.

- Illustration: Fig. 7.18.

- Internal dating evidence: Only five sherds of this type occur, all in Period 4.

\section{Type: 53}

\section{Traditional ware name: none}

- Description: This is a small, fine, carinated jar with a slightly everted geometrically shaped rim in a very distinctive fine grey ware that is unique to this type. The walls are very thin (3-4 $\mathrm{mm})$ and the diameter is between 6 and $8 \mathrm{~cm}$. The surface was burnished on the exterior whilst the vessel was still on the wheel.

- Ware: This is a type-specific fabric. It is well levigated with a fine, grainy structure and an almost smooth fracture. It is medium to soft fired and breaks easily. The grainy structure is caused by fine grits that are almost too small to see with a $\times 10$ lens. There are no other inclusions. The fabric fires to an even olive grey to light olive brown (5Y $5 / 2-2.5 Y 5 / 3)$.

- Illustration: Fig. 7.18.

- Internal dating evidence: This type occurs only in Period 4 and does not seem to have been in circulation any earlier. 


\section{Type: 54}

\section{Traditional ware name: none}

- Description: This is a short-necked jar with an everted rim that is flattened and slightly grooved on top in order to hold a lid. One sherd has evidence of a spout in the upper part of the body. The rim diameter is $9 \mathrm{~cm}$. It has a mat red slip on the exterior and over the rim; the interior has a light coloured wash.

- Ware: This is a type-specific fabric. This is like a harder-fired version of Fabric 1a. Despite the better firing, it still breaks easily. It has a very rough fracture, with a coarse blocky structure. There are frequent, large $(2 \mathrm{~mm})$ air holes caused by burning vegetable temper and numerous rounded white inclusions up to $3 \mathrm{~mm}$. The core is a reddish yellow (5YR 6/6).

- Illustration: Fig. 7.18.

- Internal dating evidence: This type occurs only in Period 4 and almost certainly did not circulate any earlier.

Type: 55

Traditional ware name: none

- Description: This is a small jar with a short neck and an everted rim. The walls can be as thin as 3 $\mathrm{mm}$ in some cases. The diameter is between 10 and $14 \mathrm{~cm}$. The exterior of the jar is sometimes lightly burnished, probably on a wheel.

- Ware: Fabric 1c, but fired to an even brown to yellowish brown (10YR 5/3-10YR 5/4).

- Illustration: Fig. 7.18.

- Internal dating evidence: With the exception of one sherd in Period 1 that is probably intrusive, this type occurs only in Period 4 and almost certainly did not circulate earlier.

\section{Type: 56}

\section{Traditional ware name: none}

- Description: This is a small tobacco container from a hookah or water-pipe. It has quite an elaborate shape, the exact number of ribs and the precise form varying somewhat, but always being defined by the ash-stained crucible connected by small holes to the hollow tube below it. The height is about 5.5 $\mathrm{cm}$ and the diameter of the widest part is about 3.5 $\mathrm{cm}$. The surface is normally covered with a slip on the interior and exterior that is either mat red or sometimes purple-brown.

- Ware: This is a type-specific fabric. It is a welllevigated fabric with a smooth fracture and a very fine grainy structure. There are no visible inclusions. The body is fired to an even reddish yellow (5YR 7/6).

- Illustration: Fig. 7.18.

- Internal dating evidence: This type occurs only in Period 4. It is common enough for its absence from earlier periods to be significant.

Type: 57

Traditional ware name: none

- Description: This appears to have been the tobacco container from a hookah or water pipe. It has a broader crucible than Type 56 above, and no grill of holes is visible on any of the preserved examples. It is a small object (diameter $8 \mathrm{~cm}$ ) with a wall thickness of $3 \mathrm{~mm}$. In some cases, the surface is burnished. The quality of the turning and the clay is variable.

- Ware: This is a type-specific fabric. It is a very fine, grey ware, well fired with a smooth fracture. It has a very grainy structure and there are no visible inclusions. The body is a dark grey (5YR).

- Illustration: Fig. 7.18.

- Internal dating evidence: Apart from a single sherd in Period 1, which must be intrusive, this type occurs only in Period 4, and its absence from earlier periods is likely to be significant.

\section{Type: 58}

(Black Burnished ware) Traditional ware name: Burnished black ware

- Description: This is a small jar with a slightly flaring neck and a thickened rim with an almost angular profile. The diameter is about $11 \mathrm{~cm}$. The body is black and the surface is heavily burnished inside and out.

- Ware: Fabric 3.

- Illustration: Fig. 7.18.

- Internal dating evidence: This type occurs only in Periods 1 and 2. Nine sherds were recorded from Period 1 and a single sherd from Period 2, which is probably residual. 


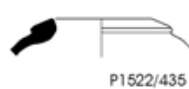

Type 52

P1522/435

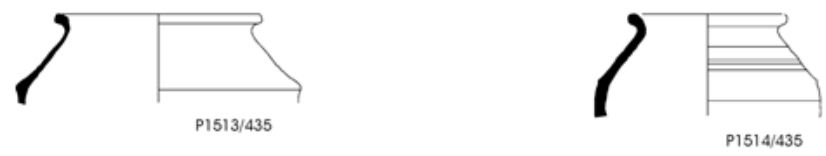

Type 53

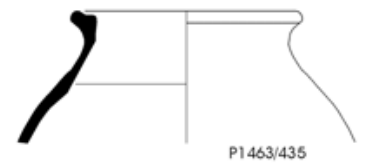

Type 54
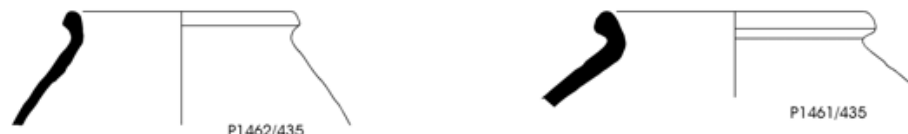

Type 55

P1461/435

Type 57

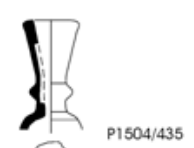

Type 56

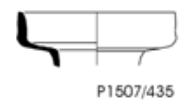

(3)
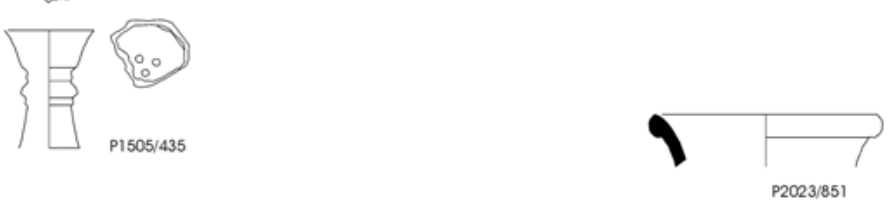

Type 58

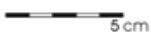

Fig. 7.18: Types 52 to 58. 


\section{Distribution on site}

The quantified pottery sequence of each of the five main trenches is presented below in a tabular format by context, type and sherd count.

\section{Trench A: Test Pit 1}

See Table 7.6 for distribution of types.

\section{Trench B}

See Table 7.7 for distribution of types.

\section{Trench C}

Trench C was excavated during the 1996 and 1997 seasons. The pottery was only briefly studied and the assemblage was not included in the main analysis that is presented in this chapter. Nonetheless, the results are of some interest and give an impression of how the sequence in this part of the site relates to that in the main trenches.

Table 7.8 shows an obvious change in the nature of the assemblage between layers 83 and 69. In layer 69, a number of new types such as 13,16, 17 and 18 occur for the first time, followed shortly by GREY forms 14 and 15. In the following deposits, most of the forms which were common in the earliest levels appear to become increasingly less frequent (i.e. Types 6, 7, 8, 9). Layers 60 and above probably correspond roughly to Period 3, but it is more difficult to allocate a period to the layers below this.

\section{Trench D1}

See Table 7.9 for distribution of types.

\section{Trench D2}

See Table 7.10 for distribution of types.

\section{Trench F}

See Table 7.11 for distribution of types.

\section{Analysis of the assemblage and sequence}

The typology-based approach to the study of the Paithan assemblage that has been set out above has proved to be successful in that it has been possible to propose a number of well-defined types that have clear and demonstrable chronological profiles that make them useful chronological markers. Quantified analysis of the occurrence of the types through the sequence has helped to refine this through the identification of obviously residual and intrusive types, despite very high levels of residuality and, more importantly, apparently high levels of continuity in pottery tradition and manufacture.

Period 1 is marked by Types 2 and 38 and, to some degree, Type 10, each of which either declined markedly or went out of use completely by Period 2. Almost all other types present in the Period 1 assemblage continued to be used in Period 2 in roughly similar quantities, and some of them also continued into Period 3, although normally in much lower quantities. In Period 2, Types 7, 19, 31, 32, 34 and 37 appeared; these were not in circulation in Period 1, and their absences from that period appear to be significant. Of these, only Types 19 and 37 appear to have ceased circulation by Period 3, whilst the others continued. When it comes to Period 3, only Types 44, 47, 48 and 50 occur that were not present in earlier periods, together with Types 14, 24, 26 and 27 that were previously in circulation in Period 2 , but in such low quantities that they were largely insignificant. Some of these types seem to go out of circulation by Period 4, for instance Types 24, 26 and 27, whilst others continued to circulate, some in increased amounts. In Period 4, we see the introduction of a large number of new types, for example Types 13, 15, 23, 45, 46, 49, 51, 52, 53 and 56, whilst types such as Types 44, 47 and 48 continued to circulate, but in notably larger amounts than in Period 3.

Having set out this preliminary framework, it would have been useful to have been able to compare it to published assemblages from other excavated sites in the region as has been done, where possible, in the description of types above. In order to attempt this, seven regional sites were looked at in detail, namely Bhokardan, Brahmapuri, Maheshwar, Nasik, Nevasa, Prakash and Ter, each yielding some parallels to the types defined at Paithan. It did not, however, prove to be the case that the closer sites, such as Nevasa (50 $\mathrm{km})$ and Bhokardan $(95 \mathrm{~km})$, yielded more parallels or 
Table 7.6: Types from Trench A: Test Pit 1 by rim-sherd count and layer in stratigraphic sequence.

\begin{tabular}{|c|c|c|c|c|c|c|c|c|c|c|c|c|c|c|c|c|c|c|c|c|c|c|c|}
\hline Type & 306 & $\begin{array}{r}310 \\
1195\end{array}$ & 308 & $\begin{array}{l}312 \\
908\end{array}$ & $\begin{array}{l}912 \\
316\end{array}$ & 913 & $\begin{array}{l}922 \\
318\end{array}$ & 921 & 930 & 933 & $\begin{array}{l}945 \\
946 \\
948\end{array}$ & 944 & \begin{tabular}{|r|}
966 \\
997 \\
985 \\
986 \\
988 \\
1009 \\
1014 \\
1043 \\
\end{tabular} & 1013 & \begin{tabular}{|l|l|l|l|}
1040 & 1 \\
& 1
\end{tabular} & $\begin{array}{l}1058 \\
1074 \\
1105\end{array}$ & $\begin{array}{l}1052 \\
1063\end{array}$ & 1077 & $\begin{array}{l}1099 \\
1110 \\
1111\end{array} \mid$ & 1120 & 11271 & 1158 & 1159 \\
\hline 1 & & & & & & & & & & & & & & & & & & 1 & & & & & \\
\hline $1 \mathrm{~A}$ & 3 & 1 & 4 & 4 & & 2 & 1 & 17 & 9 & 13 & 4 & 18 & 70 & 96 & $6 \quad 71$ & 22 & 74 & 64 & 54 & 60 & 21 & 4 & 3 \\
\hline 1B & 3 & & 7 & 9 & 1 & 11 & & 32 & 22 & 24 & 3 & 41 & 258 & 84 & $4 \quad 115$ & 66 & 172 & 54 & $4 \quad 103$ & 30 & 4 & & 1 \\
\hline 2 & & & & & & 1 & & 1 & & & & & 4 & & 3 & 1 & 4 & 2 & 2 & 2 & 2 & & \\
\hline 3 & & & & & & & & & & & & 3 & 9 & 3 & 4 & 1 & 6 & 6 & 10 & 5 & & & \\
\hline 4 & & & & & 1 & 1 & & 2 & & 1 & & 1 & 7 & 8 & 8 & 2 & 12 & 8 & 2 & 4 & & & \\
\hline 5 & & & & 1 & & & & 1 & & & & & 3 & 1 & 2 & 1 & 1 & 4 & 6 & 1 & & & \\
\hline 6 & 1 & & & & & & & & & & & & 1 & t & & & & 1 & & & & & \\
\hline 7 & & & 1 & & & & & 2 & & & & & 4 & 1 & & & 1 & 2 & 4 & & & & \\
\hline 8 & & & & & & & & & & & & 1 & 4 & 8 & 2 & & 4 & 2 & 5 & & & & \\
\hline 9 & & & & & & & & 2 & & & & & 2 & 1 & 3 & & 3 & 4 & 4 & & & & \\
\hline 10 & & & & & & & 1 & 5 & & & & & 20 & 5 & 19 & 1 & 27 & 12 & 19 & 13 & 9 & 1 & 1 \\
\hline 12 & & & & & & & & & & & & & 1 & & & & & 1 & & & & & \\
\hline 16 & 1 & & & 4 & 1 & 3 & & 5 & 1 & 2 & & 3 & 13 & 5 & 8 & 1 & 7 & 3 & 10 & 7 & & & \\
\hline 18 & & & & & & 2 & & & & & & & & & & & 1 & & & 1 & & & \\
\hline 19 & & & & & & & & & & & & & 2 & 2 & 3 & 1 & 1 & 2 & 1 & 1 & & & \\
\hline 20 & & & 1 & 5 & 1 & 2 & & 1 & & 2 & & 1 & 1 & & 2 & & 1 & 2 & 1 & & & & \\
\hline 22 & 1 & & & & & & & & & & & & 1 & & & & & & & & & & \\
\hline 24 & & 1 & 8 & 12 & & 6 & & 9 & 11 & 2 & & 2 & & & & & & & & & & & \\
\hline 25 & & & 3 & 4 & 2 & 1 & & 5 & & & & 1 & 3 & 1 & 1 & 1 & & & 1 & 1 & & & \\
\hline 26 & 4 & & 8 & 8 & & 3 & & & 2 & 6 & 1 & & 1 & & & & & & & & & & \\
\hline 27 & & 1 & 6 & 5 & 2 & 2 & 1 & & 1 & & & & 1 & & & & & & & & & & \\
\hline 29 & & & & & & & & & & & & & & & & & & & & 2 & & & \\
\hline 31 & & & & & & & & 1 & 1 & 1 & & 1 & 1 & 2 & 1 & 3 & 4 & & 2 & 1 & & & \\
\hline 32 & 1 & 1 & & & & & & & 1 & & & 1 & 2 & 2 & 3 & & 2 & 1 & 1 & & 1 & & \\
\hline 33 & & & & & & 1 & & 1 & 2 & & 1 & 1 & 1 & 8 & 2 & & 7 & 1 & 3 & 1 & & & \\
\hline 34 & & & & & & & & & & & & 1 & & & & 2 & & & 2 & & & & \\
\hline 35 & & & 1 & & & & & 1 & 1 & & & & & & 1 & & 1 & 1 & 2 & & & & \\
\hline 37 & & & & & & & & & & & & & 1 & 1 & 1 & & 2 & 1 & 3 & & & & \\
\hline RPW & & & & & & & & & & & & & 1 & & & & & & & & & & \\
\hline NON & 3 & 3 & 36 & 26 & 1 & 8 & 5 & 33 & 34 & 28 & & 45 & 97 & 41 & 45 & 14 & 44 & 21 & 31 & 7 & 6 & & \\
\hline UNIQ & & & 6 & & & & & & & 2 & 2 & & 3 & 3 & 1 & 1 & 1 & & 1 & & & & \\
\hline Rim total & 17 & 7 & 81 & 78 & 9 & 43 & 8 & 118 & 85 & 81 & 11 & 120 & 511 & 272 & 293 & 117 & 375 & 193 & 267 & 136 & 43 & 5 & 4 \\
\hline NBP body & & & & & & & & & & & & & & & & & & & & 1 & & & \\
\hline$\underline{\text { RPW body }}$ & & & & & & & & & & & & & 1 & & & & & & 1 & & & & \\
\hline Body total & 108 & & 621 & 807 & 90 & 533 & 69 & 963 & 687 & 847 & 105 & 861 & 3276 & 1069 & 1638 & 527 & 21401 & 1149 & 2112 & 686 & 451 & 38 & \\
\hline
\end{tabular}


a wider range of parallels than the more distant sites such as Maheshwar (300 km), Prakash (250 km), Nasik $(177 \mathrm{~km})$ or Ter $(148 \mathrm{~km})$. The parallels that have been found are intriguing, and they suggest that major developments in pottery technology and style followed regional trends, whilst at the same time there is evidence, in the types and wares that are restricted only to Paithan, that local pottery manufacture was the norm and each site is also likely to have had a range of types and styles that were unique to it.

More detailed comparisons with the published assemblages from the region are rendered impossible due to problems with the way in which the material has been studied and published, most notably the lack of precision in the definition of wares and fabrics and the lack of systematic quantification. Were it not for these limitations, it would by now be possible to attempt a much-needed synthetic regional review of pottery wares and types that would be an important step towards the creation of a reliable archaeological chronology of the Early Historic and Early Medieval periods in this region of India. Unfortunately, such advances are still a considerable way in the future and are dependent on a fundamental change in the way that pottery is collected, studied and published on archaeological excavations in India.

\section{Period-based analysis of pottery deposition rates}

The following analysis uses 15 'period-assemblages' from Trenches A, B, D and F to evaluate the relative density of sherds per cubic metre of excavated earth. The aim is to investigate possible changes in the rate of pottery deposition through the stratigraphic sequence at the site. A 'period-assemblage' is the assemblage from the contexts or layers from a particular period in a particular trench (a period-sequence). To give an example, 'TrB-1' indicates the Period 1 material from Trench B. The 15 period-assemblages were selected from across the site in order to give a representative sample.

Some of the same data are used in the appendix to Chapter 9 to calculate coin deposition rates in the temple foundation deposits.

In order to investigate sherd density, the amount of excavated earth was calculated for each of the periodassemblages. By combining this with the sherd count from the same levels, it is possible for the density of sherds per cubic metre to be calculated and compared (Tables 7.12 and 7.13).

The data and analysis presented above and the ranked analysis in Fig. 7.19 makes clear that, in general, the Period 1 assemblages have amongst the higher densities of sherds at the site and that this density appears to decline gradually through the history of the site, with the lowest densities occurring in Period 3 and 4 deposits.

When averages are taken by period, the figures suggest that the amount of pottery deposited at the site declined by around 20\% between Periods 1 and 2, $32 \%$ between Periods 2 and 3 and $54 \%$ between Periods 3 and 4 (Table 7.14). This represents an overall decline of $75 \%$ between Periods 1 and 4.

This very consistent pattern must be indicative of much higher levels of pottery deposition during the earlier part of the site's history. This, in turn, is probably indicative of higher levels of manufacture and use of pottery, but this is more difficult to determine with certainty as other factors related to discard and to localised conditions can be involved.

The significance and implications of these results are further discussed in Chapter 14. 
Table 7.7: Types from Trench B by rim-sherd count and layer in stratigraphic sequence.

\begin{tabular}{|c|c|c|c|c|c|c|c|c|c|c|c|c|c|c|c|c|c|c|c|c|c|c|c|}
\hline Type & $\begin{array}{l}402 \\
406 \\
414\end{array}$ & 408 & 413 & $\begin{array}{l}415 \\
426\end{array}$ & 417 & $\begin{array}{l}418 \\
420 \\
422\end{array}$ & 427 & 428 & $\begin{array}{l}430 \\
432 \\
435\end{array}$ & 429 & 438 & 440 & 439 & 437 & 441 & 443 & $\begin{array}{l}444 \\
448\end{array}$ & 450 & 451 & 452 & 453 & 456 & 457 \\
\hline 1 & 65 & & 15 & 4 & 17 & 5 & 4 & 2 & 188 & 12 & 56 & 50 & 75 & 23 & 14 & 2 & 54 & 5 & 36 & 90 & 48 & & 19 \\
\hline 2 & 1 & & 1 & & & & & & 21 & & 1 & 2 & 1 & 3 & & & & & & 1 & 2 & & \\
\hline 3 & 6 & & & 1 & & & 2 & & 11 & & 4 & 3 & 3 & & 4 & & 3 & & 1 & 1 & 2 & & \\
\hline 4 & 9 & & 3 & 1 & & 1 & & & 21 & 1 & 5 & 4 & 12 & & & 1 & 4 & & & & 12 & 1 & 1 \\
\hline 5 & 2 & & & & & & & & 6 & 1 & 1 & 1 & 4 & & 2 & & 3 & 1 & & & 3 & 1 & \\
\hline 6 & 6 & 1 & & & & & & & 7 & 1 & 2 & 1 & 5 & & 2 & 3 & 4 & & & & & & \\
\hline 7 & 2 & & & & & 1 & & & 3 & & & 8 & 9 & & & & & 1 & 1 & & & & \\
\hline 8 & 8 & & 1 & & & & & & 1 & & 4 & 1 & 5 & 1 & & & 6 & 2 & 1 & 1 & 4 & & 1 \\
\hline 9 & & & & & & & & & & & & & & & & & & 3 & 1 & 6 & & & \\
\hline 10 & 4 & & 2 & & & 1 & 1 & & 10 & 1 & 9 & 10 & 34 & & 2 & 1 & 14 & 1 & 7 & 18 & 16 & 1 & 3 \\
\hline 12 & & & & & 1 & & 1 & & 8 & & & & & & & & & & & & & & \\
\hline 13 & 16 & & 1 & & 1 & & & & 10 & & 2 & & & & & & & & & & & & \\
\hline 14 & 1 & & & & 1 & & 6 & & 2 & 3 & 6 & & & & & & & & & & & & \\
\hline 15 & & & 2 & 1 & & & & & 1 & & & 3 & & & & & & & & & & & \\
\hline 16 & 6 & & 5 & & & & 4 & & 26 & 5 & 10 & 3 & 14 & & & & 4 & & & & & & 2 \\
\hline 18 & & & 1 & & & & & & & & & & & & & & & & & & & & \\
\hline 20 & 9 & & & 1 & & 1 & 3 & & 51 & 1 & 5 & & 1 & & & & & & & 1 & & & \\
\hline 22 & & & & & & 1 & & & & & & & 1 & & & & & & & & & & \\
\hline 23 & 5 & & & & 3 & & & & & & & & & & & & & & & & & & \\
\hline 24 & & & & & & & & & 4 & & & & & & & & & & & & & & \\
\hline 25 & & & & & & & & & 1 & 1 & 1 & & 9 & 1 & & & & & & & & & \\
\hline 27 & & & & & & & & & 3 & & & & & & & & & & & & & & \\
\hline 29 & & & & & & & & & 1 & & & & & & & & 5 & & & 1 & & & \\
\hline 30 & & & & & & & & & . & & 1 & & & 1 & & & & & & & & & \\
\hline 32 & 1 & 1 & & & & & 3 & & 2 & 1 & & & 1 & & 13 & & 7 & & & & & & \\
\hline 33 & & & & & 2 & 1 & 3 & & 2 & & 1 & & 2 & & & & 2 & & & & 3 & & \\
\hline \multicolumn{24}{|l|}{35} \\
\hline \multicolumn{24}{|l|}{38} \\
\hline 40 & & & & & & & & & 1 & & & 1 & 1 & & 8 & & 1 & & & & & & \\
\hline 41 & 4 & & 3 & 1 & 6 & 2 & 1 & 1 & 10 & 5 & 2 & & 1 & & & & & & & & & & \\
\hline 43 & & & & & & & 1 & & & & 7 & 2 & 1 & & & & 1 & & & & & & \\
\hline 44 & 3 & & & 2 & 2 & & 3 & & 52 & 3 & & & & & & & & & & & & & \\
\hline 45 & 16 & & 1 & & 1 & & & & & & & & 1 & & & & & & & & & & \\
\hline 46 & 10 & & & & & 8 & & & 10 & 1 & 2 & & & & & & & & & & & & \\
\hline 47 & 10 & & & & & & & & 22 & 1 & 1 & & & & & & & & & & & & \\
\hline 48 & 17 & & 1 & & & 11 & 1 & & 91 & 3 & & & & 1 & & & & & & & & & \\
\hline 49 & 2 & & & 3 & 1 & & & & 10 & & & & & & & & & & & & & & \\
\hline 50 & 3 & & & & & & & & & & & 1 & 1 & & & & & & & & & & \\
\hline 51 & 3 & & & & & & & & 54 & & & 1 & & 4 & & & & & & & & & \\
\hline 52 & & & & & & & & & 4 & & & & 1 & & & & & & & & & & \\
\hline
\end{tabular}




\begin{tabular}{|c|c|c|c|c|c|c|c|c|c|c|c|c|c|c|c|c|c|c|c|c|c|c|c|c|}
\hline Type & 458 & 465 & 467 & 468 & $\begin{array}{l}469 \\
470\end{array}$ & 471 & 472 & 473 & 474 & 477 & 481 & 478 & 483 & 484 & 485 & 486 & 487 & 492 & 493 & $\begin{array}{l}495 \\
497\end{array}$ & 494 & 731 & 499 & $\begin{array}{l}735 \\
736\end{array}$ \\
\hline 1 & 47 & 58 & 99 & 23 & 442 & 38 & 21 & 25 & 57 & 58 & 70 & 33 & 37 & 11 & 17 & 19 & 8 & 17 & 20 & 26 & 12 & & 9 & 42 \\
\hline 2 & 2 & 4 & 8 & & 27 & 2 & 3 & 1 & 3 & 11 & 6 & 9 & 2 & 2 & 3 & & 1 & & 1 & 2 & 8 & & & 1 \\
\hline 3 & 2 & & & & 3 & & 1 & & & & 3 & & 1 & 1 & & & & & & & 1 & & & 5 \\
\hline 4 & 4 & 5 & 3 & 2 & 1 & 2 & & & & & & & & & & & & & & 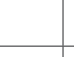 & 2 & & & 1 \\
\hline 5 & & 1 & 1 & 2 & & & & & & & & & & & & & 1 & & & 1 & 2 & & & 1 \\
\hline \multicolumn{25}{|c|}{6} \\
\hline \multicolumn{25}{|l|}{7} \\
\hline 8 & & & 4 & & 2 & 2 & 1 & & 1 & & 2 & & & & & & & & & . & 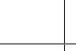 & & & 2 \\
\hline 9 & & & 2 & & & 2 & & & & & & 1 & & & & & & & & 1 & 3 & & 1 & 2 \\
\hline 10 & 9 & 6 & 20 & 4 & 5 & 2 & 3 & 2 & 6 & 1 & 4 & 2 & 3 & 2 & 2 & 2 & 1 & 1 & 3 & 2 & 9 & & 2 & 29 \\
\hline \multicolumn{25}{|l|}{12} \\
\hline \multicolumn{25}{|l|}{13} \\
\hline \multicolumn{25}{|l|}{14} \\
\hline \multicolumn{25}{|l|}{15} \\
\hline 16 & 2 & & 4 & & & & & 4 & 1 & & 1 & & & 1 & & & & & & 1 & & & & \\
\hline \multicolumn{25}{|c|}{18} \\
\hline 20 & & & & & 2 & & & & & & & 1 & & & & & & & & & & & & \\
\hline \multicolumn{25}{|l|}{22} \\
\hline \multicolumn{25}{|l|}{23} \\
\hline \multicolumn{25}{|l|}{24} \\
\hline \multicolumn{25}{|l|}{25} \\
\hline \multicolumn{25}{|l|}{27} \\
\hline 29 & & & & & & & & & & 2 & 2 & & & 1 & & & & & & 1 & & & & \\
\hline \multicolumn{25}{|l|}{30} \\
\hline \multicolumn{25}{|c|}{32} \\
\hline 33 & & 3 & 1 & & 1 & & & 1 & & & & & & & & & & & & & & & & \\
\hline \multicolumn{25}{|l|}{35} \\
\hline 38 & 2 & & 1 & & & & & & 1 & & & & & & 1 & & & & & 1 & 1 & & & 8 \\
\hline 40 & & 2 & & & & & & & & & & & & & & & & & 1 & & & & & \\
\hline \multicolumn{25}{|l|}{41} \\
\hline 43 & & & & & 4 & & & & & & & & 1 & & & & & & & & & & & \\
\hline 44 & & & & & & & & & & & & & & & & & & & & & & & & \\
\hline 45 & & & & & & & & & & & & & & & & & & & & & & & & \\
\hline 46 & & & & & & & & & & & & & & & & & & & & & & & & \\
\hline 47 & & & & & & & & & & & & & & & & & & & & & & & & \\
\hline 48 & & & & & & & & & & & & & & & & & & & & & & & & \\
\hline 49 & & & & & & & & & & & & & & & & & & & & & & & & \\
\hline 50 & & & & & & & & & & & & & & & & & & & & & & & & \\
\hline 51 & & & & & & & & & & & & & & & & & & & & & & & & \\
\hline 52 & & & & & & & & & & & & & & & & & & & & & & & & \\
\hline
\end{tabular}


Table 7.7 (continued): Types from Trench B by rim-sherd count and layer in stratigraphic sequence.

\begin{tabular}{|c|c|c|c|c|c|c|c|c|c|c|c|c|c|c|c|c|c|c|c|c|c|c|c|}
\hline Type & $\begin{array}{l}402 \\
406 \\
414\end{array}$ & 408 & 413 & $\begin{array}{l}415 \\
426\end{array}$ & 417 & $\begin{array}{l}418 \\
420 \\
422\end{array}$ & 427 & 428 & \begin{tabular}{|l|}
430 \\
432 \\
435 \\
\end{tabular} & 429 & 438 & 440 & 439 & 437 & 441 & 443 & $\begin{array}{l}444 \\
448\end{array}$ & 450 & 451 & 452 & 453 & 456 & 457 \\
\hline 53 & & & & & & & & & 15 & & & & & & & & & & & & & & \\
\hline 54 & & & & & & & & & 11 & & & & & & & & & & & & & & \\
\hline 55 & & & 3 & 4 & & 3 & 1 & & 12 & & & 1 & & & & & & & & & & & \\
\hline 56 & & & & & 1 & & 2 & & 3 & & & & 1 & & & & & & & & & & \\
\hline 57 & & & & & 2 & & 2 & & 11 & & & & & & & & & & & & & & \\
\hline RPW & 1 & & & & & & & & & & & & & & & & & & & & & & \\
\hline CHIN & 2 & & & & 1 & & & & 9 & & & & & & & & & & & & & & \\
\hline PERS & & & & & 1 & & & & & & & & & & & & & & & & & & \\
\hline NON & 102 & & 19 & 14 & 22 & 25 & 19 & 1 & 186 & 21 & 25 & 23 & 44 & 3 & 24 & 2 & 7 & 1 & 14 & 13 & 9 & 1 & 4 \\
\hline UNIQ & 5 & & & & 5 & & & & 18 & & & & 1 & 1 & 1 & & & & & & & & \\
\hline Rim Total & 319 & 2 & 58 & 32 & 67 & 60 & 57 & 4 & 898 & 61 & 145 & 115 & 228 & 38 & 70 & 9 & 115 & 14 & 61 & 132 & 99 & 4 & 30 \\
\hline NBP Body & & & & & & & & & & & & & & & & & & & & & & & \\
\hline RPW Body & 1 & & & & & & & & 2 & & & & & & & & & & & & & & \\
\hline CHIN Body & 5 & & & & 1 & & 1 & & 9 & & & & & & & & & & & & & & \\
\hline PERS Body & 1 & & & & & & & & 1 & 1 & & & & & & & & & & & & & \\
\hline SLIP Body & & & & & & & 2 & & 1 & 1 & & & 2 & 1 & & & & & & & & & \\
\hline WARP Body & & & & & & & & & 4 & & 2 & & & & & & & & & & & & \\
\hline NON Body & 3458 & 32 & 567 & 142 & 402 & 224 & 318 & 28 & 3879 & 446 & 1 & 614 & 1140 & 163 & 1248 & 173 & 292 & 128 & 121 & 513 & 229 & 65 & 166 \\
\hline Body Total & 3465 & 32 & 567 & 142 & 403 & 224 & 321 & 28 & 3896 & 448 & 3 & 614 & 1142 & 164 & 1248 & 173 & 292 & 128 & 121 & 513 & 229 & 65 & 166 \\
\hline
\end{tabular}




\begin{tabular}{|c|c|c|c|c|c|c|c|c|c|c|c|c|c|c|c|c|c|c|c|c|c|c|c|c|}
\hline Type & 458 & 465 & 467 & 468 & $\begin{array}{l}469 \\
470\end{array}$ & 471 & 472 & 473 & 474 & 477 & 481 & 478 & 483 & 484 & 485 & 486 & 487 & 492 & 493 & $\begin{array}{l}495 \\
497\end{array}$ & 494 & 731 & 499 & $\begin{array}{l}735 \\
736\end{array}$ \\
\hline \multicolumn{25}{|l|}{53} \\
\hline \multicolumn{25}{|l|}{54} \\
\hline \multicolumn{25}{|l|}{55} \\
\hline \multicolumn{25}{|l|}{56} \\
\hline 57 & & & & & & & & & & & & & & & & & & & & & & & 1 & \\
\hline \multicolumn{25}{|l|}{ RPW } \\
\hline \multicolumn{25}{|l|}{ CHIN } \\
\hline \multicolumn{25}{|l|}{ PERS } \\
\hline NON & 6 & 4 & 13 & 5 & 8 & & 2 & & 4 & 1 & 1 & 1 & & 1 & & 1 & 4 & & 2 & 1 & 2 & 1 & 4 & 15 \\
\hline \multicolumn{25}{|l|}{ UNIQ } \\
\hline Rim Total & 74 & 83 & 156 & 36 & 498 & 48 & 31 & 33 & 73 & 73 & 89 & 47 & 45 & 19 & 23 & 22 & 16 & 18 & 27 & 36 & 41 & 1 & 17 & 106 \\
\hline NBP Body & 1 & & & & & & & & & & & & & & & & & & & & & & & \\
\hline \multicolumn{25}{|l|}{ RPW Body } \\
\hline \multicolumn{25}{|l|}{ CHIN Body } \\
\hline \multicolumn{25}{|l|}{ PERS Body } \\
\hline \multicolumn{25}{|l|}{ SLIP Body } \\
\hline \multicolumn{25}{|l|}{ WARP Body } \\
\hline NON Body & 395 & 418 & 774 & 351 & 1807 & 106 & 78 & 132 & 302 & 239 & 293 & 263 & 227 & 98 & 107 & 123 & 117 & 86 & 190 & 179 & 260 & 0 & 51 & 1014 \\
\hline Body Total & 396 & 418 & 774 & 351 & 1807 & 106 & 78 & 132 & 302 & 239 & 293 & 263 & 227 & 98 & 107 & 123 & 117 & 86 & 190 & 179 & 260 & 0 & 51 & 1014 \\
\hline
\end{tabular}


Table 7.8: Types from Trench C by rim-sherd count and layer in stratigraphic sequence.

\begin{tabular}{|c|c|c|c|c|c|c|c|c|}
\hline Type & 48 & 52 & 60 & 69 & 83 & 84 & 87 & 93 \\
\hline 1 & 4 & 5 & 6 & 16 & 6 & 14 & 7 & \\
\hline 3 & 2 & 1 & 7 & 7 & 1 & 9 & 8 & 2 \\
\hline 4 & 1 & & 4 & 6 & 7 & 17 & & \\
\hline 6 & & & 3 & 2 & 3 & 11 & 1 & \\
\hline 7 & & & 1 & 2 & & & & \\
\hline 8 & 3 & & 2 & 7 & 4 & 5 & 5 & \\
\hline 9 & 1 & & 1 & 3 & 1 & 6 & & \\
\hline 10 & 2 & 2 & 5 & 15 & 8 & 23 & 1 & 5 \\
\hline 11 & 1 & 1 & & & 1 & 2 & & \\
\hline 12 & 4 & 3 & 2 & & & & & \\
\hline 13 & 3 & 4 & 1 & 1 & & & & \\
\hline 14 & 4 & & & & & & & \\
\hline 15 & 4 & 3 & 1 & & & & & \\
\hline 16 & & & 4 & 9 & & 1 & & \\
\hline 17 & 2 & & & 2 & & & & \\
\hline 18 & 1 & & & 1 & & & & \\
\hline Rim total & 32 & 19 & 37 & 71 & 31 & 88 & 22 & 7 \\
\hline
\end{tabular}

Table 7.9: Types from Trench D1 by rim-sherd count and layer in stratigraphic sequence.

\begin{tabular}{|c|c|c|c|c|c|c|c|c|c|c|}
\hline Type & 751 & 752 & 759 & 760 & 766 & 767 & 773 & 770 & 775 & 777 \\
\hline 1 & 75 & 6 & 55 & & 109 & 255 & 21 & 9 & 2 & 6 \\
\hline 2 & & & & & 2 & 7 & 1 & & 1 & \\
\hline 3 & 3 & & 2 & & 4 & 5 & & 2 & & \\
\hline 4 & 2 & & 3 & & 6 & 7 & & & 1 & 1 \\
\hline 5 & & & 1 & & 1 & 4 & & & & \\
\hline 8 & 3 & 1 & & & 1 & 2 & & 2 & & \\
\hline 9 & & & & & 1 & 2 & & & & \\
\hline 10 & 4 & 1 & 8 & & 43 & 36 & 2 & 8 & 3 & 2 \\
\hline 14 & 2 & & & & & & & & & \\
\hline 16 & 8 & & 3 & & & 4 & & & & \\
\hline 20 & 1 & & & & & & & & & \\
\hline 24 & 4 & & & & & 2 & & & & \\
\hline 32 & 5 & 1 & & & & , & & & & \\
\hline 33 & 2 & & 1 & & 1 & 3 & & & & \\
\hline 38 & & & & & 1 & 1 & & & & \\
\hline 43 & 5 & & & & & & & 1 & & \\
\hline 58 & & & & & & 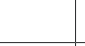 & & 1 & & 1 \\
\hline NBP & & & & & & 1 & & & & \\
\hline NON & 13 & 3 & 5 & & 5 & 23 & & 2 & 1 & \\
\hline Rim total & 127 & 12 & 78 & 0 & 174 & 352 & 24 & 25 & 8 & 10 \\
\hline NBP body & & & & & 3 & 3 & & 1 & & \\
\hline Body total & 229 & 6 & 102 & 365 & 321 & 1936 & 88 & 113 & 79 & 48 \\
\hline
\end{tabular}


Table 7.10: Types from Trench D2 by rim-sherd count and layer in stratigraphic sequence.

\begin{tabular}{|c|c|c|c|c|c|c|c|c|c|c|c|c|c|c|c|c|c|c|c|c|c|c|}
\hline Type & 701 & 702 & 703 & 705 & 706 & 707 & 709 & 710 & 711 & 712 & 713 & 715 & 716 & 718 & 719 & 721 & 723 & 722 & 725 & 726 & 728 & 729 \\
\hline $1 \mathrm{~A}$ & 2 & 24 & 74 & 11 & 10 & 8 & 188 & 88 & 243 & 301 & 4 & 244 & 2 & 211 & 12 & 36 & 4 & 46 & 13 & 13 & 21 & 12 \\
\hline 1B & 2 & 10 & 5 & 4 & & & 6 & 8 & 18 & 19 & & 10 & & 150 & 3 & 46 & & 35 & 1 & 49 & 17 & 2 \\
\hline 2 & & & & & & & & 1 & & & & 3 & & 17 & & 19 & 2 & 20 & 3 & 24 & 10 & \\
\hline 3 & 1 & 2 & 13 & 2 & 4 & & 6 & 7 & 6 & 9 & 1 & 4 & & 16 & 1 & 5 & & & & 4 & & \\
\hline 4 & 1 & 2 & 4 & 3 & & 4 & 11 & 5 & 23 & 44 & & 53 & & 33 & & 3 & & & & 3 & 1 & 1 \\
\hline 5 & & 2 & 2 & 3 & 2 & & & 1 & & 4 & & 1 & & 3 & & 4 & & 1 & & 5 & & 1 \\
\hline 6 & & & 2 & & 1 & & 1 & & & 1 & & & & 16 & & & & 1 & & 4 & & \\
\hline 7 & & & & & & 1 & & & & & & & & & & & & & & & & \\
\hline 8 & & 1 & 2 & 1 & & & 6 & 4 & 3 & 6 & & 6 & & 5 & & 2 & & 4 & & 2 & & \\
\hline 9 & & 1 & 3 & & 3 & 1 & 1 & 2 & 4 & 3 & & 3 & & 2 & & 2 & & 4 & 2 & 2 & & \\
\hline 10 & 1 & 3 & 27 & 19 & 21 & 12 & 22 & 8 & 30 & 23 & 1 & 28 & 1 & 68 & 5 & 39 & 2 & 61 & 19 & 80 & 9 & 30 \\
\hline 14 & & & & & & & & & & 1 & & & & & & & & & & & & \\
\hline 16 & & 6 & 13 & 4 & 1 & 1 & 6 & 5 & 5 & 21 & 1 & 15 & & 7 & 1 & 1 & & 1 & & & & \\
\hline 18 & & & & & & & 1 & 1 & & & & & & 1 & & & & & & & & \\
\hline 19 & & & & & & & & & 1 & & & & & & & & & & & & & \\
\hline 24 & & & 1 & & & & & & 1 & 1 & & & & & & & & & & & & \\
\hline 25 & & & & & & & & 1 & 1 & & & & & 1 & & & & & & & & \\
\hline 29 & & & & & 1 & & & & & & & & & & & & & & & & & \\
\hline 30 & & & & & & & & 1 & & & & & & 7 & & 10 & & & & 3 & & 7 \\
\hline 32 & 1 & & & 1 & & & & 4 & & 1 & & & & . & & & & & & & & \\
\hline 33 & 1 & & & & & 1 & 1 & & 2 & 4 & & 1 & & 1 & & & & & & & & \\
\hline 35 & & & & & & & & & & & & 1 & & & & & & & & & & \\
\hline 36 & & 3 & & & & & & & & 3 & & & & 8 & & & & & & 4 & & \\
\hline 37 & & & & & & & & & 3 & 2 & & & & & & & & & & & & \\
\hline 38 & & & & & & & & & & & & & & & & & & & 1 & 1 & 4 & 2 \\
\hline 39 & & & & & & & & & & & & & & & & & & & & 1 & & 2 \\
\hline 40 & & & & & & & & & & 1 & & 2 & & & & & & & & 2 & & \\
\hline 41 & & & 2 & 11 & 2 & & & & & & & 2 & & 1 & & & & & & & & \\
\hline 42 & & & & & & & 2 & 2 & & & & 3 & & 4 & & & & 1 & & & & 1 \\
\hline 43 & & & & 1 & 2 & 1 & & & & & & 1 & & 2 & & & 2 & & & 1 & & \\
\hline NBP & & & & & & & & & & & & & & 2 & 2 & & & & & & & \\
\hline NON & 2 & 2 & 4 & 4 & 4 & 3 & & 5 & 2 & 6 & & 12 & & 23 & 1 & 9 & 2 & 8 & 6 & 11 & & 4 \\
\hline UNIQ & 1 & & 2 & 1 & 2 & & 1 & & & 1 & & & & & & 1 & & & & & & 7 \\
\hline Rim Total & 8 & 22 & 75 & 50 & 43 & 24 & 58 & 47 & 81 & 131 & 3 & 135 & 1 & 217 & 10 & 95 & 8 & 101 & 31 & 147 & 24 & 55 \\
\hline NBP Body & & & & & & & & & & & & & & 4 & 3 & 1 & & & & & & \\
\hline Body Total & 6 & 151 & 498 & 238 & 270 & 115 & 30 & 345 & 101 & 950 & 31 & 839 & 11 & 1989 & 84 & 510 & 82 & 703 & 149 & 804 & 271 & 0 \\
\hline
\end{tabular}


Table 7.11: Types from Trench F by rim-sherd count and layer in stratigraphic sequence.

\begin{tabular}{|c|c|c|c|c|c|c|c|c|c|c|c|}
\hline Type & 778 & 785 & 787 & 788 & 789 & 797 & 798 & 846 & 851 & 852 & 853 \\
\hline 1 & 273 & 3 & 81 & 106 & 29 & 27 & 2 & 182 & 186 & 16 & \\
\hline 2 & & & & & & & & & 4 & & \\
\hline 3 & 9 & & 7 & 17 & 1 & 1 & 1 & 22 & 46 & & \\
\hline 4 & 1 & & 1 & 9 & & 1 & & 8 & 28 & 1 & \\
\hline 5 & 8 & & 4 & 1 & & 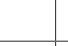 & 2 & 3 & 12 & & \\
\hline 7 & 2 & & 3 & 5 & & 1 & & 2 & & & \\
\hline 8 & & & 4 & 5 & & 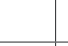 & & 14 & 70 & 1 & \\
\hline 9 & 7 & & 6 & 22 & & e & & 8 & 26 & 1 & \\
\hline 10 & 15 & & 11 & 97 & 8 & 5 & & 104 & 243 & 6 & \\
\hline 12 & 4 & & & & & & & & & & \\
\hline 14 & 8 & & & & & & & & & & \\
\hline 16 & 11 & & 9 & 17 & 2 & & & 7 & 52 & 4 & \\
\hline 20 & & & & & & & & 11 & & & \\
\hline 24 & & & & & & & & 3 & & & \\
\hline 27 & 1 & & & & & & & & & & \\
\hline 29 & & & 1 & & 2 & & & 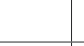 & & & \\
\hline 30 & & & & & & & & 12 & & & \\
\hline 33 & & & & 2 & & & & & & & \\
\hline 34 & 3 & & & & & & & & & & \\
\hline 40 & & & & & & & & & 5 & & \\
\hline 41 & & & & & & 1 & & 23 & & & \\
\hline 43 & 9 & & & 9 & & & & & 33 & & \\
\hline 44 & 5 & & & & & & & & & & \\
\hline 48 & 1 & & & & & & & & & & \\
\hline 50 & 7 & & & & & & & & & & \\
\hline 58 & & & & 1 & & & & & 7 & & \\
\hline NON & 40 & & 11 & 23 & 3 & 7 & 1 & 38 & 111 & 5 & 4 \\
\hline Rim total & 404 & 3 & 138 & 314 & 45 & 43 & 6 & 437 & 823 & 34 & 4 \\
\hline NBP body & & & & & & & & & 1 & & \\
\hline Body total & 882 & 31 & 594 & 1322 & 183 & 203 & 86 & 2571 & 4446 & 216 & 50 \\
\hline
\end{tabular}




\section{Conclusion}

In addition to the points set out above, a number of further points can be made on the basis of the combined discussion of the types, wares and fabrics in relation to the site's sequence. The first is the high level of residuality that is present in Period 4. This can be seen, for example, in the occurrence of Types 2, 6, 7, 12, 14, $16,20,25,41$ and a few others, which make up a similar or higher percentage of the Period 4 assemblage than they do the assemblages of earlier periods when the types were actually in circulation. This suggests that the layers of Period 4 contain a lot of redeposited earth from earlier levels. This is probably due to the deep foundations that were dug when the large brick town houses were built in the later Medieval period, which resulted in earth from 2- or 3-m depth being brought to the surface along with the archaeological material that it contained. This material then entered the deposits of the later Medieval period and it is from such deposits that it was recovered by the excavation. Only full quantification of the pottery assemblage allows this sort of detail to become clear. If it is true for the pottery, then it will also be true for small finds, coins and other antiquities.

Period 3-temple presents something of an enigma. It is made up of layers that are largely foundation deposits and construction layers related to the two temples and might therefore be expected to contain a largely re-deposited assemblage from earlier periods. This is in fact likely to be the case as is suggested by the fact that Types 1 and 10 are over-represented in Period 3-temple compared to Period 3, whilst other types, most notably Type 24 but also Types 3, 25 and 27 , appear to be markedly under-represented. These anomalies suggest that, although the Period 3-temple and Period 3 assemblages are broadly contemporary, it is likely that they have quite different depositional histories, with Period 3-temple deposits containing much higher amounts of re-deposited material that is much earlier and relatively few examples of contemporary types. Having said this, it should be remembered that the Period 3-temple assemblage is quite small - between one third and one thirteenth the size of the other assemblages - meaning that it is less likely to contain rarer examples of types and wares and also that the figures from it are more likely to be affected by freak occurrences of one or two sherds that would not affect a larger assemblage.
Period 4 is also notable for a slightly greater variety of classes than are found in earlier periods, especially of higher-quality wares (Table 7.4). In Periods 1 and 2, the presence of small quantities of NBP and RPW is noted, but by Period 4, four high-quality classes are present in the assemblage (CHIN, PERS, SLIP and WARP), at least three of which are imported to Paithan. It is also notable that Period 4 has a higher number of new types than other periods (see above) and a greater number of 'unique' sherds. Both of these points suggest, again, that there was a greater variety of types and wares in circulation at this time. A similar picture is given by the pottery fabrics. In Periods 1 and 2, Fabric 1 and its variants make up over $75 \%$ of the pottery. This drops to $60 \%$ in Period 3 and 51\% in Period 4 (as noted above, the Period 3-temple assemblage is too small to be statistically reliable in such a comparison). These observations suggest a much greater diversity of pottery manufacture and trade in the later Medieval period, when it seems likely that Paithan might have been somewhat better integrated into a broader regional distributive economy than perhaps it had been during the Early Historic period. It is therefore strange to note that the late period, which is sometimes referred to as the 'Muslim-Maratha' period in regional excavation reports, is often said to show a declining quality of pottery production, although no such decline was noted at Paithan.

Conversely, the predominance of a single fabric (Fabric 1a) in Periods 1 and 2, where it makes up over $70 \%$ of the total assemblage, might suggest exactly the opposite, that is to say, a production and distribution system with very little diversity, focussed, at least as far as pottery is concerned, on a single production location and possibly a single industry. But this is somewhat speculative. More work needs to be done on these issues before any more can be said with any degree of certainty. They do, however, point the way to some potentially interesting and useful avenues for further research.

In summary, it seems that the use of a formal typology linked to detailed definitions of fabrics and wares and a system of full quantification of the assemblage is likely to yield more useful results than the traditional system of loosely defined wares has done to date. It is difficult to see, otherwise, how progress might be made towards a better understanding of the Early Historic and Early Medieval pottery chronology. 


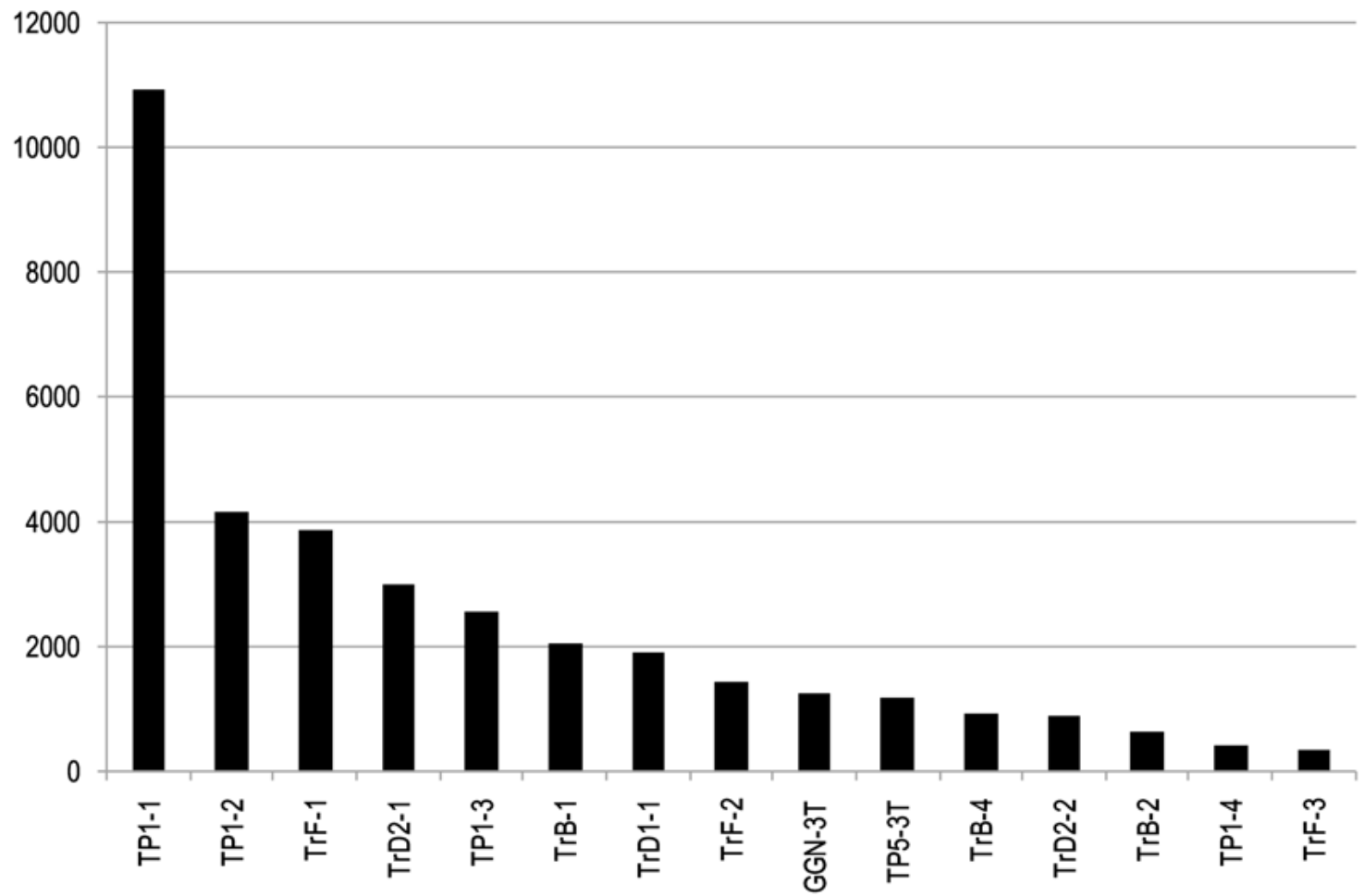

Fig. 7.19: Ranked analysis of the density of sherds per metre cubed from 15 period-assemblages from across the site.

Table 7.12: The number of sherds and the amount of earth excavated from a sample of period-assemblages from across the site (Trench $A$ Test Pit 1 (TP1) Periods 1-4; Trench B (TrB) Periods 1, 2 and 4; Trench D1 (TrD1) Period 1; Trench D2 (TrD2) Periods 1 and 2; Trench F (TrF) Periods 1, 2 and 3; Trench A Garbha Griha of the North Temple (GGN), Period 3-Temple and Trench A Test Pit 5 (TP5) Period 3-Temple).

\begin{tabular}{lrrr}
\hline & Period & Sherds & Meters $^{3}$ \\
\hline TrB-1 & 1 & 10,602 & 5.15 \\
\hline TrB-2 & 2 & 2,646 & 4.11 \\
\hline TrB-4 & 4 & 15,832 & 16.64 \\
\hline TP5-3T & $3 T$ & 10,184 & 8.60 \\
\hline TrF-1 & 1 & 5,787 & 1.49 \\
\hline TrF-2 & 2 & 6,423 & 4.46 \\
\hline TrF-3 & 3 & 1,286 & 3.53 \\
\hline TrD1-1 & 1 & 6,772 & 3.53 \\
\hline TrD2-1 & 1 & 7,658 & 2.54 \\
\hline TrD2-2 & 2 & 4,382 & 4.92 \\
\hline TP1-1 & 1 & 3,500 & 0.32 \\
\hline TP1-2 & 2 & 17,516 & 4.19 \\
\hline TP1-3 & 3 & 6,263 & 2.42 \\
\hline TP1-4 & 4 & 837 & 2.02 \\
\hline GGN-3T & $3 T$ & 3,088 & 2.45 \\
\hline
\end{tabular}

Table 7.13: The density of sherds per cubic metre from 15 periodassemblages from across the site.

\begin{tabular}{lrr}
\hline Period & Period-assemblage & Sherd density \\
\hline 1 & TP1-1 & 10,938 \\
\hline 1 & TrF-1 & 3,884 \\
\hline 1 & TrD2-1 & 3,015 \\
\hline 1 & TrB-1 & 2,059 \\
\hline 2 & TrD1-1 & 1,918 \\
\hline 2 & TP1-2 & 4,180 \\
\hline 2 & TrF-2 & 1,440 \\
\hline 2 & TrD2-2 & 891 \\
\hline 3 & TrB-2 & 644 \\
\hline 3 & TP1-3 & 2,588 \\
\hline $3 T$ & TrF-3 & 364 \\
\hline $3 T$ & GGN-3T & 1,260 \\
\hline 4 & TP5-3T & 1,184 \\
\hline 4 & TrB-4 & 951 \\
\hline & TP1-4 & 414 \\
\hline
\end{tabular}


Table 7.14: Average density of sherds per meter cubed based on the data from Table 7.13 (not including the anomalously high figure for TP1-1 of 10,938 per $\left.\mathrm{m}^{3}\right)$.

\begin{tabular}{lr}
\hline Period & Average sherds per $\mathbf{m}^{3}$ \\
\hline 1 & 2,719 \\
\hline 2 & 2,170 \\
\hline 3 & 1,476 \\
\hline 3 -temple & 1,222 \\
\hline 4 & 683 \\
\hline
\end{tabular}

\section{Catalogue of 'unique' sherds}

A total of 82 'unique' sherds (UNIQ) was recorded that either could not be classified according to the typology and classes set out above or which have specific traits that are of particular interest. The most significant of these sherds are illustrated in Figs 7.20-7.22 and are described below (Table 7.15).

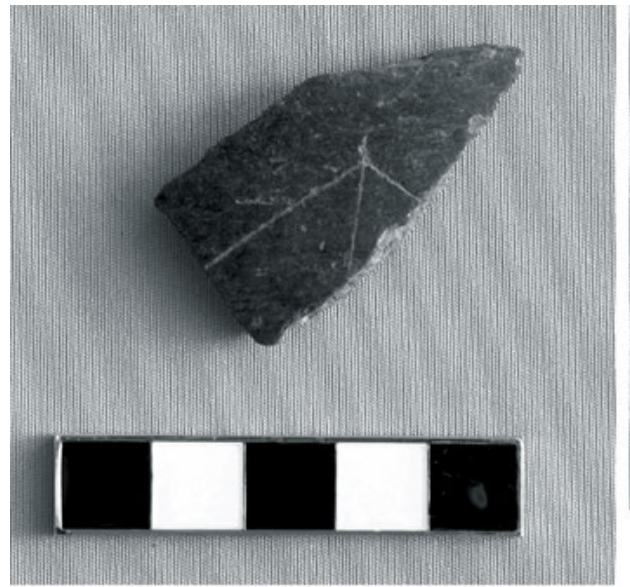

\section{P1766}

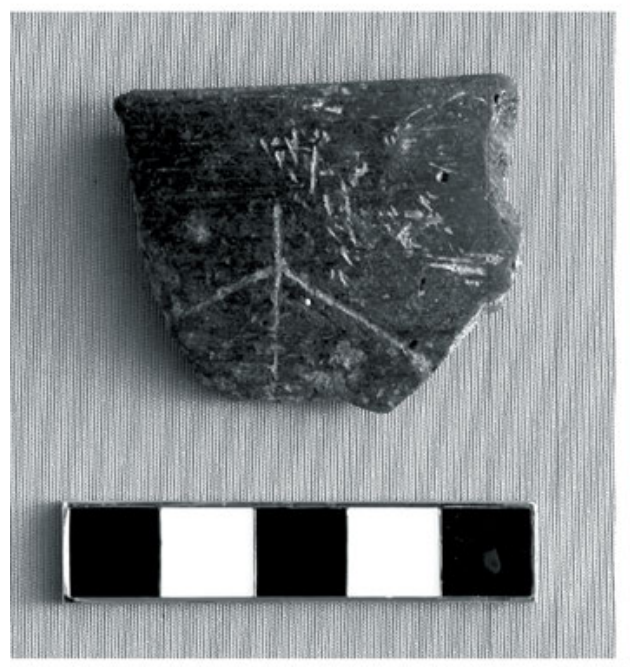

P863

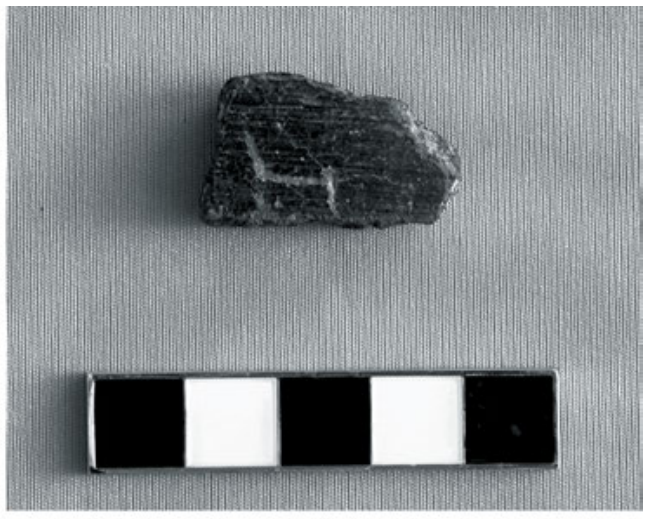

P2552
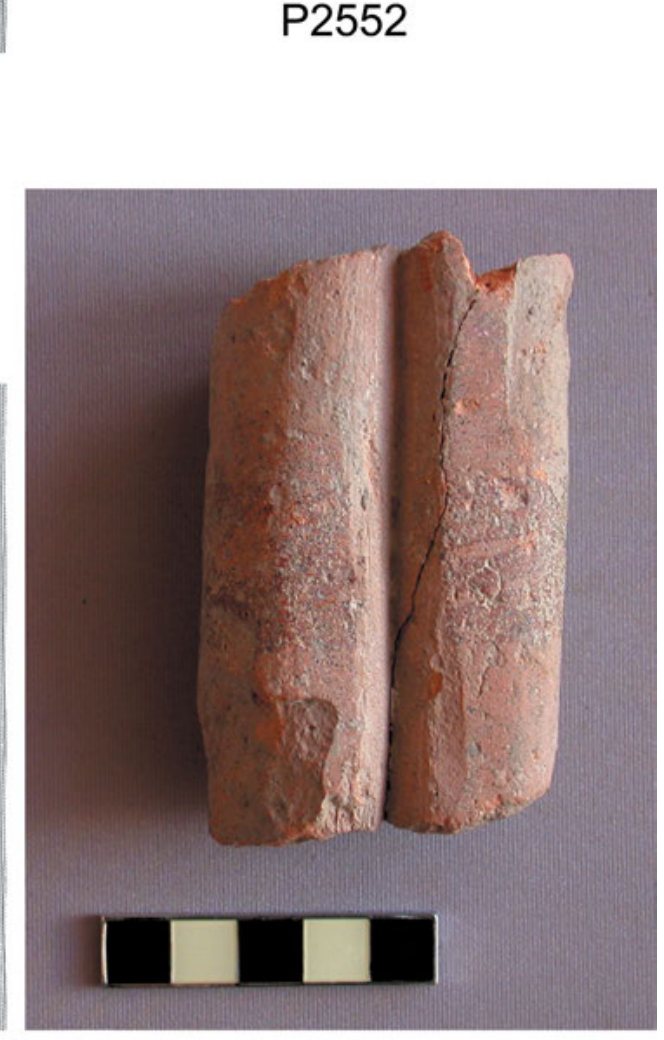

\section{P2553}

Fig. 7.20: Sherds with incised marks: P863, P1766, P2552 and sherd P2553, Roman amphora. 
Table 7.15: Catalogue of unique sherds.

\begin{tabular}{|c|c|c|c|c|}
\hline P. No. & Context & Period & Description & Figure \\
\hline 863 & 729 & 1 & $\begin{array}{l}\text { Black burnished ware (Fabric 3). Symbol or letter incised onto } \\
\text { sherd after firing. }\end{array}$ & $\begin{array}{l}\text { Fig. } 7.9 \text {, } \\
\text { Fig. } 7.20\end{array}$ \\
\hline 1173 & 729 & 1 & Coarse red ware, thick red slip, no trace of burnish. & Fig. 7.21 \\
\hline 1254 & 715 & 1 & Black burnished ware, no slip or burnish on the interior. & Fig. 7.21 \\
\hline 168 & 966 & 2 & Light orange-red ware, soft-fired, no slip or burnish. & Fig. 7.21 \\
\hline 216 & 988 & 2 & $\begin{array}{l}\text { Red earthenware, partial slip and burnish on the exterior but none on the interior. } \\
\text { Stamped or moulded decoration exterior. }\end{array}$ & Fig. 7.21 \\
\hline 1257 & 712 & 2 & $\begin{array}{l}\text { Very unusual fabric, very light, pink ( } 7.5 Y R 7 / 4) \text {, lots of } \\
\text { organic temper and very coarse. No slip or burnish. }\end{array}$ & Fig. 7.21 \\
\hline 2263 & 586 & 3 & $\begin{array}{l}\text { Coarse red ware, breaks easily, slightly rough fracture, fine sandy texture, grey } \\
\text { corer and reddish exterior (pink } 7.5 \text { YR } 8 / 4 \text { ) but grey core very thin (c. } 4 \mathrm{~mm} \text { ). Exte- } \\
\text { rior and rim painted white with red blotches and lines on rim. }\end{array}$ & Fig. 7.21 \\
\hline 2264 & 586 & 3 & $\begin{array}{l}\text { Coarse reddish sandy ware, rough fracture. No visible inclusions. Body reddish brown } \\
(5 Y R \text { 5/3), surface smoothed, small mica grains visible. }\end{array}$ & Fig. 7.21 \\
\hline 2267 & 632 & 3 & Grey ware with incised decoration, Fabric 2. & Fig. 7.21 \\
\hline 2277 & 632 & 3 & Grey ware with incised decoration, Fabric 2. & Fig. 7.21 \\
\hline 2278 & 632 & 3 & Fabric 2 but fired to a variable reddish colour. & Fig. 7.21 \\
\hline 2279 & 632 & 3 & Red ware, slipped but no polish. & Fig. 7.21 \\
\hline 2280 & 632 & 3 & Grey ware, Fabric 2. & Fig. 7.21 \\
\hline 2281 & 632 & 3 & Grey ware, Fabric 2. & Fig. 7.21 \\
\hline 2282 & 632 & 3 & $\begin{array}{l}\text { Light grey, buff ware with burnish but apparently no slip. Lots of organic temper. } \\
\text { Fabric is dark grey with a reddening on the exterior surface } 3 \mathrm{~mm} \text { deep. Sandy texture, } \\
\text { occasional large }(2 \mathrm{~mm}) \text { white rounded inclusions. }\end{array}$ & Fig. 7.22 \\
\hline 2285 & 632 & 3 & Grey ware, Fabric 2. & Fig. 7.22 \\
\hline 1388 & 402 & 4 & Spout, slipped but not polished. & Fig. 7.22 \\
\hline 1390 & 402 & 4 & $\begin{array}{l}\text { Fabric 1c. Small thickened rim of a narrow-necked vase or jar. Traces of mat red slip on } \\
\text { the exterior and interior. }\end{array}$ & Fig. 7.22 \\
\hline 1556 & 430 & 4 & $\begin{array}{l}\text { Heavy, well-fired grey ware with a dark core and lighter grey edges. Surface is } \\
\text { smoothed. Incised decoration. }\end{array}$ & Fig. 7.22 \\
\hline 1608 & 435 & 4 & Red earthenware, slip and burnish on the exterior only, stamped/moulded decoration. & Fig. 7.22 \\
\hline 1610 & 435 & 4 & Grey ware with traces of pink or red mat paint on the exterior only. & Fig. 7.22 \\
\hline 1611 & 435 & 4 & $\begin{array}{l}\text { Thin body up to } 3.5 \mathrm{~mm} \text {, soft-fired, fine sandy texture. Body greyish brown (10YR 5/2). } \\
\text { No slip on the interior (closed vessel). The exterior has a fine red burgundy slip. Body } \\
\text { moulded with petal decoration. }\end{array}$ & Fig. 7.22 \\
\hline 1660 & 432 & 4 & $\begin{array}{l}\text { Heavy, well-fired grey ware with a dark core and lighter grey edges. Surface is } \\
\text { smoothed. Incised decoration. }\end{array}$ & Fig. 7.22 \\
\hline 1662 & 432 & 4 & Coarse red earthenware, no slip or burnish, fired grey and red. & Fig. 7.22 \\
\hline 1766 & 438 & 4 & $\begin{array}{l}\text { Black burnished ware (Fabric 3). Symbol or letter incised onto } \\
\text { sherd after firing. }\end{array}$ & $\begin{array}{l}\text { Fig. } 7.9 \text {, } \\
\text { Fig. } 7.20\end{array}$ \\
\hline 2553 & 334 & 4 & $\begin{array}{l}\text { Roman Dressel 2-4 amphora handle. Dense hard fabric, very strong. Breaks with a } \\
\text { sub-conchoidal fracture. Dense badly sorted, sub-angular black inclusions up to c. } 0.5 \\
\text { mm. Fabric reddish yellow (5YR 6/6). }\end{array}$ & $\begin{array}{l}\text { Fig. } 7.20 \text {, } \\
\text { Fig. } 7.22\end{array}$ \\
\hline 2552 & 532 & $4 ?$ & $\begin{array}{l}\text { Black burnished ware (Fabric 3). Symbol or letter incised onto } \\
\text { sherd after firing. }\end{array}$ & Fig. 7.20 \\
\hline
\end{tabular}



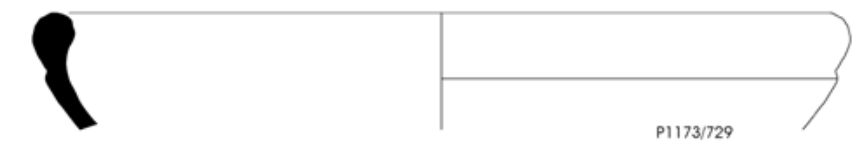

Period 1
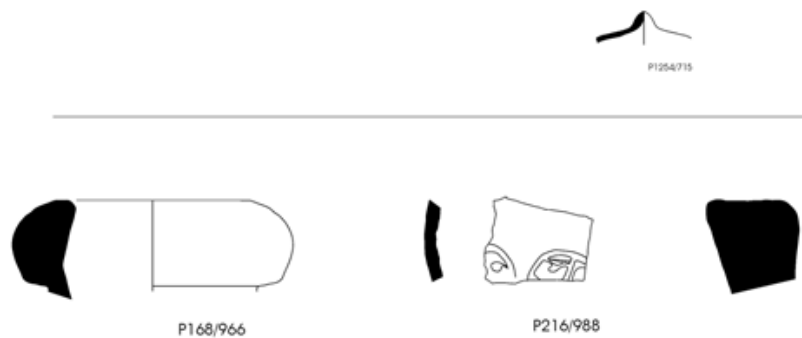

P1257/712

Period 2
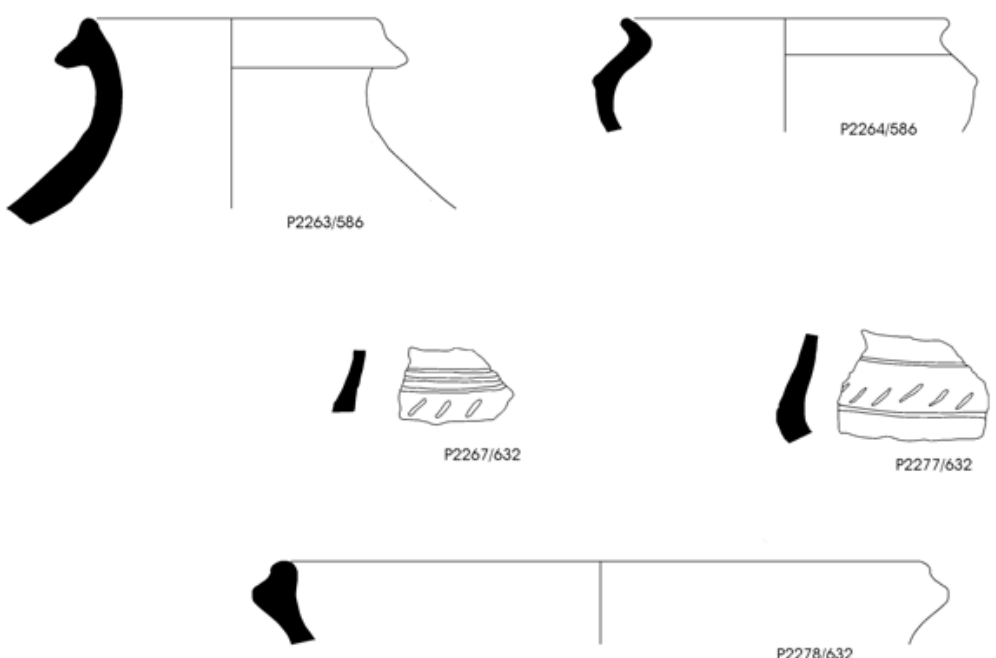

Period 3
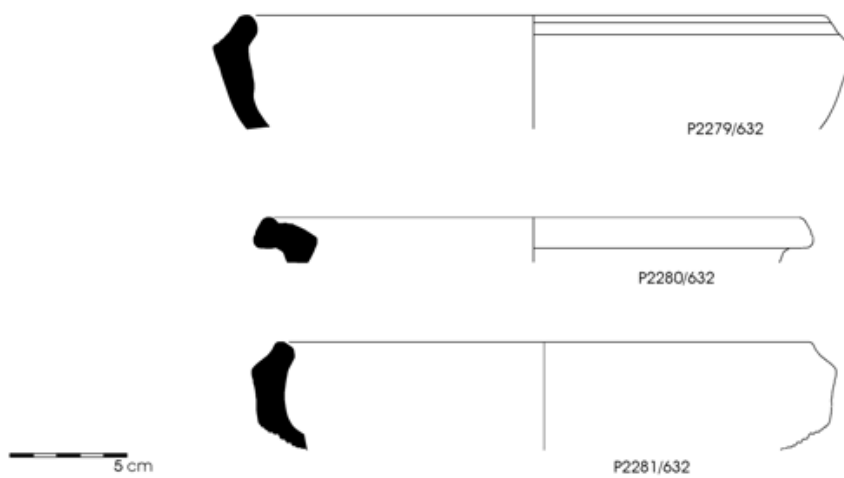

Fig. 7.21: Unique sherds, Periods 1 to 3. 


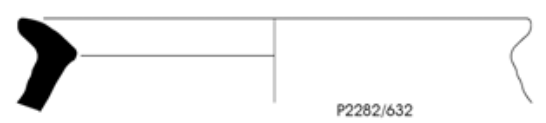

Period 3 (cont.)
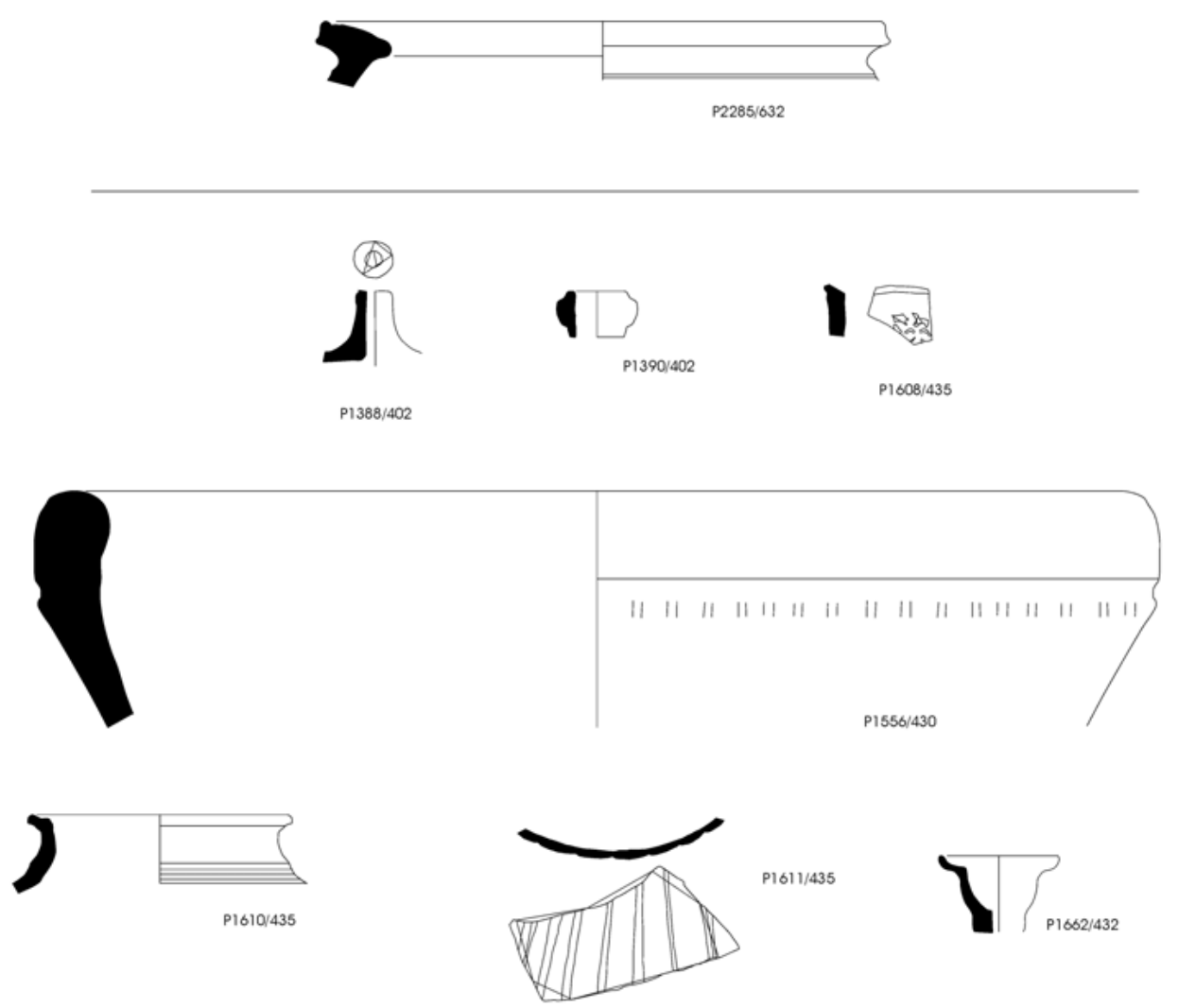

Period 4
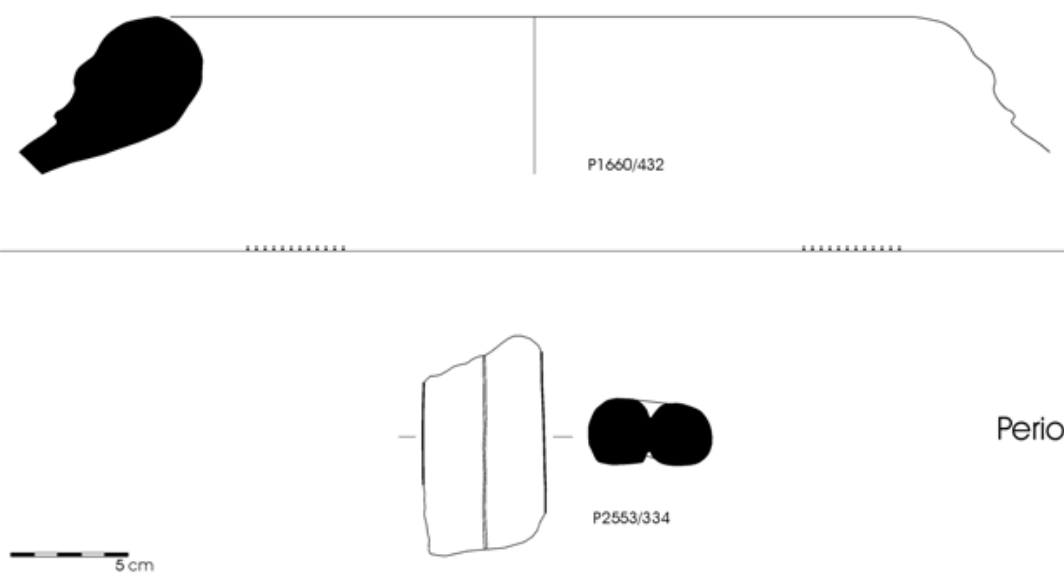

Period 4?

Fig. 7.22: Unique sherds, Periods 3 and 4. 


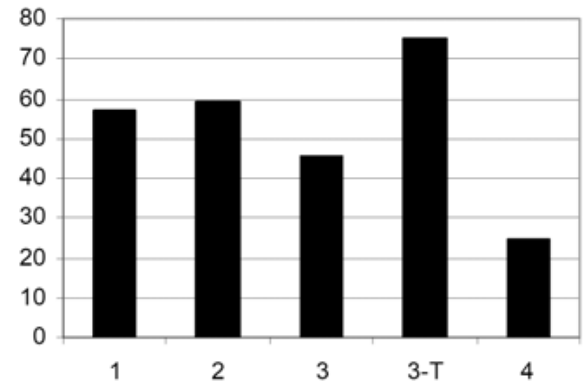

Type 1 combined

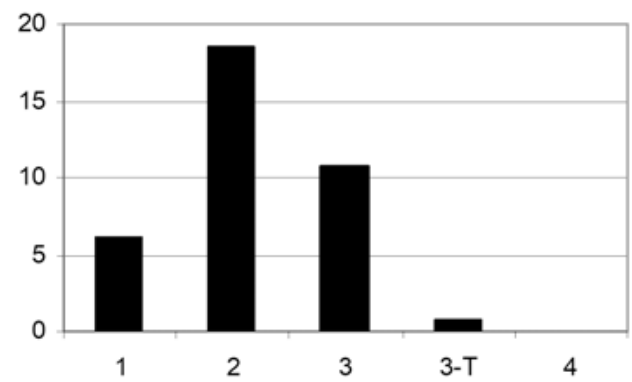

Type 1b

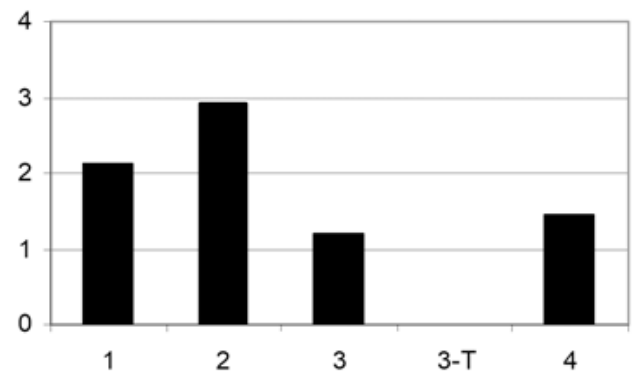

Type 3

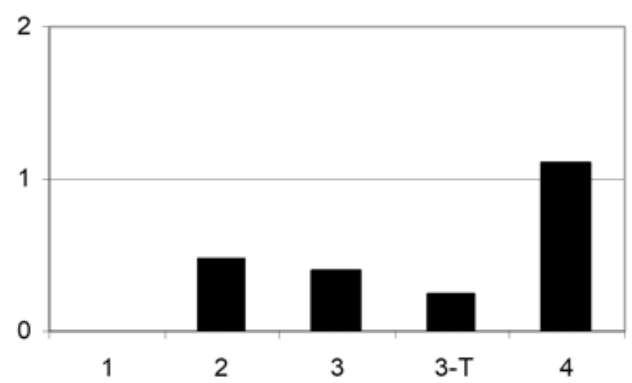

Type 7

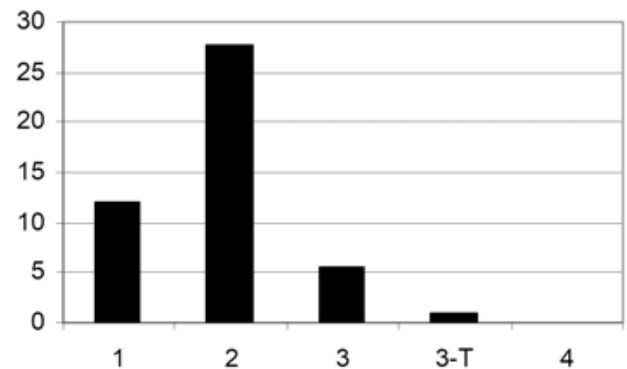

Type 1a

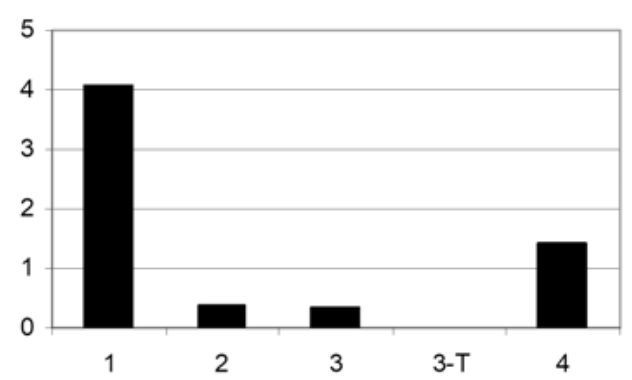

Type 2

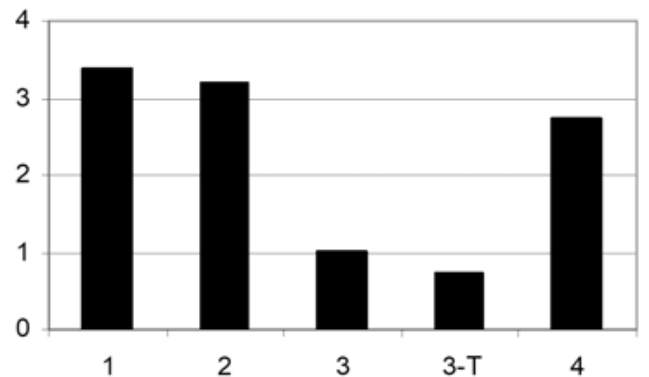

Type 4

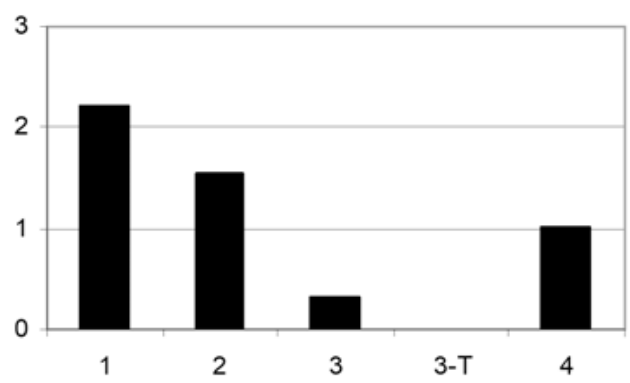

Type 8

Fig. 7.23: Occurrence profiles of Types 1, 2, 3, 4, 7 and 8. The histograms show occurrence as a percentage of the total period rimsherd assemblages. Note that vertical scales differ on the histograms. 


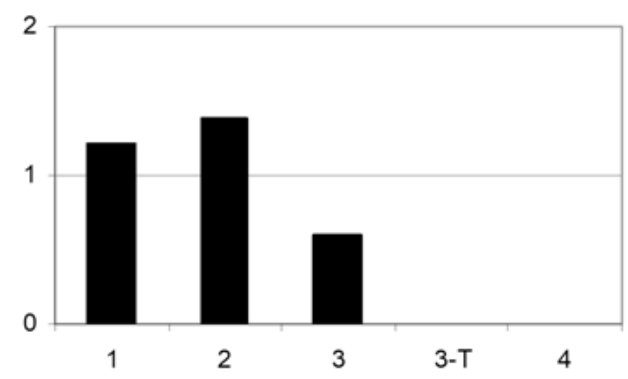

Type 9

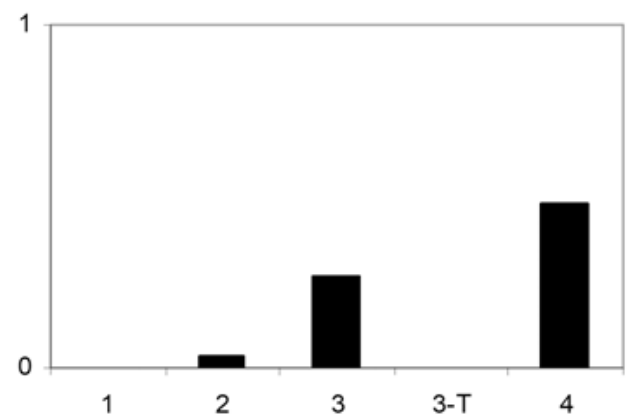

Type 12

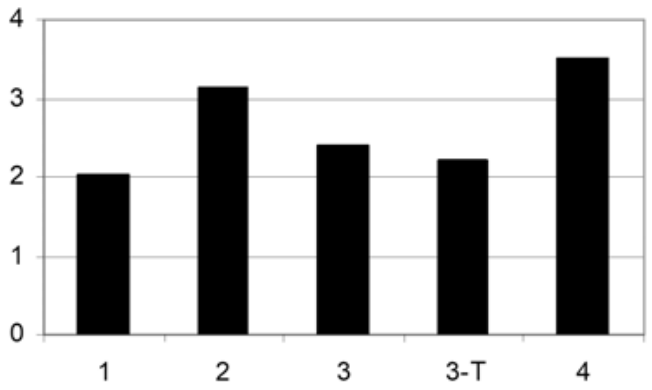

Type 16

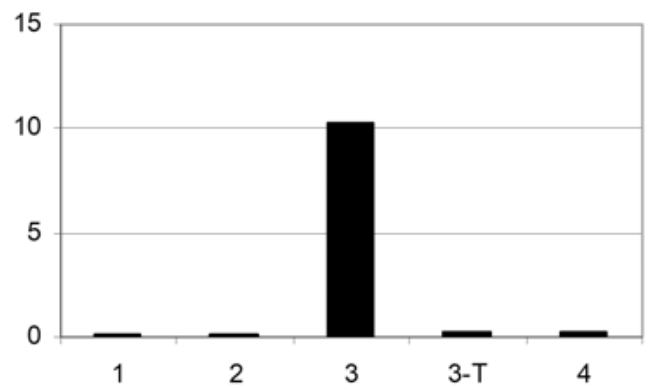

Type 24

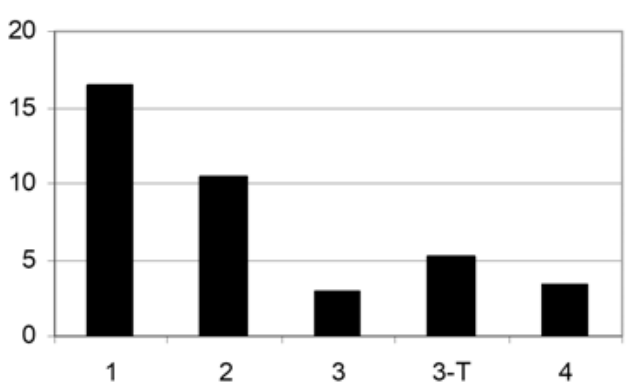

Type 10

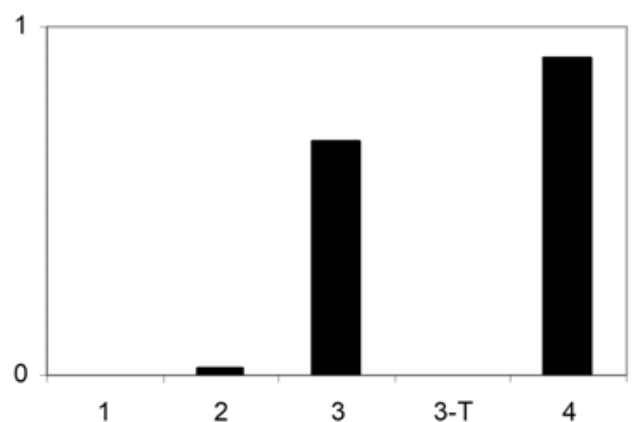

Type 14

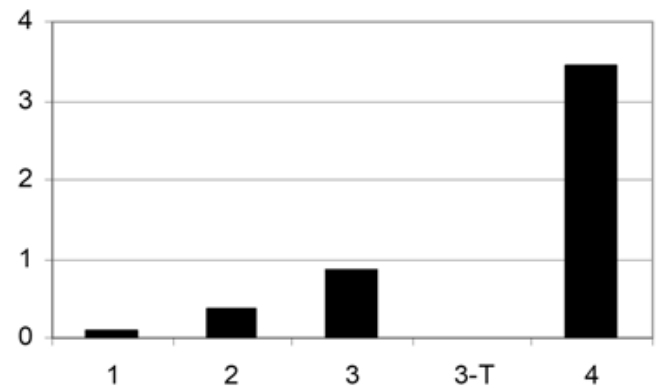

Type 20

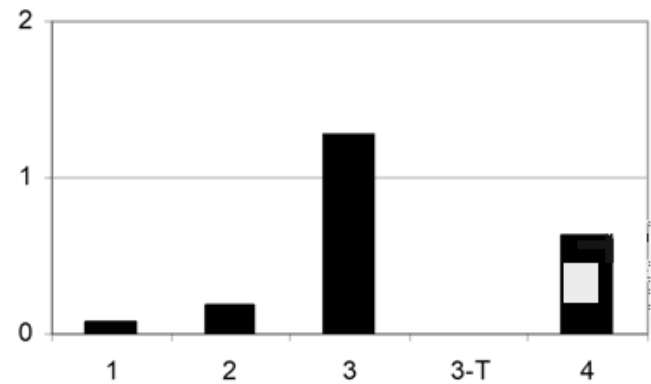

Type 25

Fig. 7.24: Occurrence profiles of Types 9, 10,12,14, 16, 20, 24 and 25. The histograms show occurrence as a percentage of the total period rim-sherd assemblages. Note that vertical scales differ on the histograms. 


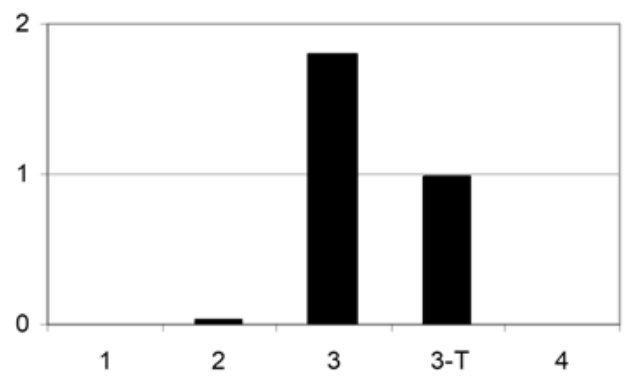

Type 26

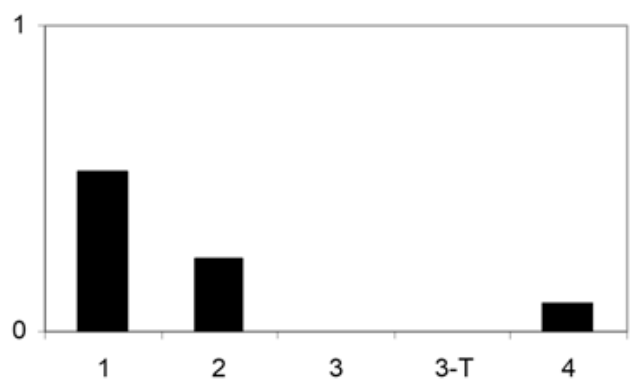

Type 30

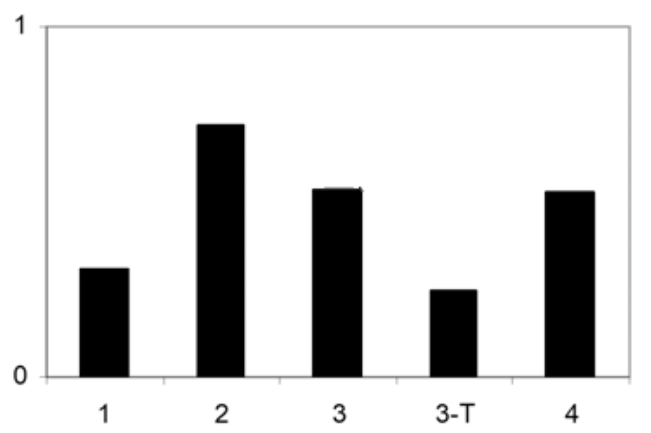

Type 33

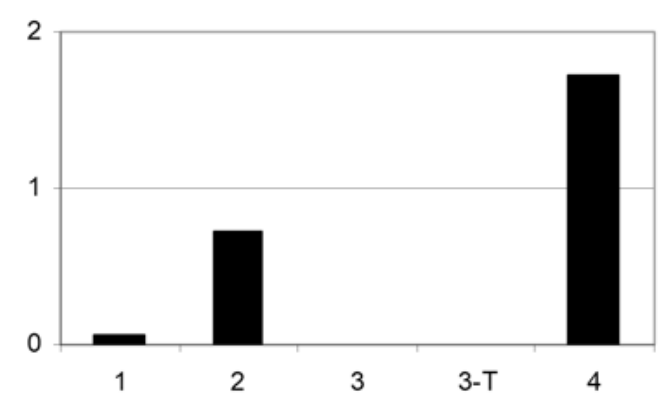

Type 41

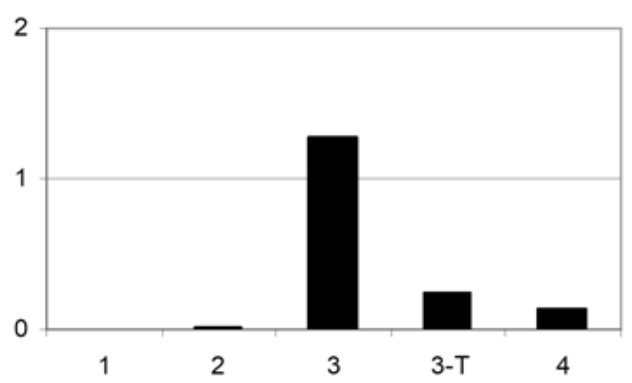

Type 27

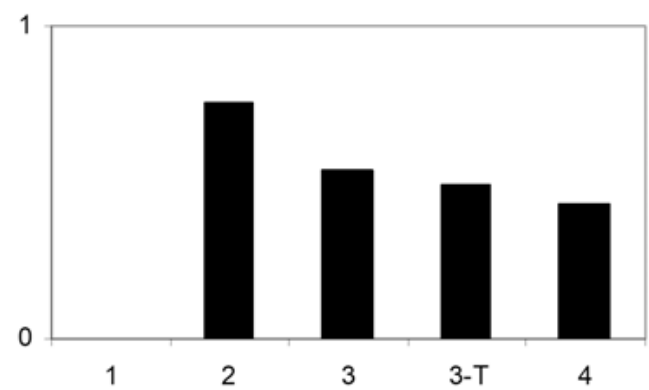

Type 32

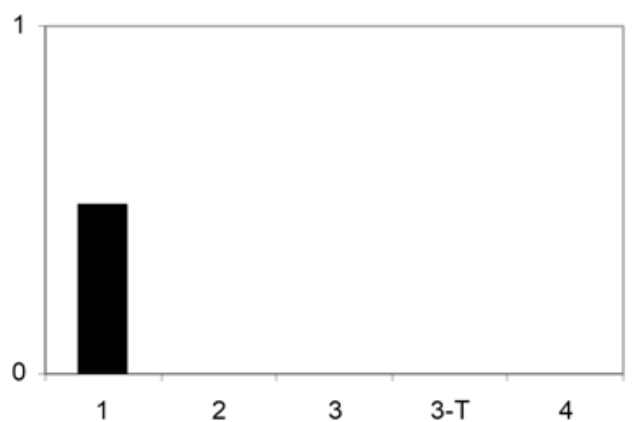

Type 38

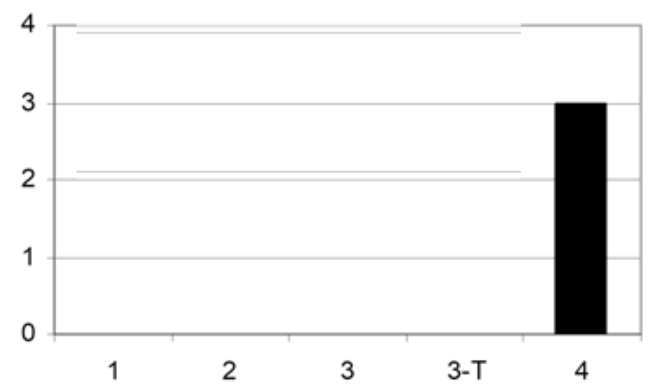

Type 51

Fig. 7.25: Occurrence profiles of Types $26,27,30,32,33,38,41$ and 51 . The histograms show occurrence as a percentage of the total period rim-sherd assemblages. Note that vertical scales differ on the histograms. 